\title{
Understanding the occurrence of cyanobacteria and cyanotoxins
}

\author{
Bastiaan W. Ibelings, Rainer Kurmayer, \\ Sandra M. F. O. Azevedo, Susanna A. Wood, \\ Ingrid Chorus, and Martin Welker
}

\section{CONTENTS}

Introduction 214

4.1 What makes many planktonic cyanobacteria dominant? 214

4.1.1 Nutrient storage and nitrogen fixation 214

4.1.2 Buoyancy, vertical migration, surface scums and metalimnetic layers 215

4.1.3 Light harvesting 222

4.1.4 Carbon concentrating mechanisms 222

4.1.5 Resistance to grazing and other losses 222

4.1.6 Overwintering strategies 224

4.2 Where do which cyanobacteria occur? 226

4.2.1 Planktonic cyanobacteria 226

4.2.2 Benthic and tychoplanktonic cyanobacteria 232

4.3 Which environmental factors favour cyanobacterial dominance? 234

4.3.1 The concept of "trophic state" 235

4.3.2 Nutrients 239

4.3.3 Light availability 245

4.3.4 Temperature, thermal stratification and mixing 246

4.3.5 Hydrodynamics and waterbody morphometry 248

4.3.6 pH: acidity and alkalinity 249

4.4 Can cyanobacterial blooms be predicted by models? 250

4.4.1 Models to predict surface blooms and scums 256

4.5 Will climate change affect cyanobacterial blooms? 258

4.6 Which factors determine cyanotoxin concentrations? 260

4.6.1 Composition of blooms and cyanotoxin types 261

4.6.2 Toxin content in biomass 262

4.6.3 Toxin concentrations in water 267

4.6.4 Spatial heterogeneity of toxin concentrations 270

4.6.5 Estimating cyanotoxin concentration from other
limnological parameters

References 275 


\section{INTRODUCTION}

Cyanobacteria are found in almost every aquatic ecosystem. Yet their presence does not automatically pose a risk to public health. Whether or not toxins reach health-relevant concentrations depends on the taxonomic (and genotypic or clonal) composition of the phytoplankton as well as on the cyanobacterial biomass. Clearly, the risks of elevated biomass, loosely named blooms, are higher under eutrophic conditions. However, certain cyanobacteria, for example, Planktothrix rubescens, tend to decrease under eutrophic conditions, while others like species of Microcystis may still reach hazardous levels under much reduced nutrient concentrations if a relatively low biomass accumulates as scums near the lake shore. Hence, to assume a very close link between cyanobacterial proliferation and eutrophication is too restrictive for a good understanding of toxin risks. Therefore, for the assessment and management of cyanobacterial hazards to human health, a basic understanding of their properties, their behaviour in natural ecosystems and the environmental conditions that support their excessive growth is important. This chapter provides a general introduction to key traits of cyanobacteria that support their proliferation in aquatic ecosystems. It focuses on cyanobacteria thriving suspended in the water of lakes and reservoirs, that is, those with a planktonic way of life. It also gives information on conditions potentially promoting the growth of benthic cyanobacteria, that is, those growing on surfaces such as rocks, sediments or submersed vegetation. How to use this information for controlling and managing cyanobacterial proliferation is discussed in Chapter 8 .

\section{I WHAT MAKES MANY PLANKTONIC CYANOBACTERIA DOMINANT?}

To proliferate, cyanobacteria must be able to satisfy their demands for light energy and nutrients, particularly phosphorous $(\mathrm{P})$ and nitrogen $(\mathrm{N})$. They compete for these resources with other phytoplankton and with each other. Cyanobacteria have a number of specific traits that favour their dominance over algal phytoplankton as well as bloom formation in many lakes, rivers and oceans. Some traits are only found in a restricted subset of cyanobacteria, such as the capability to fix atmospheric nitrogen or the regulation of buoyancy.

\section{I.I Nutrient storage and nitrogen fixation}

Cyanobacteria can sustain growth during temporal and spatial shortage of dissolved nutrients by storing them - particularly phosphorous $(\mathrm{P})$ and to a lower extent also nitrogen $(\mathrm{N})$ in amounts exceeding their current demands for cell division and growth (Li \& Dittrich, 2019). They store surplus P as polyphosphate in the cell, sometimes enough for several cell divisions even when external supplies are depleted below the analytical detection levels. 
As a consequence, one cell can multiply into 8 or even 16 cells without any further phosphorus uptake (Reynolds, 2006).

In addition, cyanobacteria can acquire nitrogen in different forms, such as nitrate, nitrite, and ammonium or urea. While under oxidised conditions, $\mathrm{N}$ occurs as nitrate and is used as such by cyanobacteria, they can rapidly take up reduced forms of $\mathrm{N}$ (ammonium and urea), for example, from sewage inflows or released from sediments or by mussels (Gobler et al., 2016). Furthermore, some cyanobacteria, for instance, the genera Aphanizomenon or Dolichospermum, can utilise atmospheric $\mathrm{N}_{2}$, a capacity termed "diazotrophy". This is a distinct advantage for cyanobacteria compared to eukaryotic microalgae at times when other sources of nitrogen are in short supply (Oliver \& Ganf, 2000). The widely occurring genera Microcystis and Planktothrix cannot fix atmospheric nitrogen, but they can benefit from a smaller biomass of co-occurring $\mathrm{N}$-fixing taxa whose degrading cells may leak $\mathrm{N}$ into the surrounding water (Salk et al., 2018).

Nitrogen fixation (diazotrophy) in most taxa is located in specialised cells, the heterocytes (see Chapter 3). These cells do not perform photosynthesis since the nitrogenase enzyme complex that carries out nitrogen fixation is inactivated by oxygen released through photosynthesis. Heterocytes are generally easily recognised microscopically due to their different shape and pronounced cell wall, but may appear similar to vegetative cells in some species (Gallon, 2004). Cyanobacterial $\mathrm{N}_{2}$ fixation can cause considerable $\mathrm{N}$ input into aquatic ecosystems and affect global geochemical cycles, as shown, for instance, for the marine cyanobacterium Trichodesmium in the Atlantic Ocean (Capone et al., 2005). Diazotrophy, however, requires high amounts of energy for the heterocytes to maintain anoxic conditions inside the cell while being in an oxygenated environment, and therefore, $\mathrm{N}_{2}$ fixation is limited in turbid water.

Cyanobacteria are able to store excess $\mathrm{N}$ mainly in the form of cyanophycin (a copolymer of aspartate and arginine; Simon, 1971; Ziegler et al., 1998). Even species that cannot fix atmospheric $\mathrm{N}_{2}$ may thus have competitive advantage against microalgae under conditions of low $\mathrm{N}$ concentrations (Li et al., 2001a).

\section{I.2 Buoyancy, vertical migration, surface scums and metalimnetic layers}

The formation of surface blooms or scums (see Box 4.1) is one of the most prominent visual expressions of cyanobacterial development. The cyanobacteria best known for the formation of surface blooms are colony- or filament-forming species of genera such as Dolichospermum, Cuspidothrix, Aphanizomenon, Microcystis and Nodularia, and under specific circumstances also species of Planktothrix and Raphidiopsis (Cylindrospermopsis). Surface blooms may cover an area reaching from a few square metres up to hundreds of square kilometres, such as blooms of Nodularia spumigena that can cover large areas of the brackish Baltic Sea (Bianchi et al., 2000). 
In order to grow, cyanobacteria, being photoautotrophic organisms, need to spend sufficient time where there is sufficient light. Many species of cyanobacteria can be buoyant through their gas vesicles (see Chapter 3), thus avoiding sedimentation into deeper layers with low or no light availability.

\section{BOX 4.I: BLOOMS, SCUMS, MASS DEVELOPMENTS - SOME DEFINITIONS}

In the literature on cyanobacteria, the use of terms describing high cell density varies widely. This book proposes and uses the following definitions (see also Fig. 4.I and 4.2):

Bloom: high average phytoplankton (i.e., algae and/or cyanobacteria) cell density in a waterbody (in this book, usually referring to blooms of cyanobacteria), also referred to as "mass development" or "proliferation". Blooms can be visually recognised by low transparency and water colour.

Surface bloom: buoyant cyanobacteria accumulating near or at the surface forming visible streaks, sometimes discernible in remote sensing images. Surface bloom formation may occur even where average cyanobacterial cell density is low if vertical and horizontal concentrating mechanisms lead to pronounced cell accumulation at the surface. Surface blooms can occur at large scales covering tens of square kilometres in large lakes or oceans.

Scum or surface scum: massive accumulation of buoyant cyanobacteria at the water surface forming a cohesive layer, often the result of secondary horizontal concentration at the shore, which can reach up to several centimetres thickness. In very dense scums, the surface of the scum can become nearly dry, and this may lead to massive cell lysis, colouring the water blue through the release of phycocyanin. Scums can also be formed by other phytoplankton, like Euglenophytes, but these are generally only a few millimetres thick.

Under eutrophic conditions, water is turbid, rendering light gradients in the water column quite steep and photosynthesis restricted to the uppermost water layer of a few metres or even less than $1 \mathrm{~m}$. The water layer in which light for photosynthesis is available is termed "euphotic zone". If waterbody mixing is deeper than the euphotic zone, phytoplankton cells spend only a limited part of the day in layers with sufficient light for photosynthesis, and light may then limit growth rates. During calm periods, vertical mixing ceases and thermal (micro)stratification develops in waterbodies (Box 4.2). Under these conditions, nonbuoyant plankton sinks out of the euphotic zone, but buoyant cyanobacteria float up, into the near-surface layer, where the cells spend all or most of the daytime in the light. This is typical for colonial cyanobacteria, because due to their large size, they develop high flotation velocities, as can be observed when a water sample is placed in a glass cylinder (Humphries \& Lyne, 1988). 


\section{BOX 4.2: THERMAL STRATIFICATION}

Many lakes develop temperature gradients over depth. Thermal stratification develops when two water layers of differing average temperature are stably separated. This happens because the specific density of water is the highest at $4^{\circ} \mathrm{C}$ and decreases at higher as well as at lower temperatures. In spring, water temperature increases at the surface, and above a certain temperature difference onwards, the warmer, less dense water in the upper part of the water column no longer mixes with colder, denser water in deeper parts. Further heating of the upper layer of water eventually leads to a sharp separation of warm and cold water. The layer where the temperature difference over depth is most pronounced is called the thermocline. For practical purposes, stratification is defined as a temperature difference of more than one degree centigrade over one metre of water depth. The upper, warm layer is called epilimnion, the deeper, cooler layer the hypolimnion and the layer around the thermocline metalimnion. The more pronounced the temperature gradient, the more stable the stratification, and more energy, for example, wind, is needed to overcome it by deep mixing. Thus, once stable stratification is established, cooling of surface water at night or periods of cold weather will cause some mixing of the surface layer, but not the total circulation of the waterbody. While thermal stratification distinctly separates these water layers, some exchange of water between the epilimnion and the hypolimnion may yet occur (e.g., through eddy diffusion), the extent of which depends on the stability of stratification. This in turn is affected by the ratio of the waterbody's surface area to its depth, wind exposition and frequency of storms, for example.

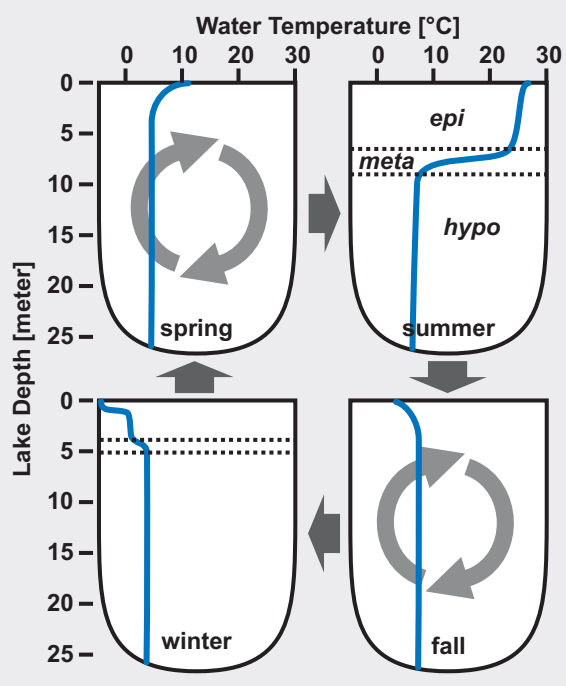


At the end of the summer, the epilimnion successively becomes cooler and once temperatures - and in consequence water densities - of the epiand hypolimnion have converged, complete mixing of the water column occurs. This process is called mixis or overturn. Further cooling at the surface can lead to an inverse stratification during winter, in particular when an ice-cover is present, because water density decreases at temperatures below $4^{\circ} \mathrm{C}$.

Stratification not only affects water temperature, but also many biological, chemical and physical processes. Particles such as planktonic organisms (dead or alive) and excreta of fish or zooplankton can settle and reach the hypolimnion and the sediment where they decay. This process consumes oxygen and releases minerals, including phosphorus and nitrogen, from the decaying material settling or already deposited on the sediment surface. As there is little exchange between epi- and hypolimnion in a stratified waterbody, substances such as phosphorus and nitrogen accumulate in the hypolimnion. Therefore, thermal stratification also causes chemical and biological stratification, frequently leading to an anoxic hypolimnion that is rich in dissolved inorganic nutrients.

Depending on the stability of thermal stratification and frequency of mixing, several types of lakes are distinguished.

In shallow polymictic waterbodies, stratification occurs irregularly but frequently while lasting only for hours, days or at most for weeks, depending on meteorological conditions such as air temperature, wind speed and direction. Temperature gradients generally are not pronounced, and hence, stratification is not stable, yet this type of microstratification has important effects on, for instance, buoyant phytoplankton.

In dimictic lakes, thermal stratification is stable during summer as well as during winter, and mixing occurs twice a year, that is, as "spring overturn" and "autumn overturn". Dimictic lakes generally are deep in relation to their surface area.

In monomictic waterbodies, mixing occurs only once, generally during the winter, in lakes and reservoirs that do not freeze. This is common for large reservoirs in tropical and subtropical climates, but may also occur in temperate regions. Monomixis can also arise from factors such as seasonal precipitation patterns, for example, monsoon seasons.

Besides the frequency of water column mixing, the completeness of the mixing process is classified. In holomictic waterbodies, mixing is from the surface to the bottom, while in meromictic ones, a bottom layer remains excluded and never or very infrequently gets mixed with the overlaying water 
layer. This occurs in lakes with a particular morphometry like deep crater lakes that may be classified as dimictic and meromictic.

One of the ongoing and forecasted effects of climate warming is shifts between mixing regimes, for example, from poly- or dimictic to monomictic or, in some situations, less stable stratification if the frequency of storms increases. Given the importance of mixing regimes for lake ecosystem functioning, the consequences can be far reaching.

Buoyancy regulation - that is, a variation in the buoyancy state - depends on the availability of resources such as carbon, nitrogen and phosphorous (e.g., Klemer et al., 1982; Konopka et al., 1987), but most importantly, buoyancy is regulated by light. Cyanobacteria produce more gas vesicles under low irradiance, thus increasing their buoyancy. Under high irradiance, gas vesicles may be diluted by growth, or - after extended light exposure - collapse under high turgor pressure (Kinsman et al., 1991). In addition, cyanobacteria exposed to light produce carbohydrates, the excess of which may be stored as glycogen that acts as ballast, so that buoyancy can decrease to a point where cells start to sink. In darker, deeper layers, the cells consume their glycogen storage as energy source, and thus, they regain buoyancy. This may result in diel changes in buoyancy and vertical migration, with populations being maximally buoyant during the night and a percentage of the cells losing buoyancy during the day (Ibelings et al., 1991; Rabouille \& Salençon, 2005; Medrano et al., 2013).

Since the vertical migration of Microcystis can span large amplitudes, Microcystis can also proliferate in deep lakes. Typically, however, Microcystis becomes dominant in eutrophic lakes of intermediate depth, which are sufficiently stratified to allow them to control buoyancy and thus to position themselves vertically. In these ecosystems, Microcystis colonies are among the best-adapted phytoplankton to overcome mixing forces (provided these are relatively weak) - allowing the colonies to disentrain from turbulence - and gain a competitive advantage by floating upwards during periods of increased stability (Reynolds, 1994; Dokulil \& Teubner, 2000).

In waterbodies with thermal stratification, buoyancy regulation can lead to different accumulation patterns of cyanobacterial biomass and consequently of cyanotoxins, depending on the taxa involved (Figure 4.1, Figure 4.6):

- formation of surface blooms or scums, typical for blooms of Microcystis, Dolichospermum and Aphanizomenon. Formation of a cohesive scum is generally preceded by the occurrence of visible streaks at the surface. Once congregated at the surface, the cells can be further accumulated by wind-drift at leeward sites; 
- largely homogeneous distribution of cells in the water column with scum formation occurring only exceptionally under the conditions of extreme water column stability. A typical example is Planktothrix agardhii, which only rarely creates surface blooms or scums, but may lead to pronounced greenish turbidity of homogeneously distributed filaments. Further examples include Limnothrix and Pseudanabaena as well as other taxa that have not been shown to produce known toxins;

- the accumulation of cells in a deep layer (deep chlorophyll maximum), either between upper warm and deeper cold water (i.e., the "thermocline" or "metalimnion"; see Box 4.2) or at low light intensity. Typical examples include the red-coloured Planktothrix rubescens in deep, stratified lakes and reservoirs. However, green-pigmented cyanobacteria (Aphanizomenon flosaquae, Dolichospermum) have also been reported to form metalimnetic layers that may last for several months (Konopka, 1989). In stratified subtropical reservoirs, Raphidiopsis (Cylindrospermopsis) raciborskii has been found in deep layers with low light intensity (see section 4.5). Occasionally, such cyanobacteria may leave their position in the metalimnion and accumulate at the surface, in the case of $P$. rubescens, leading to purple surface blooms. Seasonal or storm-induced mixing may also carry them into the upper layers.

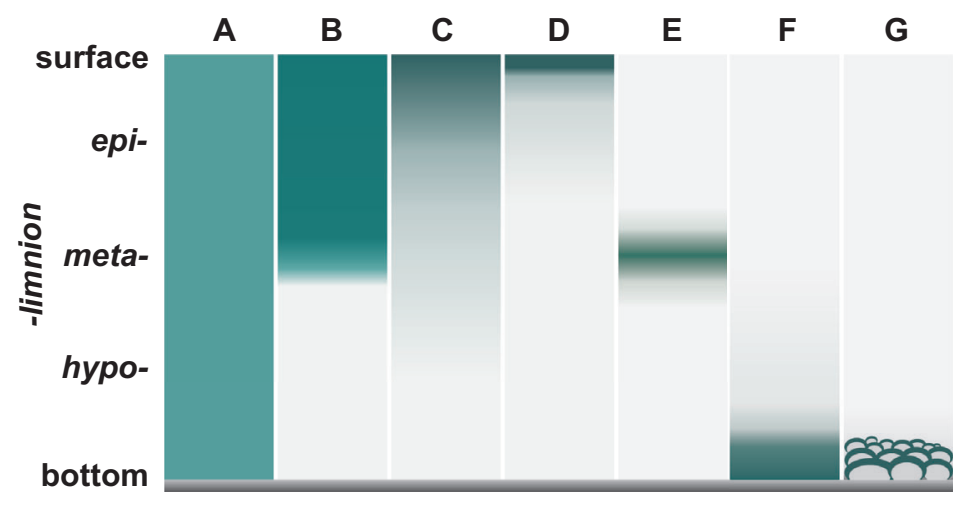

Figure 4.I Distribution patterns of cyanobacteria (cyanotoxins) in the water column. A: homogeneous distribution, $\mathrm{B}$ : homogeneous distribution in the epilimnion of thermally stratified waterbodies, C: gradual concentration of buoyant cyanobacteria towards the surface in a stable water column, D: surface bloom of buoyant cyanobacteria, E: accumulation in a metalimnetic layer in stratified waterbodies, F: accumulation in bottom layers through sedimentation, G: benthic cyanobacteria growing on hard substrate. Transitions between all individual patterns are possible. 
(a)
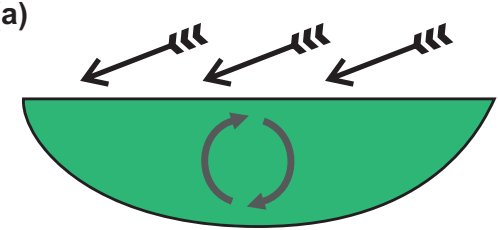

$\begin{array}{ll}\text { cells/L: } & 10^{7} \\ \text { chl-a } \mu \mathrm{g} / \mathrm{L}: & 2 \\ \text { MC } \mu \mathrm{g} / \mathrm{L}: & 1 \\ \text { risk level: } & \text { low }\end{array}$

(b)

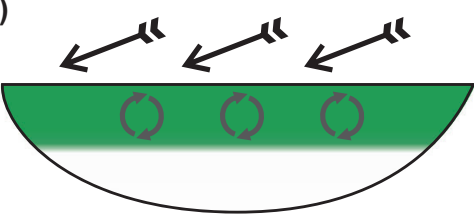

max cells/L: $\quad 10^{8}$

max chl-a $\mu \mathrm{g} / \mathrm{L}: 20$

$\max \mathrm{MC} \mu \mathrm{g} / \mathrm{L}: \quad 10$

(c)

risk level:

moderate

max cells/L: $\quad 10^{9}$

max chl-a $\mu \mathrm{g} / \mathrm{L}: 200$

$\max M C \mu g / L$ : 100

risk level: high

(d)

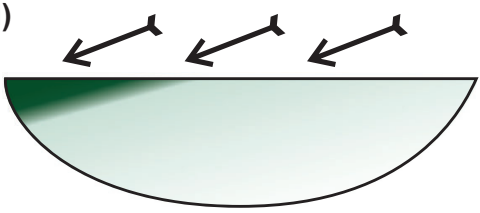

max cells/L: $\quad 10^{12}$

max chl-a $\mu \mathrm{g} / \mathrm{L}: 200000$

$\max \mathrm{MC} \mu \mathrm{g} / \mathrm{L}: \quad 100000$

risk level: very high

Figure 4.2 Schematic illustration of the formation of a surface bloom and scum of buoyant planktonic cyanobacteria like Microcystis spp. The maximum toxin concentrations under given conditions are estimated assuming average cell quota of $100 \mathrm{fg}$ microcystin (MC) per cell (see Box 4.8). (a): strong winds lead to a mixing of the entire waterbody. (b): moderate wind speed allows for (temporary) thermal stratification and buoyant cyanobacteria to accumulate in the epilimnion. (c): Without wind, buoyant cyanobacteria float up and form surface blooms. (d): low wind speed causes the displacement of surface blooms and formation of scums at downwind sites. Note that cell numbers, chlorophyll- $a$ (chl- $a$ ) and MC concentrations are only crude estimates to illustrate the order of magnitude of possible spatial heterogeneities and must not be taken as reference values.

At times, surface blooms can develop into scums when cyanobacteria accumulated at the water surface are further concentrated by horizontal drift, generally at downwind sites (Figure 4.2). Scum formation is typically restricted to parts of a waterbody only, but strongly affects water quality in terms of odour, appearance and sometimes extremely high concentrations of cyanotoxins. When scums are not dissolved after a short time, for example, by wind or wave action, massive cell lysis may set in as a result of unadapted cells being exposed to full sunlight and additional stress factors such as high 
temperature or depleted inorganic carbon (Ibelings \& Maberly, 1998). This can consequently result in the massive release of cyanotoxins and phycocyanin, indicated by bluish plaques, often accompanied by a strong and unpleasant odour.

\section{I.3 Light harvesting}

Cyanobacteria contain phycocyanin and phycoerythrin as photosynthetic pigments in addition to chlorophyll- $a$. These harvest light in the green, yellow and orange parts of the solar spectrum $(500-650 \mathrm{~nm})$, which is not commonly used by other phytoplankton species. Cyanobacteria therefore are efficient at light harvesting and generally have the capacity to grow at very low light intensities. This applies in particular to the most filamentous forms, especially for Planktothrix, which ranks among the best competitors for light (Reynolds, 1997).

In contrast, while colony formation - for example, of Microcystis - offers advantages such as buoyancy and grazing protection, it also has disadvantages: it diminishes the capacity for light harvesting (and also for nutrient uptake) because in a colony, the cells' surface-to-volume ratio is reduced, and as a consequence, the overall growth rate is also lower. In fact, Reynolds (1997) ranks Microcystis among the poorest resource competitors and slowest growing species in the phytoplankton - would it not have the potential for flotation and buoyancy regulation, it would probably not be a strong competitor in the phytoplankton community (Ibelings et al., 1994).

\section{I.4 Carbon concentrating mechanisms}

Cyanobacteria have a carbon concentrating mechanism (CCM), which allows the $\mathrm{CO}_{2}$-fixing enzyme RUBISCO to operate efficiently. The first part of the CCM consists of various inorganic carbon uptake systems, two for $\mathrm{CO}_{2}$ and three for bicarbonate. The carbon, assimilated carbon in the form of bicarbonate, is transported to specific cellular compartments containing the enzyme carbonic anhydrase, known as carboxysomes. Carbonic anhydrase transforms bicarbonate (back) to $\mathrm{CO}_{2}$, raising it to levels where RUBISCO can perform optimally. Cyanobacterial taxa vary in the combination of carbon uptake systems present in the cell, and this allows them to adapt to environments that differ in the availability of inorganic carbon (Price et al., 2007; Sandrini et al., 2014).

\section{I.5 Resistance to grazing and other losses}

Cyanobacteria seem well equipped to minimise two loss factors that play a major role in general phytoplankton dynamics: sedimentation and grazing by zooplankton. Resistance to grazing is a widely studied and discussed 
subject, in part because it may form an important obstacle for the success of biomanipulation (see section 8.7.1).

Toxicity, size of filaments or colonies, and poor nutritional quality may prohibit an efficient grazing on cyanobacteria by zooplankton (Kurmayer $\&$ Jüttner, 1999), but how well cyanobacteria are protected against grazing by zooplankton is still under considerable scientific debate, with grazing experiments and field studies showing different outcomes (Sarnelle, 1993; Gragnani et al., 1999). For instance, it was shown that Daphnia carinata fed on toxic cyanobacteria, including Microcystis colonies (Matveev et al., 1994), while in the microcosm experiments of Mohamed (2001), daphnids preferred green algae and diatoms over toxic Microcystis. Some of the initial studies demonstrating cyanobacterial toxicity against grazers seem to have been based upon a restricted selection of zooplankton taxa and cyanobacterial strains (Wilson et al., 2006a), and grazers that originate from lakes with a history of cyanobacteria generally show stronger tolerance against their toxins (Ger et al., 2016). Lemaire et al. (2012) studied how the co-evolutionary history of grazers and cyanobacteria results in specific grazer genotype and cyanobacterium genotype interactions that provide a further explanation for the variable outcome of research on grazing of cyanobacteria. Furthermore, grazing by zooplankton other than cladocerans may lead to very different observations: some rotifers, for example, are able to feed on filamentous cyanobacteria and are adapted to the perceived low food quality of cyanobacteria (Burian et al., 2014).

Likewise, the role of mussels in decimating cyanobacterial populations is still under debate: (toxic) cyanobacterial blooms have reappeared in Lakes Erie and Huron (USA), and this is partially interpreted as a result of zebra mussel (Dreissena polymorpha) invasion (Vanderploeg et al., 2001) and their selective rejection of Microcystis colonies as food. Dionisio Pires et al. (2005) and Baker et al. (1998) showed a positive selection for cyanobacteria (and other phytoplankton), indicating that grazing effects of mussels on cyanobacteria are not yet well understood (Raikow et al., 2004). Phytoplanktivorous fish are largely absent from temperate lakes, but in (sub)tropical regions, fish such as silver carp and bighead carp have been shown to filter feed on cyanobacteria (Zhang et al., 2008), thus potentially controlling Microcystis blooms (reviewed in Triest et al., 2016).

Besides grazing, losses through infection by fungal parasites, phages and heterotrophic bacteria have been recognised as potentially important drivers of cyanobacterial population dynamics (Box 4.3; Steenhauer et al., 2016; Yoshida-Takashima et al., 2012; Rohrlack et al., 2013; Van Wichelen et al., 2010). Respective losses may not affect the entire populations but only selected genotypes, thus contributing to the clonal dynamics in cyanobacterial blooms (Van Wichelen et al., 2016; Agha et al., 2018). Recognition, and in particular, quantification of losses through microbial interactions in waterbodies, is still only in the beginnings. 


\title{
BOX 4.3: EMERGING INSIGHTS INTO THE ROLE OF CYANOPHAGES
}

\author{
Helena L. Pound, Steven W. Wilhelm
}

While viruses are well documented in marine systems and virus-induced cell lysis contributes to the conversion of microbial biomass into dissolved organic matter, less is known about their role in freshwaters, particularly for cyanobacteria. Yoshida et al. (2006) isolated and sequenced the first phage capable of lysing Microcystis aeruginosa, proposing that it might act as a controlling agent in seasonal blooms. While the effect of phage on growth, proliferation, and biomass of Microcystis populations has not been fully elucidated, community-sequencing studies have provided further insight. A metatranscriptomic analysis of a 2014 Microcystis bloom in Lake Erie showed an increased frequency of Microcystis phage transcripts at the termination of the bloom, with approximately one virus marker transcript for every host marker (Steffen et al., 2017), implying a massive population-level infection. This lytic infection was associated with a spike in detected microcystin concentrations in the raw water of the city of Toledo's drinking-water supply, reaching up to $>5 \mu \mathrm{g} / \mathrm{L}$. The working hypothesis arising from the observation is that virus-infected cells lysed and released cell-associated toxin into the water.

In contrast, a similar analysis of a Microcystis bloom in Taihu (Lake Tai, China) in 2014 showed a different effect associated with the Microcystis phage. That study observed the formation of lysogens with the association of the phage with the host genome (Stough et al., 2017). In this manner, Microcystis hosts may have resisted subsequent infections by other lytic phage, allowing for longer bloom maintenance. Indeed, Kuno et al. (2012) found that repeated exposure to a high diversity of phages leaves traces in the genomes of Microcystis strains, including molecular defence mechanisms. These studies provide evidence that viral infections can be relevant both in the dynamics of Microcystis blooms and in the release of otherwise cell-bound toxins.

\subsubsection{Overwintering strategies}

In (sub)tropical regions, cyanobacteria can produce perennial blooms, whereas in temperate ones, they are often subject to pronounced seasonal changes in environmental conditions. Phytoplankton populations - including cyanobacteria - usually decline in winter because a decrease in daily insolation and 
increased mixing depth minimise light availability for photosynthesis. In the next growing season, the size of the inoculum of overwintering cells can be decisive for the outcome of competition between phytoplankton species for light and nutrients, and overwintering strategies are therefore an important trait for attaining high levels of biomass and/or dominance in the phytoplankton.

Microcystis typically blooms in (late) summer, and its biomass decreases in autumn when growth conditions become less favourable. Part of the colonies can sink to the lake bottom (Reynolds et al., 1981; Takamura et al., 1984). Verspagen et al. (2004) demonstrated that viable colonies, capable of photosynthesis, were present in large numbers in and on the sediment not only in winter but throughout the year. Several studies (Takamura et al., 1984; Boström et al., 1989) found that the total amount of Microcystis in the sediment can be much higher than in the water column, even during Microcystis blooms. Preston et al. (1980) observed that recruitment of Microcystis from the sediment to the water takes place before the establishment of the summer bloom, so that this recruitment may be a crucial factor that initiates the bloom (Ihle et al., 2005).

Filamentous cyanobacteria like Planktothrix agardhii seem to follow a different strategy. Even in temperate climates, they may prevail or even bloom throughout the year in eutrophic systems. In some situations, they prevent competing phytoplankton from growing by maintaining the system turbid and light availability too low for microalgae to compete efficiently (Scheffer et al., 1997; Ibelings et al., 2007).

The annual cycle of Planktothrix rubescens in Lake Zürich studied by Walsby \& Schanz (2002) shows a specific time pattern for this species: deep winter mixing of the lake entrained the metalimnetic population of $P$. rubescens. About half of the filaments survived this winter period, whereas others lost their gas vesicles because of the hydrostatic pressure resulting from deep winter mixing. After annual stratification in spring, the surviving filaments resumed their position in the metalimnion.

A number of cyanobacteria produce specific resting cells called akinetes that sink to the sediment where they can survive for extended periods of time (see Chapter 3). These include, in particular, the $\mathrm{N}_{2}$-fixing taxa Anabaena, Dolichospermum, Aphanizomenon and Raphidiopsis. Recruitment and germination of akinetes from the sediment contributes to bloom onset, and prolonged benthic recruitment may strongly promote the presence of respective species (Karlsson-Elfgren et al., 2003). Several factors, especially light and temperature, determine their germination (Karlsson-Elfgren et al., 2004; Wiedner et al., 2007). Cirés et al. (2013) show how blooms of Dolichospermum circinale and D. flosaquae are both initiated and maintained in the Murray River (Australia) by the germination of akinetes that are present in the sediment, although vegetative cells also overwinter in the water. 


\subsection{WHERE DO WHICH CYANOBACTERIA OCCUR?}

Cyanobacteria causing toxin concentrations of concern for human health are usually planktonic, that is, suspended in the water. However, as mentioned above, some forms grow on surfaces. As discussed in Chapter 3, "benthic" or "epiphytic" cyanobacteria do so continuously until they are physically detached and dislocated to the surface or beaches. "Tychoplanktonic" cyanobacteria inhabit surfaces, including those of submersed aquatic plants, and may at times also be suspended in the water.

\subsection{Planktonic cyanobacteria}

As a taxonomic group, cyanobacteria are highly successful in colonising a wide variety of habitats - with numerous special adaptations to extreme environmental conditions, for example, resistance to high concentrations of copper and zinc, tolerance of low oxygen conditions and of free sulphide, high tolerance of UV-B and UV-C as well as of high temperature (see Whitton, 2012).

Due to their small size and the extremely high abundance, it is frequently argued that microbial species are globally ubiquitous, growing and multiplying where they find suitable conditions ("Baas Becking hypothesis everything is everywhere but the environment selects"; Finlay, 2002). Accordingly, geographic barriers would not restrict the global distribution of particular taxa, and indeed, cyanobacterial species are cosmopolitan in general and not restricted to geographic regions like, for example, many higher plants (Pridmore \& Etheredge, 1987). Later observations, however, suggest that geographic variation in microbial diversity is apparently more common than originally expected (Martiny et al., 2006), which could well be because the environment - which clearly varies between regions - selects indeed, as postulated in the second part of the Baas Becking hypothesis. A (potentially) global distribution of a particular species does, however, not imply genetic homogeneity across the globe. Regional and local differences in genotype occurrence can cause differences in the distribution of (toxic) secondary metabolites. For example, as strains of Raphidiopsis raciborskii differ genetically between geographic regions (see below), cylindrospermopsin (CYN) production was found only for Australian strains, while not for European or South American ones (Neilan et al., 2003; Piccini et al., 2011).

While it is impossible to prove that a specific taxon is absent from a given location, documented observations of occurrence provide some indication of which species to expect or not to expect under which conditions. Furthermore, in analogy to plant-sociological groupings for terrestrial plants, phytoplankton, including cyanobacteria, can be grouped 
in associations of species that typically occur under specific conditions (Reynolds et al., 2002, updated by Padisák et al., 2009). Box 4.4 shows how a grouping on the basis of key functional traits of cyanobacteria helps to reduce - taxonomic - complexity and to understand why certain cyanobacteria occur under certain conditions. Moreover, the close association between cyanobacterial traits and preferred environmental conditions can provide guidance in selecting the most promising measures for successful control of cyanobacterial blooms (Mantzouki et al., 2016).

\section{BOX 4.4: CYANOBACTERIAL FUNCTIONAL GROUPS BASED ON THE CLASSIFICATION BY REYNOLDS (2006)}

\section{Evanthia Mantzouki}

A functional group is defined by containing species with similar morphological and physiological traits, and ecological functioning (see Padisák et al., 2009 and Salmaso et al., 2015). Reynolds (2006) clustered species on the basis of the typical habitats in which they occur, morphological traits such as shape and dimension or specialised structures such as gas vesicles and heterocytes, as well as functional traits that are linked to resource acquisition, optimum growth temperatures and toxin production. From the extensive list given by Reynolds (2006), the table below (modified after Mantzouki et al., 2016) selects the functional groups with cyanobacteria, listing typical representative taxa and highlighting environmental tolerances and key sensitivities. This may aid in finding suitable management actions to control cyanobacteria. The classification is simplified compared to Reynolds (2006) and Padisák et al. (2009) by combining groups that are found in similar habitats and, more importantly, require similar management actions, that is, the $\mathrm{SI} / \mathrm{S} 2, \mathrm{HI} / \mathrm{H} 2$ and LO/LM groups. Notable differences in the various preferred habitats of the combined groups are as follows: S2 species prefer warmer mixed and alkaline waters compared to those in group $\mathrm{Sl} ; \mathrm{H} 2$ taxa are found in mesotrophic lakes with high light conditions, and although $\mathrm{HI}$ taxa are found in more eutrophic lakes, their nitrogen content is relatively low; LO taxa are found in medium to large lakes, while LM species occur in small to medium-sized lakes. Note that the most frequently occurring, typical taxa are given in bold.

Adapted by permission from Springer Nature, Aquatic Ecology, Understanding the key ecological traits of cyanobacteria as a basis for their management and control in changing lakes. Mantzouki E, Visser PM, Bormans M, Ibelings BW (2016). Copyright Springer Nature 2016. www.springernature.com/gp. 


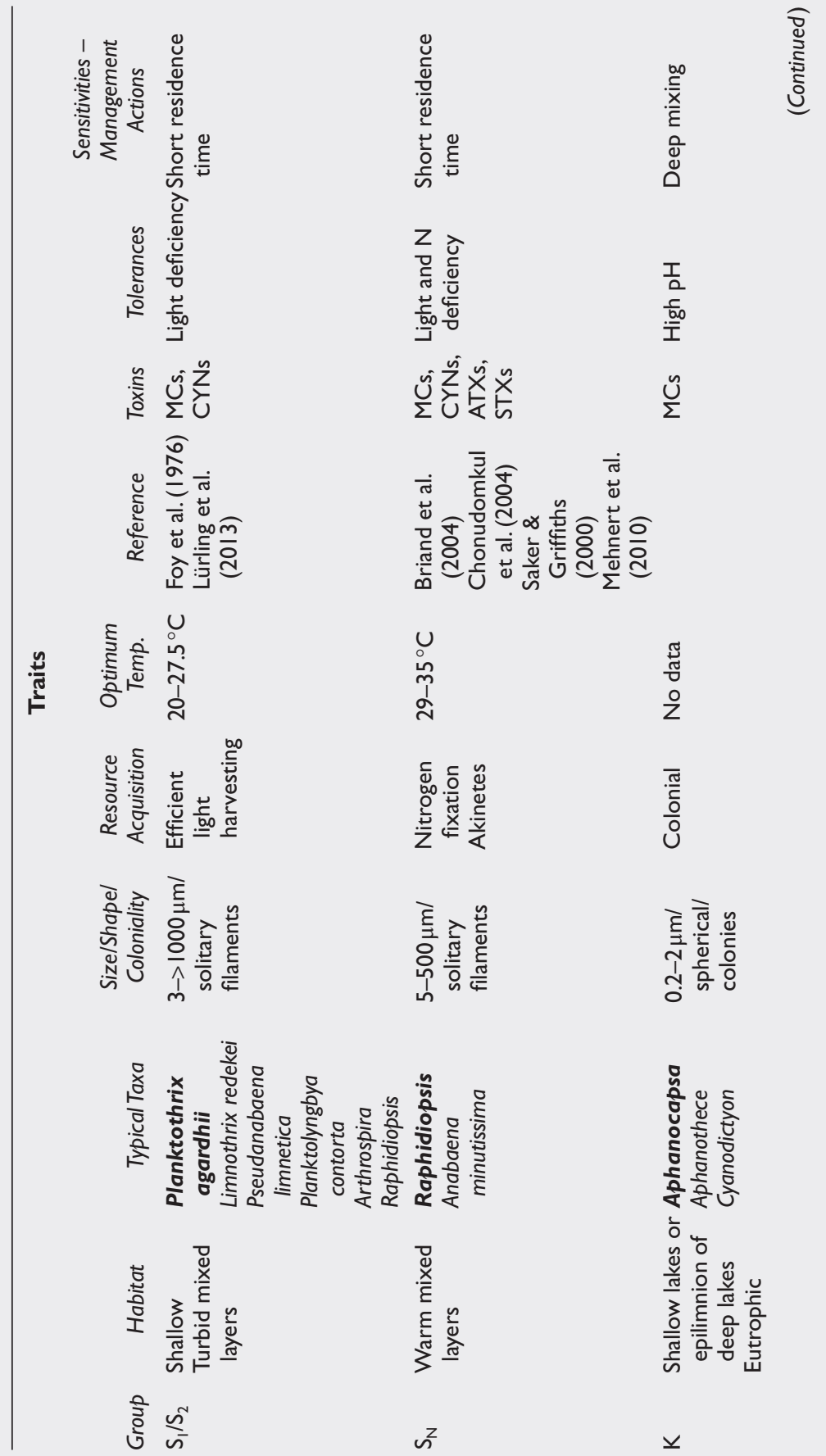




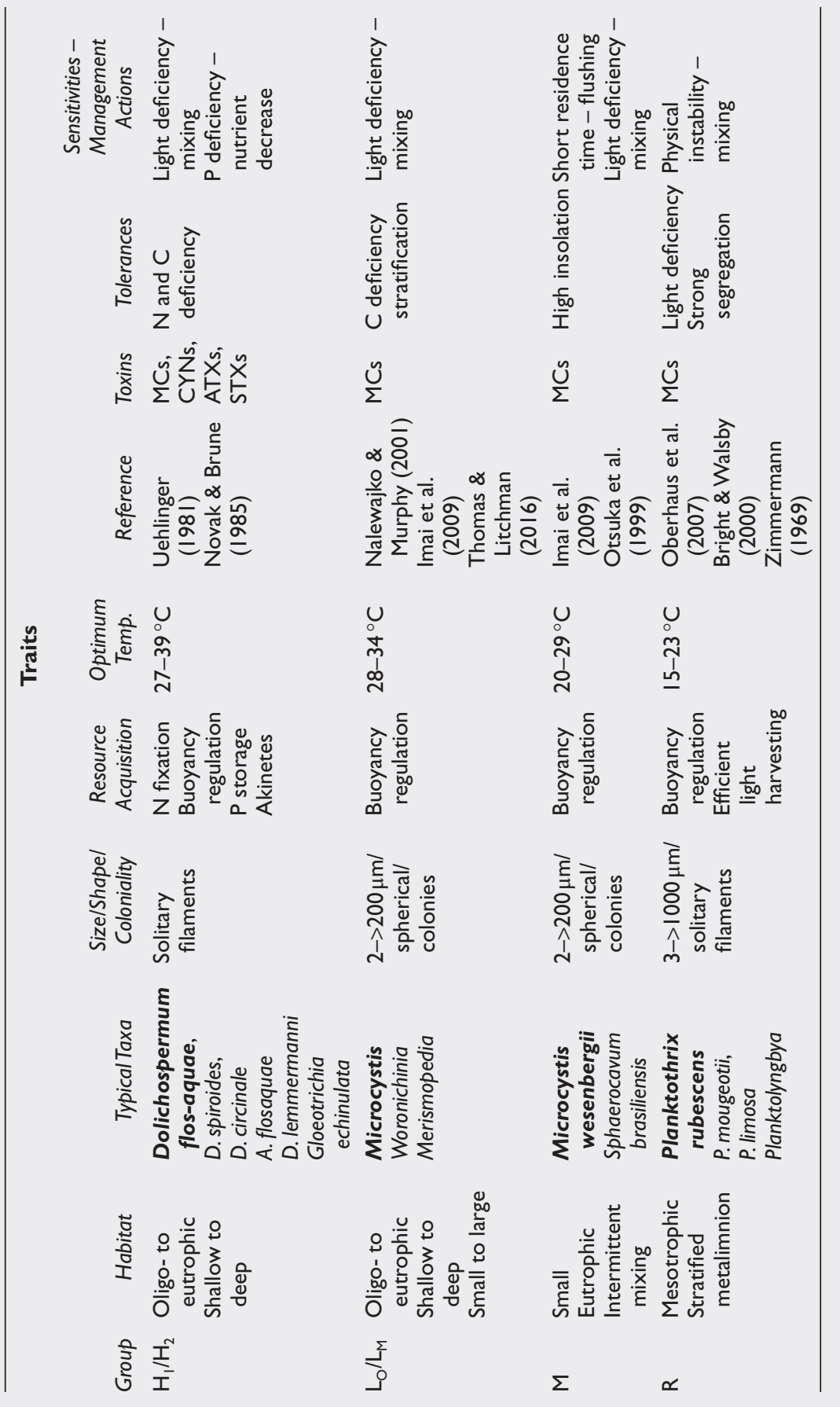


Prochlorococcus is probably the most abundant cyanobacterium, numerically dominating the oligotrophic areas of tropical and subtropical oceans, followed by marine Synechococcus and Trichodesmium. Planktonic freshwater cyanobacteria contribute only a relatively small percentage of the global cyanobacterial biomass as surface freshwaters are only a small fraction of the global surface water (Garcia-Pichel et al., 2003).

Microcystis species have a cosmopolitan distribution and have frequently been reported from lakes worldwide, from temperate to tropical zones of both hemispheres. They occur in a range of waterbodies, typically (though not exclusively) proliferating at temperatures above $15^{\circ} \mathrm{C}$ and under mesotrophic to eutrophic conditions. While thermal stratification may give them a competitive advantage, Microcystis occurs both in thermally stratified lakes (generally deeper than $6 \mathrm{~m}$ ) and in relatively shallow, polymictic waterbodies which show recurrent periods of re-stratification and mixing, allowing Microcystis to benefit from its buoyancy (Ibelings et al., 1991).

The widespread filamentous species Planktothrix agardhii is a typical and frequently reported species for shallow temperate lakes, particularly in the Northern Hemisphere (Suda et al., 2002). It tolerates a wide range of temperatures, and in some regions (e.g., lowland areas of the Netherlands and northern Germany), it perennially dominates (or dominated) shallow eutrophic and hypertrophic waterbodies for many years (Van Liere \& Mur, 1980; Mur, 1983; Rücker et al., 1997). However, it is also reported from subtropical climatic regions in South America (Kruk et al., 2002), Australia (Baker \& Humpage, 1994) and from the temperate climatic region of New Zealand (Pridmore \& Etheredge, 1987). Because this species is a superior competitor under conditions of low light availability, Planktothrix agardhii - sometimes together with Limnothrix generates a positive feedback loop, creating a "shaded" environment in which it can hardly be outcompeted by other phytoplankton (Scheffer et al., 1997).

The nitrogen-fixing genera, Dolichospermum and Aphanizomenon, typically occur in larger mesotrophic lakes (Dokulil \& Teubner, 2000; Reynolds et al., 2002) promoted by surface warming, high light and phosphorus levels together with low nitrogen concentrations (see section 4.2.3). Species of Dolichospermum and Anabaenopsis have been reported from all five continents, occurring in temperate regions of the Northern and the Southern Hemisphere as well as in subtropical and tropical climatic regions. As the chemical reduction of atmospheric nitrogen is energy demanding, these taxa typically proliferate in environments with high light availability, that is, fairly clear water, rather than in turbid, highly eutrophic systems. Species of Aphanizomenon have been widely reported from temperate regions of the Northern Hemisphere (Konopka, 1989; Barker et al., 2000; Porat et al., 2001) as well as from subtropical regions (Porat et al., 2001), from Australia (Baker \& Humpage, 1994) and from South 
America (Kruk et al., 2002). Frequently, Aphanizomenon flosaquae occurs codominant together with Microcystis (Teubner et al., 1999).

Raphidiopsis raciborskii has originally been considered a tropical species, first described from Java (Gugger et al., 2005a). R. raciborskii was first reported in Europe during the 1930s (Padisák, 1997) and appeared to invade temperate regions of Europe during the 1990s (e.g., Dokulil \& Mayer, 1996; Briand et al., 2004). However, newer genetic and ecophysiological analysis demonstrated that $R$. raciborskii shows positive net growth over a wide range of temperatures $\left(20-35^{\circ} \mathrm{C}\right)$ (Briand et al., 2004), and rather than spreading from warm refuge areas across the American and European continents, it shows distinct and geographically separate ecotypes (Gugger et al., 2005b; Haande et al., 2008), which also differ with respect to producing CYNs (Neilan et al., 2003; Piccini et al., 2011; Antunes et al., 2015).

Other potentially toxin-producing cyanobacteria show a more restricted pattern of geographic occurrence. Mass developments of the red-pigmented, filamentous Planktothrix rubescens have been reported frequently over several decades but largely from thermally stratified lakes and reservoirs across Europe (e.g., Skulberg \& Skulberg, 1985; Feuillade, 1994; Barco et al., 2004; Gallina et al., 2017), North America (e.g., Edmondson \& Litt, 1982; Nürnberg et al., 2003) and New Zealand (Pridmore \& Etheredge, 1987). In these waterbodies, they typically inhabit the thin layer between warm surface water and the cold deep layer, called the metalimnion. Waterbody mixing can distribute the filaments throughout the whole water column, thus causing a distinctly visible reddish discoloration (Nürnberg et al., 2003). Their preferred habitat in the metalimnion may be the reason why $P$. rubescens populations are sensitive to eutrophication, since having enough light in these depths for growth depends on water being relatively clear in the epilimnion. In peri-alpine lakes such as Lake Hallwil (Switzerland) or Lake Bourget (France), P. rubescens (re)appeared as nutrient levels declined and water became clearer and disappeared again only after total phosphorus (TP) had further declined to very low concentrations (e.g., below $10 \mu \mathrm{g} / \mathrm{L}$ in Lake Bourget; Jacquet et al., 2014). In Lake Constance, at similarly low phosphorous levels, metalimnetic blooms of $P$. rubescens have reappeared since 2014, and in other lakes like Lake Zurich (Switzerland), it shows little response to decreases in TP concentrations (Schanz, 1994; Gammeter \& Zimmermann, 2001; Posch et al., 2012).

Nodularia spumigena has been reported from marine and brackish waters typically estuaries and coastal lagoons of Southern Australia (Francis, 1878; Jones et al., 1994) and less frequently in alkaline, brackish lakes (Bolch et al., 1999). In addition, it has been reported from brackish coastal lakes in New Zealand (Carmichael et al., 1988), South Africa and the North Sea (Nehring, 1993). Nodularia spumigena regularly forms blooms in the Baltic Sea (Bianchi et al., 2000). Notably, a freshwater strain of Nodularia originally isolated from a benthic mat in a thermal source also produced the nodularin (Beattie et al., 2000). 


\subsubsection{Benthic and tychoplanktonic cyanobacteria}

Benthic cyanobacteria generally need a substrate to attach to, like sediment ("epipsammic"), pebbles or stones ("epilithic") or macrophytes ("epiphytic"), while "tychoplanktonic" includes phases of planktonic occurrence. Benthic cyanobacteria occur in a variety of freshwater and marine habitats, including wetlands, lakes, coral reefs and estuaries, hypersaline and geothermal ponds, streams and rivers (Scott \& Marcarelli, 2012). Water transparency allowing light to penetrate to the bottom is a prerequisite for the growth. While planktonic cyanobacteria are well known to thrive in eutrophic conditions, benthic cyanobacterial proliferation is common in oligotrophic environments such as alpine lakes or headwater streams with sufficient substrate stability to enable cyanobacterial growth (Scott \& Marcarelli, 2012). Where lakes and reservoirs become clearer in consequence of successful reduction of nutrient loads, benthic, epiphytic and/or tychoplanktonic planktonic cyanobacteria may replace planktonic ones, thus causing new exposure scenarios: while the health risk from cyanotoxins in the bulk water declines, a more localised risk may then arise in the vicinity of detached mats of benthic cyanobacteria or of macrophyte tufts containing cyanobacteria - either floating or beached. It is therefore important to observe the possible expansion of such taxa in the course of restoration efforts (Shams et al., 2015).

Some benthic species form mats which can grow on a wide range of substrates such as fine sediment, rocks, artificial substrates and aquatic plants. These cyanobacterial-dominated mats usually range from a few millimetres to several centimetres in thickness, although when environmental conditions are favourable, they can continue to grow and become much thicker. As benthic, cyanobacteria-dominated mats are increasingly being investigated for cyanotoxins worldwide, these are increasingly being found, particularly in wadeable streams, littoral zones of lakes and coastal lagoons (Fetscher et al., 2015; Cantoral Uriza et al., 2017). For both, freshwater and marine benthic taxa, occurrence is often highly variable on small spatial scales of metres or less. In shallow marine environments in tropical and subtropical zones, Moorea (formerly Lyngbya) and other benthic taxa potentially producing toxins can occur (see also section 2.6).

In freshwater, the dominant cyanobacterial taxa in the mats are usually filamentous Oscillatoriales, including Oscillatoria, Microcoleus, Phormidium, Microseira, Moorea (formerly Lyngbya), Leptolyngbya, Tychonema, Calothrix and Schizothrix. The Chroococcales Aphanothece and Synechococcus are also common components of the mats, with some reports of mats dominated by these genera, for example, in hot spring environments. Among the nitrogen-fixing Nostocales, the most frequently reported genera are Anabaena, Scytonema and Nostoc (Quiblier et al., 2013, Wood et al., 2020). Although dominated by cyanobacteria, the mats usually contain many other organisms (e.g., heterotrophic bacteria and eukaryotic algae) and inorganic matter (e.g., sediment) bound together by 
extracellular polymeric substances (McAllister et al., 2016). Over 20 species of benthic cyanobacteria are known to produce a range of cyanotoxins, similarly wide as that of planktonic species, that is, MCs, nodularins, CYNs, saxitoxins and anatoxins. Toxicity that could not be attributed to any of the known cyanotoxins has also been identified (Quiblier et al., 2013). As in planktonic cyanobacteria, both toxic and nontoxic genotypes of a given species usually coexist within mats (Cadel-Six et al., 2007) and cyanotoxin content can be highly variable spatially and temporally. Little is known about factors which may upregulate toxin production or promote the dominance of toxic over nontoxic strains. However, again as for the planktonic cyanobacteria, the abundance of toxic genotypes appears to be the key contributor to toxin content variability among benthic cyanobacterial-dominated mats (Wood \& Puddick, 2017).

In contrast to planktonic cyanobacteria, research exploring factors that regulate the growth and expansion of benthic cyanobacterial-dominated mats has been relatively limited, and detailed studies are restricted to a few taxa from specific environments. In general, the variables that have been identified as most important in regulating the proliferation of benthic cyanobacterial mats are physical disturbance (wet-dry cycles, wave action, shear stress, abrasion), light, temperature, nutrients and grazing. Once mats are established, they contain diverse microbial communities and these taxa appear to play a vital role in cycling nutrients within the mat (BoumaGregson et al., 2019). This is in concert with internal biogeochemical conditions, which have been shown to facilitate the release of phosphorus from sediment trapped in the mats, leading to nutrient conditions within mats that are very different to those of the overlying water. For example, Wood et al. (2015) showed that dissolved reactive phosphorus concentrations in water extracted from benthic cyanobacterial mats was over 300 times higher than in the stream water. These nutrient-rich within-mat conditions probably partly explain how cyanobacterial-dominated mats can form very high biomass in nutrient-replete environments.

A synthesis of research results on the anatoxin-producing mat-forming species Microcoleus autumnalis (formerly Phormidium autumnale) in wadeable streams in New Zealand shows that Microcoleus proliferations are most likely to occur when there is slightly elevated dissolved inorganic nitrogen during the colonisation phase, but when water column dissolved reactive phosphorus is less than $0.01 \mathrm{mg} / \mathrm{L}$. Once established, Microcoleus-dominated mats trap sediment, and biochemical conditions within the mats can mobilise sedimentbound phosphorus which is then available for growth. These streams are highly dynamic systems and the mats are primarily removed through shear stress and substrate disturbance, although there is also evidence for autogenic (natural) detachment. As cyanobacterial-dominated mats mature and biomass increases, oxygen bubbles, produced through photosynthesis, become trapped among the cyanobacteria and the extracellular polymeric substances they produce, causing the mat to become buoyant and detach from the substrate. 
Tychonema species have repeatedly been recorded in lakes of the temperate zones (Salmaso et al., 2016). Tychonema spp. can produce neurotoxins, primarily anatoxins. These filamentous cyanobacteria primarily grows in stands of macrophytes but can occasionally be found in plankton samples and has been identified as the cause of dog deaths where these ingest Tychonema together with decaying macrophyte material accumulated at the shoreline (Fastner et al., 2018).

The health risk that benthic cyanobacteria proliferations pose to humans is still relatively unknown. There have been numerous cases of domestic and wildlife poisoning following the ingestion of cyanobacterial mats (Quiblier et al., 2013; McAllister et al., 2016). Anecdotal reports of human illness after recreating in streams containing cyanobacterial proliferations are documented, but conclusive evidence is lacking. As long as the mats are attached to the substrate, the risks of human ingestion are probably limited. However, detached mats often accumulate at the banks of rivers, streams and lakes, where animals are much more likely to consume them (Quiblier et al., 2013; McAllister et al., 2016, Wood et al., 2020). Dogs may be attracted to them by the smell of the decaying material, and numerous cases of dog deaths have been documented, sometimes with cyanobacterial cells and cyanotoxins found in their stomachs (Wood et al., 2007; Fastner et al., 2018). For some species, "free" toxin, that is, dissolved in water, can be detected in lake and stream water, although the concentrations are usually well below drinking-water guideline values (Wood et al., 2018). Assessing risks for human health is challenging in situations where deaths of pets and wildlife have been observed, while the water appears clear and toxin concentrations in the water are low or nondetectable. In such situations, it is best to inform users about the situation, to show what the mats look like and to advise avoiding contact with floating or beached benthic material (see Chapter 15).

\subsection{WHICH ENVIRONMENTAL FACTORS FAVOUR CYANOBACTERIAL DOMINANCE?}

Phytoplankton communities generally consist of species belonging to diverse taxonomic groups of photosynthetically active microorganisms. Yet the formation of massive, long-lasting blooms to the extent known from cyanobacteria is rarely reported for eukaryotic microalgae such as desmids, chrysophytes or chlorophytes, for example. Specific environmental conditions strongly favour the dominance of certain cyanobacterial taxa over other taxa of both cyanobacteria and microalgae. Understanding these conditions is important for management, allowing us to estimate under which conditions to expect cyanobacterial blooms. Key abiotic conditions determining phytoplankton growth rates and the outcome of competition between species are the availability of resources (nutrients and light), temperature, mixing regime, flushing rate and $\mathrm{pH}$. In addition, biological interactions, including resource and 
Table 4.I Trophic state categories and their definition as given by Vollenweider \& Kerekes (1982)

\begin{tabular}{lccccc}
\hline & TP mean & $\begin{array}{c}\text { Chl-a } \\
\text { mean } \\
\text { Trophic state }\end{array}$ & $\begin{array}{c}\text { Chl-a } \\
\text { maximum } \\
\mu \mathrm{L} / \mathrm{L}\end{array}$ & $\begin{array}{c}\text { Transparency } \\
\text { mean } \\
m\end{array}$ & $\begin{array}{c}\text { Transparency } \\
\text { maximum } \\
\mathrm{m}\end{array}$ \\
\hline Ultraoligotrophic & $\leq 4$ & $\leq \mathrm{I}$ & $\leq 2.5$ & $\geq 6$ & $\geq \mathrm{I}$ \\
Oligotrophic & $\leq 10$ & $\leq 2.5$ & $\leq 8$ & $\geq 3$ & $\geq 6$ \\
Mesotrophic & $10-35$ & $2.5-8$ & $8-25$ & $3-1.5$ & $6-3$ \\
Eutrophic & $35-100$ & $8-25$ & $25-75$ & $1.5-0.7$ & $3-1.5$ \\
Hypertrophic & $\geq 100$ & $\geq 25$ & $\geq 75$ & $\leq 0.7$ & $\leq 1.5$ \\
\hline
\end{tabular}

TP: total phosphorus concentration; Chl- $a$ : chlorophyll- $a$ concentration; Transparency measured as Secchi depth readings; see Chapter 13.

competition, grazing by zooplankton, phage infection and lysis (Stough et al., 2017; Šulčius et al., 2018; Box 4.3) as well as parasitism (Frenken et al., 2017; Agha et al., 2018), can play a decisive role, and these are included in the discussion below.

\subsection{The concept of "trophic state"}

This concept integrates a classification of levels of nutrient concentrations with their outcome in terms of phytoplankton biomass and turbidity. Initially, Vollenweider \& Kerekes (1982) proposed a classification of five trophic states based on data from lakes in temperate climates (Table 4.1). This classification uses the annual mean concentration of total phosphorus (TP) as the chief limiting nutrient in these waterbodies (see section 4.3.2 and Box 4.5), annual mean and maximum concentrations of chlorophyll-a as measure of phytoplankton biomass (see Box 4.6), as well as water transparency, measured as Secchi disc reading (see Chapter 13).

\section{BOX 4.5: N LIMITATION VERSUS P LIMITATION: SCIENTIFIC CONTROVERSY OR CONSENSUS?}

Vollenweider's (1968) keystone report on the scientific background of eutrophication of inland waters starts with the sentence "Nitrogen and phosphorus appear to be the most important among the nutrients responsible for eutrophication". Since then, the debate whether N or P or both are responsible for eutrophication has not ceased and with it, the discussion on approaches how to revert eutrophication is ongoing (Schindler, 2006). During the last decades of the 20th century, eutrophication control of freshwaters largely focused on $P$ with success in many cases. One reason is that $P$ does not, unlike $N$, have an 
unlimited atmospheric reservoir: $\mathrm{N}$ can be imported into the surface water by $\mathrm{N}$ fixation; also in shallow waterbodies, it can be exported by denitrification and thus potentially be lost more quickly than $\mathrm{P}$, which may be recycled between the sediment and water if water exchange rates are low (Shatwell \& Köhler, 2019). As phases of $\mathrm{N}$ limitation are common in many shallow waterbodies, some authors have concluded that therefore $\mathrm{N}$ needs to be reduced together with P (Conley et al., 2009; Paerl et al., 2016).

The controversy of $\mathrm{P}$ versus $\mathrm{N}$ limitation can be exemplified with a series of publications on Lake 227. This small experimental lake has been fertilised for 37 years with constant annual inputs of $P$ and decreasing inputs of $N$. Even after ceasing $\mathrm{N}$ fertilisation, the phytoplankton abundance remained on an "eutrophic" level, leading Schindler et al. (2008) to the conclusion that attempts to reduce eutrophication by reducing $\mathrm{N}$ loads are compensated by cyanobacterial $\mathrm{N}$ fixation and hence reducing $\mathrm{N}$ loading as a management tool may be futile. This conclusion was challenged by re-analysing the same data set by Scott \& McCarthy (2010) who found a decline of phytoplankton biomass after $\mathrm{N}$ fertilisation stopped with a rate of some $6 \%$ per year. With four more years of data, this trend, however, could not be verified, thus supporting the original conclusion (Paterson et al., 20II). In turn, Scott \& McCarthy (20II) argued that $\mathrm{N}$ limitation may nonetheless be present but will affect phytoplankton biomass only after a time delay. Yet a few years later, Higgins et al. (2018) suggest that $\mathrm{N}$ limitation is still not significantly affecting this phytoplankton community.

This example shows how difficult it is to reach unambiguous conclusions since even a small lake is a very complex ecosystem. On a larger scale, Elser et al. (2007) showed that both increased $\mathrm{N}$ and $\mathrm{P}$ lead to increased biomass in freshwater as well as in marine and terrestrial ecosystems, with most pronounced responses for combined $\mathrm{N}$ and $\mathrm{P}$ fertilisation. It could therefore be argued that both $\mathrm{N}$ and $\mathrm{P}$ inputs need to be reduced to effectively revert eutrophication. Arguments held against this proposal (see review in Chorus \& Spijkerman, 2020) are that

I. Experiments adding both $\mathrm{N}$ and $\mathrm{P}$ show that if all other resources, particularly light, are available in surplus, adding both nutrients can lead to higher biomass compared to adding of only $\mathrm{N}$ or only P. Such results, however, do not allow the inverse conclusion, that is, that both must be reduced to allow an efficient reduction of phytoplankton biomass. Reducing either $\mathrm{P}$ or $\mathrm{N}$ alone likely would likely suffice to reduce biomass, and the choice may be driven by practical considerations.

2. Even if $N$ is currently limiting biomass, reducing $P$ sufficiently will shift a waterbody to $\mathrm{P}$ limitation. 
3. In many situations, $\mathrm{P}$ reduction is easier to achieve and results can be predicted with less uncertainty (Chapters 7 and 8).

4. $\mathrm{N}$ limitation may shift species composition between cyanobacteria and algal phytoplankton (Harris et al., 20l4) and between cyanobacterial taxa (Teubner et al., 1999; Dolman et al., 2012), and such shifts are, as of yet, scarcely predictable. The concern that $\mathrm{N}$ limitation may promote $\mathrm{N}$-fixing cyanobacteria (Schindler et al., 2008) has rarely proven relevant in practice.

5. So far, successful cases of lake or reservoir restoration with substantially reduced cyanobacterial biomass have been achieved by reducing P (Fastner et al., 2016; Schindler et al., 2016); success due to reducing $\mathrm{N}$ has scarcely been demonstrated (see Shatwell \& Köhler (2019) for a successful example).

Jeppesen et al. (2007) contributed to resolving this controversy with data from 56 lakes showing that "if $P$ can be reduced to low concentrations, $N$ is not likely to be of major importance".

Reduction of $\mathrm{P}$ loads to many lakes and reservoirs has been successfully achieved with techniques such as $\mathrm{P}$ elimination or $\mathrm{P}$ precipitation in sewage treatment, appropriate use of mineral fertilisers, reduction of phosphates in laundry detergents or a combination of any of these measures. Therefore, from a practical point of view, $P$ load reduction is often considered a first choice for an efficient management tool to revert eutrophication of lakes and reservoirs and thus to control cyanobacterial blooms.

However, ecological considerations, particularly for downstream coastal areas, may also necessitate controlling $\mathrm{N}$, and when planning measures to control cyanobacteria, it may be effective to take this wider context into account (Chapter 7). Particularly for shallow lakes with several months of $N$ limitation during summer, it is important to avoid any new $\mathrm{N}$ loads, and an option to control cyanobacteria may be to seasonally target measures that reduce prevalent $\mathrm{N}$ loads (see section 7.I).

This classification of trophic state may be adapted to local or regional circumstances, and systems have been proposed with further "fine-tuning" of the trophic state definitions: regional re-assessments of trophic state boundaries are given, for example, by Nürnberg (1996) for North American Lakes, including the impact of conditions such as lake morphometry, water hardness and fulvic/humid acid concentrations, and by Salas \& Martino (1991) for warm-water lakes in Latin America and the Caribbean. Carlson (1977) developed a widely used numerical trophic state index (TSI) ranging 
from 0 to 100 and including Secchi depth, TP and chlorophyll- $a$ concentrations. In spite of controversy over details of the definition of each category and its boundaries, the trophic state concept is widely used in practice. It is valuable for cyanobacterial management, because a few general statements apply to most cases:

- In oligotrophic waterbodies, planktonic cyanobacteria are unlikely to attain cell densities that cause hazardous cyanotoxin concentrations. However, benthic or epiphytic cyanobacteria may be present and cover littoral sediments.

- In mesotrophic waterbodies, cyanobacterial blooms occur rarely; exceptions include metalimnetic accumulations of Planktothrix rubescens (which may be at depths of drinking-water offtakes or come to the surface, increasing risk of exposure), detached mats of benthic cyanobacteria (see above) and - in large waterbodies - recruitment of cyanobacteria (particularly of Dolichospermum) from low cell density but very large water volumes and surface areas to visible scums along a downwind shoreline (section 4.5).

- In eutrophic and particularly bypertrophic waterbodies, cyanobacteria occur frequently and abundantly, often constituting a major share of the total phytoplankton biomass for extended parts of the year.

\section{BOX 4.6: MONITORING TOTAL PHOSPHORUS AS OPPOSED TO SOLUBLE PHOSPHATE FRACTIONS}

Considerable confusion prevails in the use of the term "phosphate". Historically, soluble reactive phosphate (SRP), also termed "dissolved inorganic phosphate" (DIP) or "orthophosphate", has been measured and addressed when dealing with phytoplankton growth, because this is the fraction of TP which is directly available for uptake by cyanobacteria and algae. However, recycling of phosphate molecules within the plankton communities is often extremely rapid (within minutes), and phosphate liberated by the degradation of organic material will be rapidly taken up by bacteria and algae. Furthermore, cyanobacteria and algae can store enough phosphate for up to four cell divisions, even if no SRP can be measured. If SRP is found above the detection limits, this means that it is available in excess to the requirements of cyanobacteria and other phytoplankton. The only informational value of such a finding is that $\mathrm{P}$ is being "left over" and growth is limited by some factors other than $\mathrm{P}$.

The upper limit of the biomass of cyanobacteria and/or algae that can develop in a given waterbody is, therefore, often largely determined by the amount of $\mathrm{P}$ bound within the cells, and total phosphate phosphorus is the variable that should be studied for biomass management. Strictly, this 
variable is not equivalent to total phosphorus (TP), which includes the mineral form (like apatite) unavailable for biological uptake. However, mineral forms are of quantitative importance only in particular waterbodies (e.g., with high silt loading), and for the sake of simplification, TP has become widely used to represent total phosphate phosphorus.

It is of importance to note that concentrations of TP refer to the molecular weight of the phosphorus atom $(30.97 \mathrm{~g} / \mathrm{mol})$ and not to that of phosphate molecule $\left(\mathrm{PO}_{4}, 94.97 \mathrm{~g} / \mathrm{mol}\right)$. Where this is not clearly stated, it has caused considerable confusion in the literature.

"Eutrophication" is the process of nutrient enrichment with the consequence of a massive increase in the biomass of phytoplankton - often in particular of cyanobacteria - and reduced transparency. Eutrophication has become a widespread problem in many regions of the world in the 1960s in the wake of intensified application of mineral fertilisers, intensified animal husbandry as well as urbanisation and increased sewage discharges causing intensified nutrient loading to waterbodies. "Re-oligotrophication" is the reverse of eutrophication, and measures to achieve this started being implemented already in the late 1970s. While in some regions they are increasingly showing success, with the trophic state of waterbodies decreasing, in many regions eutrophication is still increasing, particularly in response to clearing of land for settlements or for agricultural use.

\subsubsection{Nutrients}

Phytoplankton biomass - that is, microalgae and cyanobacteria - chiefly consists of carbon $(\mathrm{C})$, oxygen $(\mathrm{O})$, hydrogen $(\mathrm{H})$, nitrogen $(\mathrm{N})$ and phosphorus (P). Under the conditions of rapid growth not limited by shortage of nutrients, it contains these elements in the following relative proportions (known as Redfield ratio; Redfield (1934)), expressed either in molar ratios or in mass units:

\begin{tabular}{lccc}
\hline & $C$ & $N$ & $P$ \\
\hline Molar ratios & 106 & 16 & I \\
Mass ratios & 42 & 7 & I \\
\hline
\end{tabular}

Higher ratios of C:P have been suggested by Anderson \& Sarmiento (1994) and Sterner et al. (2008). There is no lack of O and $\mathrm{H}$ in water, and concentrations of $\mathrm{C}$ become limiting only in very acidic water - or sometimes in extremely dense cyanobacterial blooms (Ibelings \& Maberly, 
1998). Thus, nitrogen $(\mathrm{N})$ and phosphorus $(\mathrm{P})$ are the key nutrients that promote - or limit - the growth of cyanobacteria and other phytoplankton in freshwaters. Although in consequence of the Redfield ratio, biomass production requires only about 1 mole of $\mathrm{P}$ per 16 moles of $\mathrm{N}$, in many types of freshwater environments phosphorus is the resource which most frequently limits phytoplankton growth, while $\mathrm{N}$ limitation occurs frequently but often not for longer periods of time.

Nitrogen $(\mathrm{N})$ may enter waterbodies leaching from soils particularly after spreading of manure or fertiliser, as run-off from animal feedlots and sewage (see Chapter 7). It is also recycled within a waterbody through the degradation of organic matter and excretion by animals. Cyanobacteria - like microalgae - can take up inorganic dissolved nitrogen in the form of nitrate, nitrite and ammonium. While utilisation of atmospheric nitrogen through diazotrophy has been considered unlikely to fully supply the $\mathrm{N}$ demands of an aquatic ecosystem because this process requires a high amount of energy (Conley et al., 2009; Moss et al., 2013; Shatwell \& Köhler, 2019), there are, however, case examples even of quite turbid waterbodies like Sandusky Bay (Lake Erie, USA) in which $\mathrm{N}$ fixation periodically contributes up to $85 \%$ of total $\mathrm{N}$ uptake of the phytoplankton (Salk et al., 2018 and literature therein). Aquatic systems loose dissolved inorganic nitrogen through denitrification: under anoxic conditions, microorganisms use nitrate as source for oxidation processes, thus reducing nitrate to atmospheric nitrogen $\left(\mathrm{N}_{2}\right)$ which diffuses out of the water into the atmosphere.

Phases of $\mathrm{N}$ limitation are common in many waterbodies (reviewed by Sterner, 2008 and Søndergaard et al., 2017), in some pristine mountain lakes (Diaz et al., 2007) and particularly in eutrophic waterbodies and during warmer months in shallow zones with high rates of denitrification at the sediment surface. $\mathrm{N}$ limitation is more frequent in some regions than in others (Conley et al., 2009): for example, phytoplankton biomass is N-limited in many lakes in South America (Soto, 2002) or in New Zealand (Abell et al., 2010) - possibly due to lower rates of input from the atmosphere and/or less use of nitrogen fertilisers (Schindler, 2006).

Excessive $\mathrm{N}$ concentrations have detrimental effects on aquatic macrophytes that are important competitors of phytoplankton, including cyanobacteria, in shallow lakes (Moss et al., 2013).

When assessing which nutrient is limiting phytoplankton biomass at which time of the year, it is important to realise that $\mathrm{N}$ limitation is unlikely if concentrations of dissolved inorganic $\mathrm{N}$ are above $30-100 \mu \mathrm{g} / \mathrm{L}$ (Reynolds, 2006; Kolzau et al., 2014).

Phosphorus (P) enters waterbodies from sewage, animal feedlots and soils, particularly if these were fertilised with minerals or manure (see Chapter 7). As it binds to soil particles more effectively than nitrate, the main entry route into waterbodies from land is as surface run-off, often combined with erosion. Carvalho et al. (2013) evaluated a data set from 
more than 800 lakes of medium or high alkalinity in Europe and show that cyanobacterial biomass generally increases in relation to the concentrations of total phosphorus (TP). Using large data sets from several hundred waterbodies or the response of individual lakes to reduced TP concentrations, several authors (discussed below in section 4.4) have found that cyanobacterial biomass scarcely reaches health-relevant levels at TP concentrations below $10 \mu \mathrm{g} / \mathrm{L}$. In the concentration range of $20-100 \mu \mathrm{g} / \mathrm{L}$, TP strongly determines cyanobacterial biomass levels, while at the concentrations of TP exceeding $100 \mu \mathrm{g} / \mathrm{L}$, curves level off and a further increase in cyanobacterial biomass is rarely observed (in many cases because light then becomes limiting).

$\mathrm{P}$ limitation is unlikely if concentrations of soluble reactive phosphorus (SRP) are above 3-10 $\mu \mathrm{g} / \mathrm{L}$ of P (Reynolds, 2006; see also discussion in Kolzau et al., 2014).

$N$-, $P$ - or light-limiting biomass carrying capacity: At any one point in time, one resource will determine the maximum possible amount of phytoplankton biomass - a concept termed "carrying capacity" (Box 4.7), while other resources may be available in excess. In turbid water or during winter in temperate climates, light is usually the limiting resource, while the available $\mathrm{N}$ and $\mathrm{P}$ would allow a higher level of biomass. The limiting resource may change seasonally, for example, light availability changes - at higher latitudes - in relation to the angular height of the sun and day length, or - as often the case in tropical climates - in relation to turbidity changes caused by pronounced seasonality of the flow regime. Seasonal patterns of light, $\mathrm{N}$ and $\mathrm{P}$ are likely to be quite specific for a given waterbody. Figure 4.3 shows a conceptual model for a shallow lake in a temperate climate: as light intensity increases in spring, phytoplankton begins to grow and incorporates available $\mathrm{N}$ and $\mathrm{P}$ into new biomass, depleting $\mathrm{P}$ to where it becomes limiting so

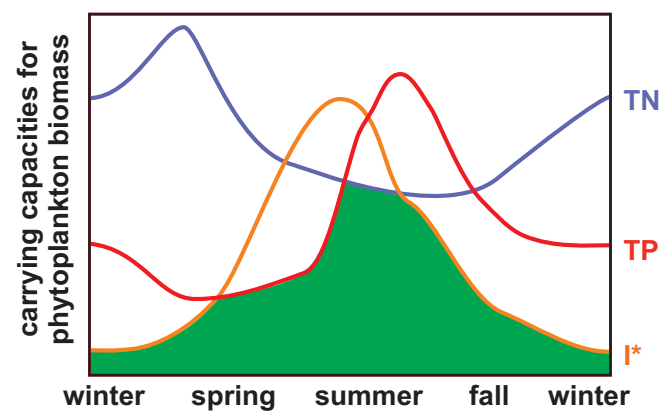

Figure 4.3 Schematic model of the seasonal course of the carrying capacity for phytoplankton biomass in the temperate zone of the Northern Hemisphere. Solid lines indicate carrying capacities determined by light intensity $\left(I^{*}\right)$, total phosphorus (TP) and total nitrogen (TN) as the most important limiting factors (Reynolds \& Maberly, 2002). The green area shows the resulting composite carrying capacity for phytoplankton biomass. Adapted from Reynolds (1997). 
that further increase of biomass is no longer possible - that is, biomass has reached the carrying capacity of the system. In this model case, $\mathrm{N}$ is available in excess during most of the year, but by mid-summer, $\mathrm{P}$ availability increases again through release from the sediment and $\mathrm{N}$ briefly becomes the limiting resource. In autumn, it is once again light that limits carrying capacity. At lower latitudes, the seasonal pattern for the light-limited carrying capacity is less pronounced - or determined by patterns of turbidity caused by monsoon events.

\section{BOX 4.7: THE ECOLOGICAL CONCEPT OF CARRYING CAPACITY}

The concept of an ecosystem carrying capacity has a long history in theoretical ecology. Although intuitively easily accessible, the concept involves some complexities due to differences in use in different fields, including ones that are not related to ecology (Sayre, 2008) or ambiguities associated with mathematical modelling (Gabriel et al., 2005; Mallet, 2012; Chapman \& Byron, 2018).

In the definition given by Odum (1953), carrying capacity is the number of individuals of a given species that a given habitat can support without being permanently damaged. In this sense, the concept is largely applied to animals such as mammals, bivalves or humans, and considers a long-term equilibrium of the population with the entire environment (Begon et al., 1996).

In plankton ecology, the concept of carrying capacity has been adapted with a somewhat different meaning: for one, it rather refers to the maximal population or biomass density that can be reached at a given point in time - for example, during late summer in temperate lakes - than to a persisting equilibrium population (Reynolds, 1984). Further, carrying capacity is differentiated for each major resource: resource-specific carrying capacities are estimated to determine which resource limits biomass in a given system at a given point in time (Reynolds \& Maberly, 2002).

In this volume, the term "carrying capacity" is used in this sense, as maximally attainable biomass in relation to a particular resource. This means analysing dynamics of individual carrying capacities for phosphorus and nitrogen concentrations and light intensity to explain occurrence and dynamics of cyanobacterial blooms (Figure 4.3) and to support the development of management approaches (Chapters 6 and 7 ).

If this model lake had extremely high concentrations of $\mathrm{P}$ and $\mathrm{N}$, its carrying capacity for biomass would remain limited by light year-round: phytoplankton biomass would increase to such high turbidity that cells shade each to the point that no further increase is possible. In shallow lakes, higher biomass concentrations are possible than in waterbodies with 
deeper mixing because deep mixing entrains cells into darker layers. Using the concentration of chlorophyll- $a$ as a measure of phytoplankton biomass, Figure 4.4 illustrates this with a selection of lakes: the deep lakes in the lower panel scarcely touch the curve for the 1:1 relationship of chlorophyll- $a$ to TP, whereas some of the shallow ones summer mean values even occasionally exceed this curve. Moreover, at higher phosphorus concentrations, the curves for Lake Constance (Bodensee), Lake Tegeler See and

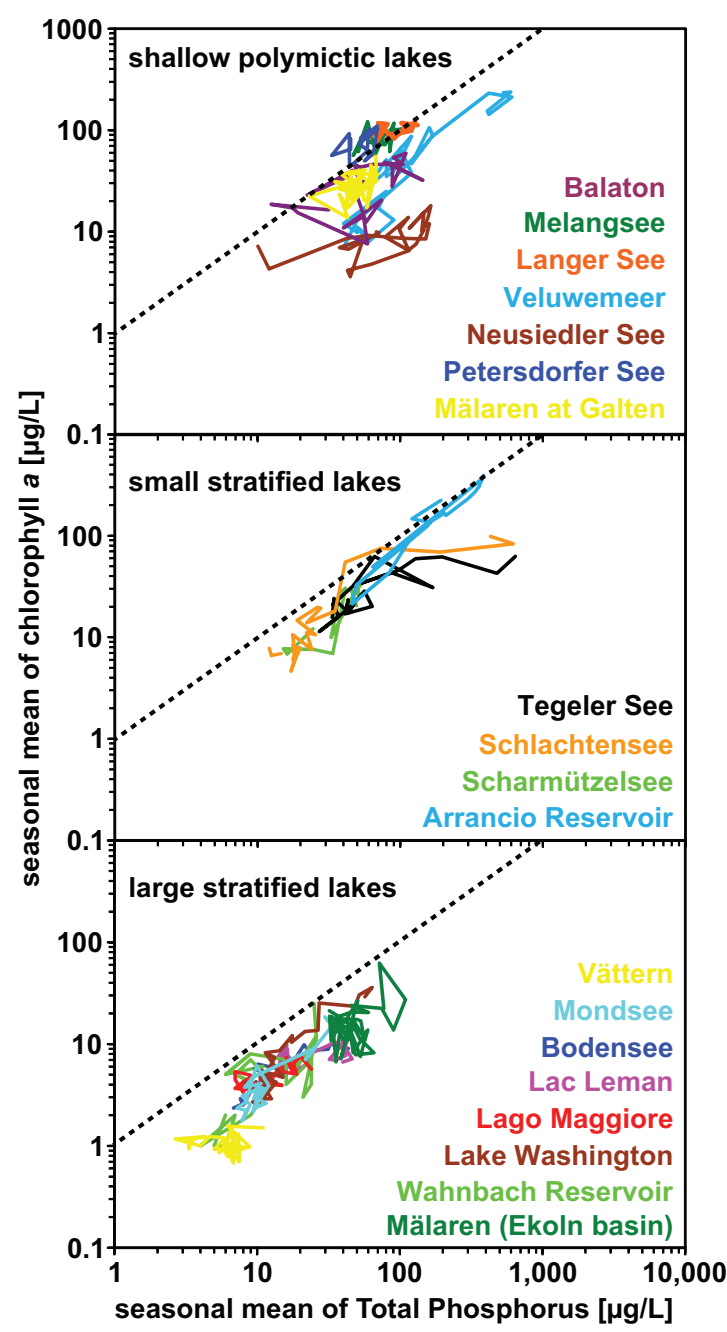

Figure 4.4 Phytoplankton biomass (as chlorophyll-a) and total phosphorus (TP) seasonal means (May - October or September) of epilimnion or surface layer in $\mu g / L$, connected chronologically for each lake for consecutive years. The dotted line shows the I:I relationship of chlorophyll- $a$ with TP. See online version for colour code of waterbodies. (Modified from Chorus et al., 20II. Electronic version in colour) 
Lake Schlachtensee level off asymptotically at 20-50 $\mu \mathrm{g} / \mathrm{L}$ TP rather than showing further increase. Balaton and Neusiedler See show lower means for chlorophyll- $a$ because of the strong impact that suspended sediment can have in the large, wind-exposed shallow lakes: in these lakes, suspended sediment particles shade the phytoplankton, which therefore cannot develop as high a biomass per unit phosphorus as it can in other, smaller and less wind-exposed lakes (Fastner et al., 2016). Downing et al. (2001) show curves for 99 lakes that level off at $100 \mu \mathrm{g} / \mathrm{L} \mathrm{TP}$ and $1000 \mu \mathrm{g} / \mathrm{L} \mathrm{TN}$. For mostly shallow lakes in northern Germany, Dolman et al. (2012) assume that nutrient limitation of the carrying capacity can fairly reliably be excluded only at nutrient concentrations exceeding $300 \mu \mathrm{g} / \mathrm{L}$ of TP and $4000 \mu \mathrm{g} / \mathrm{L}$ of TN.

Moreover, because of losses (e.g., grazing, phage and parasite infection), phytoplankton biomass rarely fully reaches the levels that carrying capacity in terms of $\mathrm{N}, \mathrm{P}$ and light would allow. This is manifestly observed particularly during a seasonal clear-water phase in many lakes when loss through zooplankton grazing exceeds phytoplankton growth to a degree that results in a population collapse and a steep increase in water transparency (Lampert et al., 1986). Cyanobacteria, however, tend to be more resistant to grazing (see section 4.2.4) than many other phytoplankton taxa and thus are more likely to attain the maximum possible biomass level given by the carrying capacity.

$N$ or P limitation and N:P ratios: The occurrence of cyanobacterial blooms has often been linked to the relative availability of $\mathrm{N}$ in relation to $\mathrm{P}$, proposing cyanobacteria in general to become dominant when the $\mathrm{N}$ :P ratio drops below 29 to 1 , even for non $\mathrm{N}_{2}$ fixers like Microcystis (discussed in Downing et al., 2001). Indeed, some published field and experimental data show correlations between the dominance of cyanobacteria and low N:P ratios (Smith, 1983; Bulgakov \& Levich, 1999; Elser \& Urabe, 1999; Harris et al., 2014). However, other studies do not confirm this: for example, the analysis of 99 of the most studied lakes in the temperate zone by Downing et al. (2001) showed N:P ratios to be the weakest predictor of cyanobacterial dominance as compared to the concentration of $\mathrm{N}$ or P individually. Also, in an extensive analysis of 210 Danish lakes, Jensen et al. (1994) found no relationship between amounts of $\mathrm{N}$-fixing cyanobacteria and low ratios of total nitrogen (TN) to TP, nor did their biomass correlate with low concentrations of inorganic $\mathrm{N}$. What causes these contradicting findings?

Reynolds (1999a) explains them by emphasising the importance of "absolute quantities" rather than ratios for driving the outcome of competition between species and emphasises that the N:P ratio becomes meaningless when concentrations of either $\mathrm{N}$ or $\mathrm{P}$ or both are too high to be limiting phytoplankton growth (Reynolds, 1999b). Limitation is highly unlikely if concentrations of TP and TN support a high capacity for phytoplankton biomass (see above in this section), and in many waterbodies, particularly in deep 
ones, thresholds for the limitation of biomass by TP and TN will be lower. Moreover, if dissolved nutrients are present in concentrations above 5-10 $\mu \mathrm{g} / \mathrm{L} \mathrm{P}$ or $100 \mu \mathrm{g} / \mathrm{L} \mathrm{N}$, this indicates that these are not limiting the phytoplankton's uptake rates, that is, that phytoplankton cells are saturated (note that in practice for dissolved $\mathrm{P}$, the limit of quantification for most analytical methods corresponds to the threshold for limitation, i.e., $10 \mu \mathrm{g} / \mathrm{L}$; see Chapter 13). Unfortunately, N:P ratios have been used widely and erroneously without excluding data from such clearly nonlimiting situations. Whether $\mathrm{P}$ or $\mathrm{N}$ is limiting phytoplankton growth and at which time during the season can be of relevance for water managers who need to prevent further increase in cyanobacterial blooms or find the locally most effective measures to reduce cyanobacterial abundance in a specific waterbody (see section 7.1 and Box 4.5). However, even where $\mathrm{N}$ is the limiting resource at times, sufficiently reducing $\mathrm{P}$ will turn $\mathrm{P}$ into the limiting resource and lastingly limit phytoplankton biomass.

\subsubsection{Light availability}

Light is exponentially attenuated with increasing depth (following the Lambert-Beer equation), and how steeply it diminishes over depth depends on the water's constituents. There may be complete darkness already at a few metres depth (Kirk, 1994). The zone in which photosynthesis can occur is termed the "euphotic zone" $\left(Z_{\text {eu }}\right)$. By definition, the euphotic zone extends from the surface to the depth at which the light intensity amounts to $1 \%$ of that at the surface. It is frequently estimated by measuring transparency with a Secchi disc (see Chapter 13) and multiplying the Secchi depth reading by a factor of $2.3-2.5$.

Phytoplankton species - including cyanobacteria - differ in the dependency of their growth rate on light. Light availability therefore is an important factor determining the outcome of competition between species and thus whether the phytoplankton biomass consists chiefly of certain microalgae or certain species of cyanobacteria. At low light intensity, some cyanobacterial species (e.g., Planktothrix agardhii and P. rubescens) can maintain a higher growth rates than other phytoplankton organisms. This is why $P$. rubescens can thrive in the metalimnion of thermally stratified lakes and reservoirs. Also, in waters with high turbidity, P. agardhii can outcompete other species, reaching very high biomass, which in turn decreases transparency, thus improving growth conditions for itself in the sense of a positive feedback loop (Mantzouki et al., 2016).

Other cyanobacterial taxa need higher light intensities than Planktothrix in order to develop substantial populations, for example, many taxa of the order Nostocales. For R. raciborskii in lakes of northern Germany, Wiedner et al. (2007) demonstrated that light intensity is the most important factor determining population growth. Dolichospermum species are 
also known to occur more frequently in fairly clear water, for example, early in the growing season before turbidity increases due to increased phytoplankton density, or in less eutrophic lakes.

Using field data from Lake Victoria, Loiselle et al. (2007) show how the availability of solar irradiation, strongly influenced by mixing depth, determines the carrying capacity in waterbodies with excessive nutrient concentrations and how maximum phytoplankton biomass levels can be estimated from light availability.

\subsubsection{Temperature, thermal stratification and mixing}

Temperature is a further strong determinant of species composition, acting in two ways: (i) temperature in relation to the depth of a waterbody determines whether it develops thermal stratification or whether the water is mixed down to the sediment and (ii) all species grow faster at higher temperatures, up to a limit, but species differ in the temperature dependency of their growth rate, and for some cyanobacteria, the increase in growth rates as a function of temperature is steeper than for most of their eukaryotic competitors (Visser et al., 2016b).

In continental-scale surveys, cyanobacteria have been shown to dominate at locations with higher temperatures (Kosten et al., 2009; Kosten et al., 2012), and links between blooms and heatwaves (Jöhnk et al., 2008; Huber et al., 2012) have been established, albeit not always in a straightforward manner and partly only based on theoretical considerations (see below). Field data on species occurrence in relation to temperature scarcely allow a distinction between the indirect impact of temperature (i.e., determining the extent of mixing $v s$. stratification) and its direct effect on growth rates, and temperature alone is not a good predictor of blooms.

Often the indirect impacts of temperature are more important than the direct effects (Carey et al., 2012). In temperate climates, many waterbodies develop thermal stratification in spring, as energy input into the surface layer increases with increasing solar insolation and temperature (Box 4.2). Together with irradiation, wind and convection, thermal energy input determines whether waterbodies are well mixed or develop thermal stratification. As discussed above, thermal stratification is of paramount importance for growth and proliferation of all phytoplankton - cyanobacteria as well as microalgae. The strength of stratification, for example, of a deep alpine lake like Lake Zurich (Switzerland) has increased by more than $20 \%$ over the last few decades (Livingstone, 2003), compared to a less than $1{ }^{\circ} \mathrm{C}$ warming of the surface water of the lake over the same period, thus illustrating the relevance of indirect versus direct effects of climate warming. Wagner \& Adrian (2009) propose more stable stratification to promote cyanobacterial blooms in eutrophic waterbodies. 
Thermal stratification determines

- to which depth an average phytoplankton cell is entrained in the mixed upper layer and thus how much light it is exposed to while being moved across the underwater light gradient;

- the temperature and nutrient gradients that cells and colonies experience while entrained in mixing;

- whether cyanobacterial surface blooms and scums can accumulate at the surface of a waterbody or mixing energy is sufficient to maintain cyanobacteria in suspension;

- whether phytoplankton cells are likely to sink to the bottom through sedimentation (thus getting - at least temporarily - lost from the growing population when light does not penetrate to the sediment), or whether they remain entrained in the mixed layer;

- whether nutrients liberated from decaying biomass are redistributed in the water or whether they accumulate near the sediment or in the hypolimnion.

Huisman et al. (2004) modelled competition between buoyant cyanobacteria and other nonbuoyant phytoplankton as a function of access to light and turbulent mixing, and showed that under weak turbulence buoyant cyanobacteria on average may be positioned closer to the surface than their competitors. Hence, access to light, in particular for bloom-forming cyanobacteria, must always be considered in relation to the mixing processes in the lake. Under sustained, full mixing, Microcystis blooms are unlikely to form, an observation strengthened by successful control of these species through artificial lake mixing (Visser et al., 2016a).

Many cyanobacteria have higher temperature optima than many microalgae, in particular Microcystis spp. (Reynolds, 1997); thus, despite their relatively slow growth at lower temperatures, Microcystis may catch up with competitors in warmer water. Furthermore, elevated temperatures at the sediment surface may promote the recruitment of cyanobacteria from the sediments, as proposed for Microcystis (Shapiro, 1997) and R. raciborskii (Padisák, 1997; Wiedner et al., 2007). The filamentous cyanobacterium $R$. raciborskii thrives in waters with high temperature and moderately high nutrient levels, particularly in phases of elevated transparency, and was originally considered to be a typical tropical and subtropical species (Dyble et al., 2002). Although some discussions have assigned its spread to temperate climate zones to global warming, an alternative explanation is that the genotypes found on different continents (see above) may also differ in their growth rates in relation to temperature (Gugger et al., 2005b). True extremophiles can be found in hot spring microbial mat communities.

Elevated temperature also speeds up the degradation of organic matter, releasing nutrients for growth. 
Most of the studies on cyanobacterial occurrence in relation to temperature focus primarily on population growth while temperature-dependent losses are studied to a lesser extent. Yet, losses may also correlate positively with temperature and outbalance increased growth rates at higher temperatures. For example, Rohrlack (2018) found that Planktothrix can proliferate in a low temperature niche that minimises losses through microbial antagonists to a degree that allows bloom formation despite relatively low growth rates.

\subsubsection{Hydrodynamics and waterbody morphometry}

Waterbody size, depth, shape, wind exposure and water exchange rate are critical conditions determining how water stratifies (layering of water due to density differences caused by heating of surface water or salinity) or moves and how it entrains plankton. In large, shallow lakes, turbulence is often pronounced, particularly if they are exposed to wind, and even highly buoyant cyanobacteria will have little chance for vertical positioning and are mixed throughout the water column. These conditions favour species like $P$. agardhii which do not show pronounced buoyancy regulation but are good competitors for light. Deep lakes generally are thermally stratified with turbulence restricted to the epilimnion. If these lakes are small and wind-sheltered, turbulence may be minimal (with mixing only slight, due to convection as the lake cools nocturnally). However, large stratified lakes and reservoirs may develop internal seiches - with the metalimnion oscillating at regular intervals in consequence of wind moving the surface layer towards one end of the waterbody (Cuypers et al., 2011). This may move species that form distinct layers at the metalimnion, particularly Planktothrix rubescens, up and down in the regular rhythm of the seiches, by up to several metres.

The shape of a waterbody (i.e., its morphometry) is an important factor to consider, in particular for planning sites for drinking-water offtake or bathing beaches, and respective monitoring (see Chapter 11). Lake morphometry can be fairly regular, and thus, water quality (including plankton composition) may be fairly homogeneous. Other waterbodies, particularly reservoirs, have highly irregular, fractal shorelines with incised bays where tributaries enter or with more or less separated basins in which water quality varies distinctly between individual sites. In such situations, cyanobacterial blooms can develop or accumulate in one section, not in others.

A further important hydrological characteristic of a waterbody is the water residence time, that is, the theoretical average time a volume of water remains in the waterbody. It is calculated from the in- and outflow discharge, and the lake volume. Water residence times may vary between seasons and years depending on precipitation and other events in the catchment - and for reservoirs also on the abstraction regime. Low water 
residence times - that is, in the range of days - may dilute cyanobacteria faster than they can multiply. Also, depending on the variability of the quality of inflowing water, low residence times may alter other growth conditions like nutrient concentrations, with short timescales (Romo et al., 2013). Reynolds et al. (2012) show that diluting a lake by $10 \%$ per day would cause an exponential loss rate of -0.16 per day, and most phytoplankton species can scarcely reach faster net growth rates.

Both morphological and hydrological conditions also influence nutrient concentrations (Carpenter et al., 1999). Long water residence times - that is, in the range of years - may be an obstacle for reducing lake P concentrations because even at substantial external load reduction, $\mathrm{P}$ can be recycled within the waterbody and $\mathrm{P}$ concentrations in the sediment will decrease only slowly. For example, Jeppesen et al. (1991) showed that among 27 shallow lakes under restoration in Denmark, cyanobacterial dominance disappeared substantially faster in those with a water retention time of less than half a year.

Stable thermal stratification in deeper lakes can prevent most of the phosphorus released from the sediment from reaching the euphotic zone during the stratified period, whereas in shallow, turbulent lakes, sediment can be resuspended and mixed throughout the water column on windy days, severely reducing water transparency and reducing phytoplankton access to light. For nitrogen, in contrast, mixing down to the sediment particularly in shallow lakes and reservoirs can cause it to become limiting for phytoplankton biomass because higher temperatures at the water-sediment interface enhance the decay of organic substances and in consequence also denitrification rates and hence loss of nitrogen $\left(\mathrm{N}_{2}\right)$ to the atmosphere (see section 4.3.2).

\subsection{6 $\mathrm{pH}$ : acidity and alkalinity}

Cyanobacterial blooms are often associated with alkaline conditions. However, this is usually a consequence rather than a cause of these blooms: the uptake of hydrogen carbonate through intense photosynthesis shifts the equilibrium between carbonate and hydrogen carbonate to render the water alkaline (Wetzel, 2001; Lampert \& Sommer, 2007). While this can be due to a high biomass of any phytoplankton with a high rate of photosynthesis, it is typically cyanobacterial blooms that reach particularly high biomass concentrations and thus are the cause of high $\mathrm{pH}$. Vice versa, cyanobacterial blooms may be expected in waterbodies with $\mathrm{pH}$ ranges above 7 . Under acidic conditions $(\mathrm{pH}<6)$, cyanobacteria are rarely found in sufficiently high cell density to cause detectable levels of cyanotoxins (Chorus \& Niesel, 2011). However, given the array of carbon uptake systems available to cyanobacteria, they can be found to dominate at both low and high dissolved $\mathrm{CO}_{2}$ concentrations (Huisman et al., 2018). 


\subsection{CAN CYANOBACTERIAL BLOOMS BE PREDICTED BY MODELS?}

Two different types of approaches may serve to estimate the likelihood of high cyanobacterial biomass from data on conditions in the waterbody: functional approaches that strive to model the true interactions within the ecosystem and statistical approaches that investigate correlations between cyanobacterial biomass and waterbody conditions. While the advantage of functional modelling is that it depicts causalities, in practice it is limited by the complexity of ecosystem interactions which are challenging to depict in any model. In contrast, while some of the statistical approaches tend to be comparatively simple and straightforward, they only depict correlations, not causalities. Taking correlation for causality is, however, widespread, and when using regressions, it is important to keep in mind that if two factors correlate, it remains unknown whether this is because one is a cause for the other or whether there is a third, perhaps unknown factor causing both factors to increase or decrease in parallel. Correlations are indeed useful to derive hypotheses on the factors determining cyanobacterial biomass; however, before basing management decisions on their results, it is important to investigate and understand the mechanism(s) likely to be causing the correlation. Furthermore, statistical models capture the outcome of all processes determining species dominance and biomass without disentangling their relative importance. Thus, they can be useful for the waterbodies for which they were derived or for those which are similar to the ones used in the model (e.g., within the same ecoregion and similar hydrophysical characteristics), but their predictions are uncertain when applying them to other types of waterbodies.

Functional models strive to overcome this limitation and to be more generally valid by capturing key processes and relationships, including, for example, the dependency of phytoplankton growth rates on environmental conditions, loss processes and competition between some keystone species or phytoplankton groups. A range of such models has been developed that include conditions favouring cyanobacteria. Mooij et al. (2010) give an overview of models developed for the real-time prediction of cyanobacterial scums and blooms from current or recent waterbody and meteorological data, for example, CAEDYM, BLOOM and for shallow, nonstratifying lakes PCLake, PROTECH and SALMO. However, these may fail if processes other than those depicted in the model are important. Predicting cyanobacterial dominance and biomass using generic functional models is not only challenging because of the complexity of waterbody conditions determining the outcome of competition between species, but also because excessively complex models do not necessarily perform better. Reynolds \& Maberly (2002) propose a simple model to estimate the maximum possible biomass yield (carrying capacity) in terms of concentrations of chlorophyll$a$ from the concentrations of nitrogen and phosphorus as well as the photon 
flux density. While this neither includes loss processes nor a differentiation between cyanobacteria and other phytoplankton, it is useful as approach to estimating the maximum conceivable biomass to be expected (and if this is high, rendering the water turbid, a high share of cyanobacteria is likely; see section 4.3). Carvalho et al. (2013) emphasise the value of using nutrient data - particularly those for total phosphorus (TP) - to estimate the likelihood of cyanobacterial blooms because these are much more widely available than phytoplankton data.

Among the statistical approaches, a number of studies addressed the relationship between phytoplankton biomass (often quantified as chlorophyll-a) and the concentration of TP, sometimes including total nitrogen (TN). Most of these studies were conducted in temperate climates, and one of the first to be widely used in management is Vollenweider (1976). Since then, a number of studies have been published giving regressions from a varying number of waterbodies relating chlorophyll- $a$ to both $\mathrm{P}$ and $\mathrm{N}$ (see an overview in Yuan \& Jones (2020). Phillips et al. (2008) give an overview of 15 earlier studies and show the slopes of a total of 15 regressions to vary between 0.8 and 1.5 for $\log$ TP (16 lakes) and 1.0 to 1.4 for $\log$ TN (7 lakes); in consequence, the concentration of chlorophyll- $a$ that these regressions predict for $35 \mu \mathrm{g} / \mathrm{L}$ of TP (at $875 \mu \mathrm{g} / \mathrm{L} \mathrm{TN}$ ) varies by almost a factor of 4 , that is, between 5.4 and $19.5 \mu \mathrm{g} / \mathrm{L}$. Moreover, these authors give new regression equations that they developed from evaluating a data set from $>1000$ European lakes. These show less scatter of the data for chlorophyll- $a$ versus $\mathrm{TP}$ as compared to chlorophyll-a versus $\mathrm{TN}$, reflecting the limitation of biomass chiefly by TP in the larger fraction of the lakes included in the regressions.

In particular, Phillips et al. (2008) differentiated between lake types and geographic regions within Europe. While results show no influence of region, the most pronounced result is that the lowest biomass (in terms of chlorophyll-a) per unit nutrient is found in deep lakes and the highest biomass in shallow lakes (which were also those with high alkalinity). This is to be expected because, as discussed above, deeper mixing causes more pronounced limitation by light, particularly when a high density of phytoplankton cells causes high turbidity. Also reflecting increasing light limitation at high phytoplankton density, the correlation of chlorophyll- $a$ with TP levelled off at concentrations of $100 \mu \mathrm{g} / \mathrm{L}$ TP and $1000 \mu \mathrm{g} / \mathrm{L}$ TN with yet higher levels of both chlorophyll- $a$ and nutrient concentrations, found only in very shallow waterbodies. For using such a regression model to estimate target levels for nutrients, Phillips et al. (2008) emphasise that "managers should use an equation that is derived using data from a lake type that matches as closely as possible the lake they are concerned with".

For tropical climates, Huszar et al. (2006) evaluated data from 192 tropical lakes and found the relationship between chlorophyll- $a$ and TP concentrations to correlate less tightly than for the data from temperate climates, and chlorophyll- $a$ concentrations in relation to TP to be slightly 
(a)
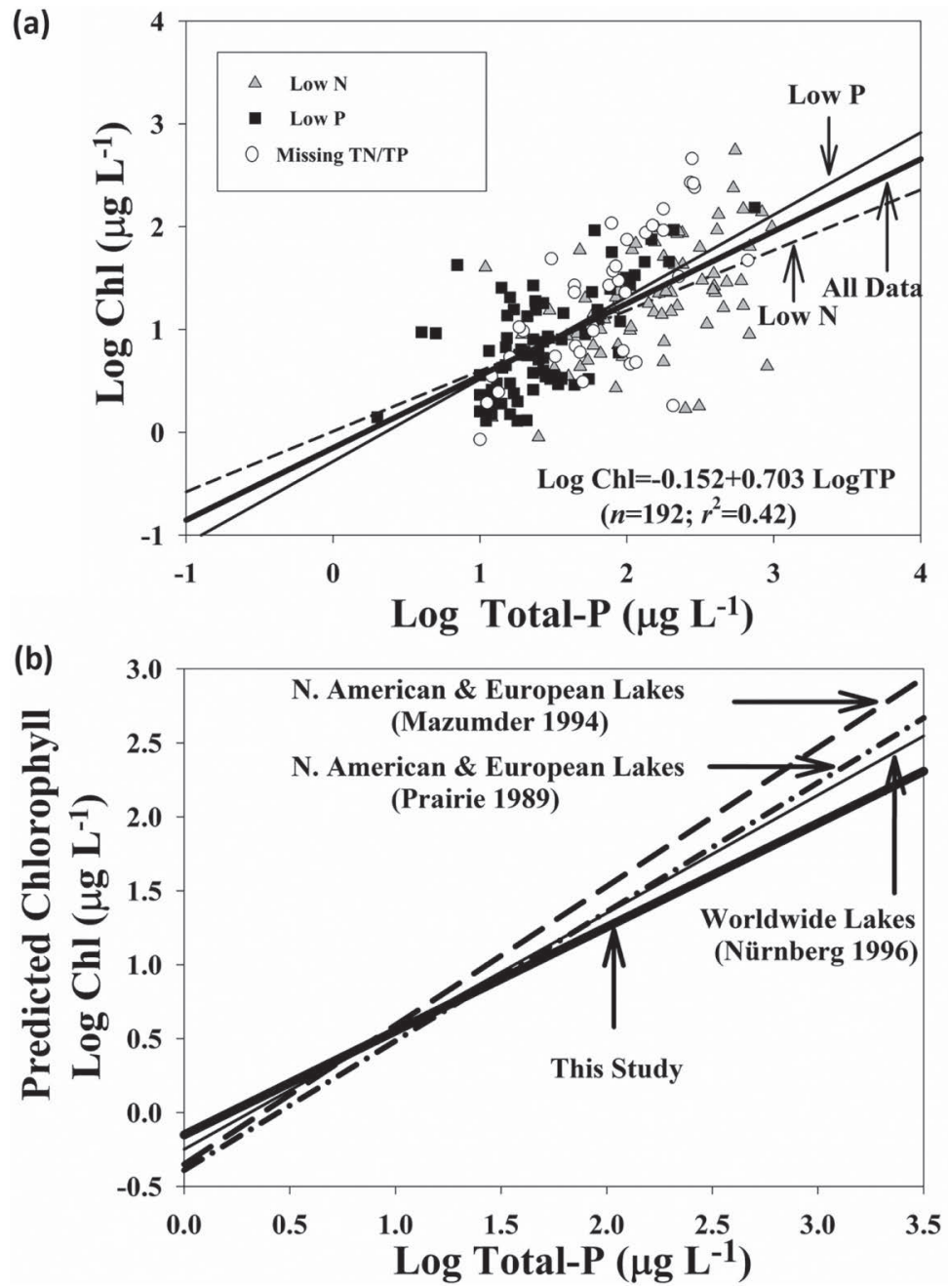

Figure 4.5 (a): annual logarithmic means of chlorophyll versus total phosphorus (TP) from 192 tropical and subtropicallakesfromAfrica, Asia and America with definitions for "low P" being TN:TP by weight $>17$ and for "low N" <17. (b): comparison ofthis relationshipwithregressionspublishedfortemperatelakes.(Reprinted with permissionfromSpringerNature, in:Nitrogen CyclingintheAmericas:Naturaland AnthropogeniclnfluencesandControls.Nutrient-chlorophyllrelationshipsintropicalsubtropicallakes: dotemperatemodels fit? HuszarV, CaracoN, RolandF, ColeJ. Copyright 2006 Springer Nature. www.springernature.com/gp.)

lower (Figure 4.5). As explanation for these phenomena, Jeppesen et al. (2005) propose a stronger impact of further factors such as light limitation in waterbodies with elevated turbidity and more complex food web interactions. In particular, loss processes may lead to phytoplankton 
biomass considerably lower than that expected from nutrient concentrations. Mamun \& An (2017) show the influence of seasonal Asian monsoon on regressions of chlorophyll- $a$ and TP with data from 182 agricultural reservoirs and demonstrate a much stronger correlation of chlorophyll- $a$ to $\mathrm{TP}$ as compared to TN for these waterbodies.

For practical purposes of predicting biomass levels, it is important to realise that the data points for the individual waterbodies behind these regressions scatter considerably: in the statistical evaluation of Huszar et al. (2006), $\log (\mathrm{TP})$ explains only $42 \%$ of the variance of $\log$ chlorophyll (and a multiple regression approach, including TN, resulted in only moderate improvement to $47 \%$ explanatory power). In consequence of this scatter, in any given waterbody observed annual mean chlorophyll concentrations can be several-fold higher or lower than those predicted from total phosphorus (TP)concentrations and the regressions shown in Figure 4.5.

However, this uncertainty in the range of a factor of 3-5 relates to data spanning three orders of magnitude, and thus, the published regressions remain useful for two purposes: (i) for first estimates of the TP target concentrations that are likely to control biomass and (ii) for investigating causes for particularly high or low mean chlorophyll concentrations in relation to those of TP.

Predicting specifically cyanobacterial biomass requires an understanding of the conditions in the waterbody which favour their dominance. Trophic state and the concentrations of TP are key: where nutrient concentrations enable high levels of total phytoplankton biomass, this has a high likelihood to consist chiefly of cyanobacteria - in temperate climates particularly during summer and early autumn: Downing et al. (2001) evaluated data from 99 lakes of the temperate zone and found that the risk of cyanobacterial dominance was related to the TP concentration as follows: $0-30 \mu \mathrm{g} / \mathrm{L} \mathrm{TP}$ : $0-10 \%$ risk of cyanobacterial dominance; $30-70 \mu \mathrm{g} / \mathrm{L}$ TP: $~ 40 \%$ risk; 100 $\mu \mathrm{g} / \mathrm{L}$ TP: $\sim 80 \%$ risk. The authors further highlight that turbidity - caused by high phytoplankton cell density - increases the risk of cyanobacterial dominance (at concentrations of chlorophyll- $a$ above $10 \mu \mathrm{g} / \mathrm{L}$, transparency tends to decline to less than $1 \mathrm{~m}$ ).

Data from shallow lakes in north-eastern Germany dominated by filamentous cyanobacteria confirm the pattern described by Downing et al. (2001): total phytoplankton biomass proved to be a good predictor of cyanobacterial biomass, particularly at high total phytoplankton biomass (Figure 4.6). Once biovolumes were higher than $13 \mathrm{~mm}^{3} / \mathrm{L}$, cyanobacteria almost always constituted at least half of this biomass, often more. The causal explanation for this is that these lakes are dominated by filamentous cyanobacteria, chiefly $P$. agardhii, which can outcompete other phytoplankton particularly under the conditions of low light availability (see section 4.2.2). A similar result is reported by Ptacnik et al. (2008) for lakes in northern Europe: at chlorophyll- $a$ concentrations above $10 \mu \mathrm{g} / \mathrm{L}$, cyanobacteria often dominated 


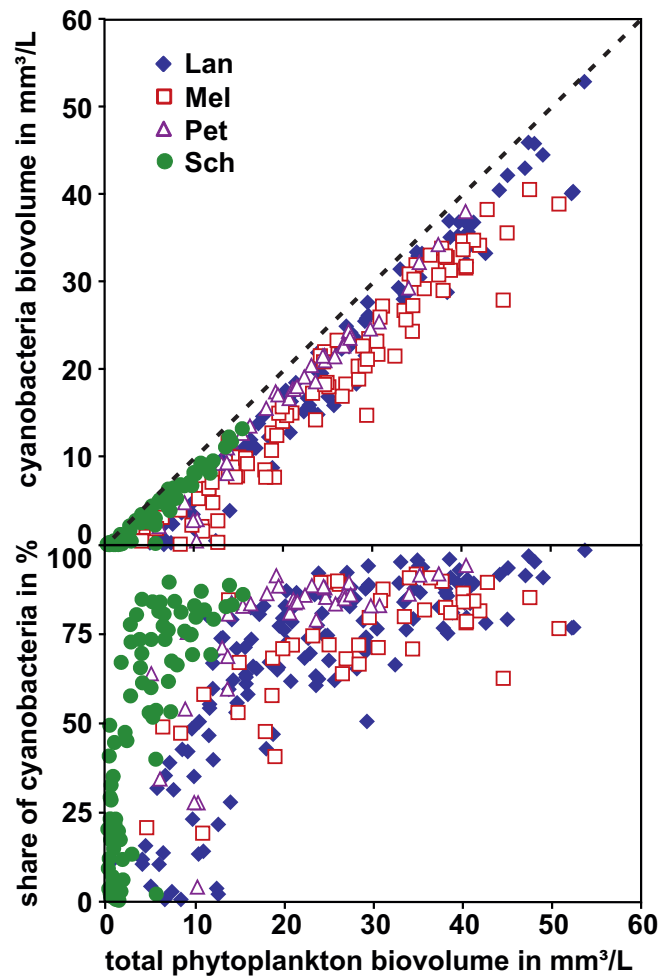

Figure 4.6 Cyanobacterial biovolume in relation to total phytoplankton biovolume for four lakes (Langer See [Lan], Melangsee [Mel], Petersdorfer See [Pet], Scharmützelsee [Sch]) in the same catchment. Upper panel: absolute values of biovolumes; lower panel: relative fraction of cyanobacteria in total biovolume. (Data kindly provided by Brigitte Nixdorf, Brandenburgische Technische Universität Cottbus.)

in samples taken in late summer, and as discussed above, Carvalho et al. (2013) evaluated a data set from more than 800 lakes of medium or high alkalinity in Europe and show a sharp increase in cyanobacterial biomass relative to TP beginning at $10 \mu \mathrm{g} / \mathrm{L}$, increasing sharply in the range of $20-100$ $\mu \mathrm{g} / \mathrm{L}$ and levelling off at $100 \mu \mathrm{g} / \mathrm{L}$.

A further confirmation of the significantly enhanced likelihood of cyanobacteria to be the organisms causing high phytoplankton biomass is given by Chorus et al. (2011) who evaluated a large database with almost 2000 samples from 210 lakes covering six European countries and three ecoregions (Central Plains, Central Highlands and Sicily) for the likelihood of the six most common cyanobacterial taxa to occur, depending on environmental conditions, that is, nutrient concentrations, seasonality, mixing and waterbody depth, turbidity, $\mathrm{pH}$ and temperature (Table 4.2). For five 


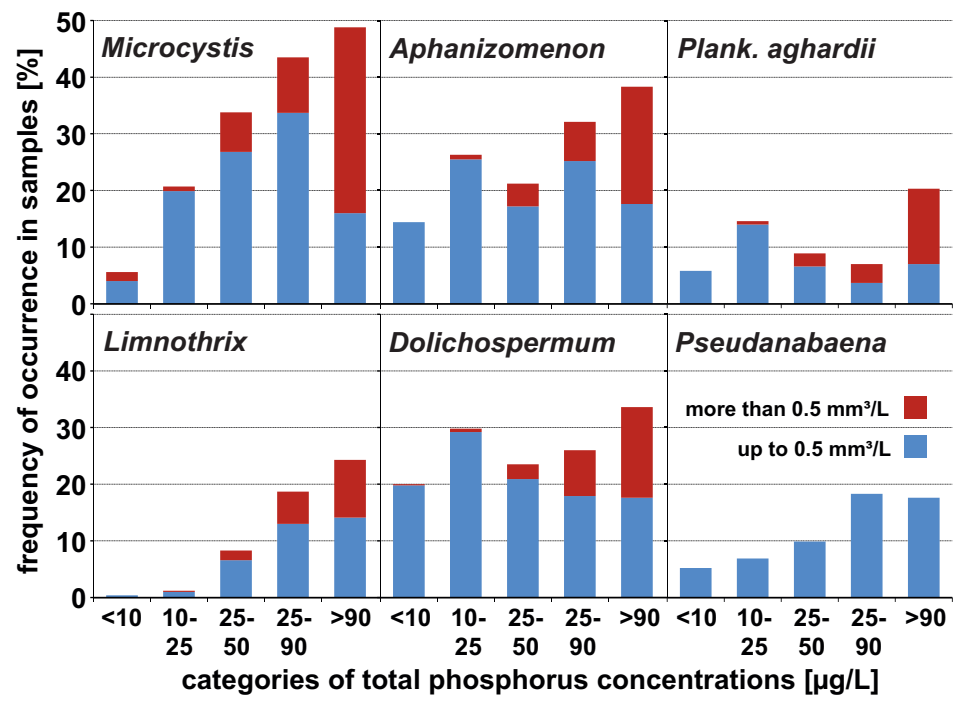

Figure 4.7 Frequency of occurrence of the six most common cyanobacterial taxa in 1928 samples from 210 waterbodies in two biomass categories (biovolumes up to $0.5 \mathrm{~mm}^{3} / \mathrm{L}$ and $>0.5 \mathrm{~mm}^{3} / \mathrm{L}$ ) and in five categories of total phosphorus (TP). Number of samples per category from lowest to highest TP concentrations: 50I, 623, 302, 246 and 256. (Modified from Chorus \& Niesel, 20II.)

categories of TP concentrations, the frequency of individual taxa (relative to all samples in the database) in samples is shown in Figure 4.7. While these taxa were found in some of the samples even at low TP concentrations, that is, $<10 \mu \mathrm{g} / \mathrm{L}$, with the exception of Aphanizomenon, this was only in less than $10 \%$ of the samples, and some taxa (Microcystis spp. and Limnothrix spp.) proved more likely to occur at higher TP concentrations. Importantly, however, cyanobacterial biovolumes above $0.5 \mathrm{~mm}^{3} / \mathrm{L}$ occurred almost only at TP concentrations above $25-50 \mu \mathrm{g} / \mathrm{L} \mathrm{TP}$ and almost exclusively in waterbodies classified as "eutrophic" or "hypertrophic" by the data providers. These cyanobacteria also occurred significantly more frequently at $>16^{\circ} \mathrm{C}$ in late summer, probably due to the time it takes for them to build up larger populations as the season progresses.

Recknagel et al. (2017) demonstrate that lake-specific models developed from historic data and cyanobacterial cell counts can - using only in situ physical-chemical sensor monitoring data - predict blooms quite accurately. Their models (based on hybrid evolutionary algorithms) for Lake Wivenhoe in Australia and the Vaal Reservoir in South Africa forecast blooms exceeding $1 \mu \mathrm{g} / \mathrm{L}$ total MCs 10-30 days ahead of their occurrence. This demonstrates the value of multiseasonal time series to refine more general models for a particular waterbody, as these can improve forecasts for parameters of high relevance for water management. 
Table 4.2 Occurrence of cyanobacteria in relation to conditions determining their growth in 20l European waterbodies

\begin{tabular}{|c|c|c|c|c|c|}
\hline \multirow[t]{2}{*}{$\begin{array}{l}\text { Cyanobacterial } \\
\text { taxon }\end{array}$} & \multicolumn{2}{|c|}{$\begin{array}{l}\text { TP concentration } \\
{[\mu g / L] \text { with }} \\
\text { occurrence of the } \\
\text { taxon significantly }\end{array}$} & \multicolumn{2}{|c|}{$\begin{array}{l}\text { Frequency ratio at } \\
\text { elevated biovolume }\end{array}$} & \multirow[t]{2}{*}{$\begin{array}{l}\text { Further conditions } \\
\text { coinciding with elevated } \\
\text { frequency of occurrence }\end{array}$} \\
\hline & $\begin{array}{c}\text { More } \\
\text { frequent }\end{array}$ & $\begin{array}{l}\text { Less } \\
\text { frequent }\end{array}$ & $\begin{array}{l}\text { Max. ratio } \\
\quad \text { at TP } \\
>90 \mu \mathrm{g} / \mathrm{L}\end{array}$ & $\begin{array}{l}\text { Min. ratio } \\
\text { at TP } \\
<10 \mathrm{~g} / \mathrm{L}\end{array}$ & \\
\hline Microcystis spp. & $>50$ & $<25$ & 3.8 & 0.2 & $\begin{array}{l}\text { Mixed, late summer, } \\
>16^{\circ} \mathrm{C} \\
\text { Secchi }<3 \mathrm{~m}, \mathrm{pH}>7\end{array}$ \\
\hline $\begin{array}{l}\text { Aphanizomenon } \\
\text { spp. }\end{array}$ & $>90$ & $<25$ & 4.6 & 0 & $\begin{array}{l}\text { Mixed, late summer, } \\
>16^{\circ} \mathrm{C} \\
\text { Secchi }<2 \mathrm{~m}, \mathrm{pH}>6\end{array}$ \\
\hline P. agardhii & $>90$ & $<25$ & 4.8 & 0 & $\begin{array}{l}\text { Late summer, }>16^{\circ} \mathrm{C} \text {, } \\
\text { Secchi }<2 \mathrm{~m}, \mathrm{pH}>6-7\end{array}$ \\
\hline Limnothrix spp. & $>50$ & $<25$ & 4.0 & 0 & $\begin{array}{l}\text { Mixed, spring, } \\
\text { Secchi >3 m }\end{array}$ \\
\hline $\begin{array}{l}\text { Dolichospermum } \\
\text { spp. }\end{array}$ & $>50$ & $<25$ & 4.2 & 0.1 & $\begin{array}{l}\text { Mixed, late summer, } \\
>16^{\circ} \mathrm{C} \text {, } \\
\text { Secchi }<3 \mathrm{~m}, \mathrm{pH}>7-8\end{array}$ \\
\hline
\end{tabular}

Source: Adapted from Chorus \& Niesel (2011).

a "Frequency ratio" is the number of samples with the taxon to the total number of samples in the database (see Figure 4.7 for details); note that these data apply only to this specific database.

b "Elevated biovolume" is defined in relation to cell size of the taxon and ranges from $>0.1$ to $>1$ $\mathrm{mm}^{3} / \mathrm{L}$ biovolume.

\subsection{Models to predict surface blooms and scums}

As discussed in section 4.1.1, the mechanisms of cell accumulation differ between the cyanobacterial genera that form surface blooms (particularly Microcystis, Anabaena, Aphanizomenon) and those that form dense populations in the metalimnion, particularly Planktothrix rubescens, but sometimes also Aphanizomenon, Dolichospermum and Raphidiopsis. While the horizontal drift of scums can be roughly inferred from prevalent wind directions (Hutchinson \& Webster, 1994; Welker et al., 2003), predicting when cells will rise to the surface is more challenging. In many settings with regularly recurring seasonal populations of surface bloom-forming cyanobacterial species, experience provides good indication of the time of year and type of weather rendering scum formation to be likely.

Beyond experience valid for individual waterbodies, models to predict scum formation from waterbody characteristics and weather forecasts can be useful. These are being developed as vertical migration velocities and buoyancy regulation mechanisms are increasingly becoming understood for frequently occurring cyanobacterial species and genera. For Microcystis 
colonies, models describe the vertical migration of cyanobacteria (e.g., Kromkamp \& Walsby, 1990; Visser et al., 1997; Wallace \& Hamilton, 2000). The fuzzy-logic-based early warning model developed by Ibelings et al. (2003; see Box 4.8) includes weather forecast (wind speed and direction), cyanobacterial biomass, buoyancy state of the cells and stratification stability to predict the timing and location of cyanobacterial scums several days in advance, giving water managers time to act. A crucial problem with all predictions of scum formation is the trade-off between false negatives (missing blooms in the prediction) and false positives (predicting blooms that then do not occur). Whereas the first may lead to public health risks, the second may lead to economic damage for lake-based operations such as restaurants, campsites and beaches when lakes are closed for recreational purposes. For P. rubescens, Walsby (2005) developed a conceptual model to explain the occurrence of surface blooms near shallow, leeward shores arising from populations floating up in the metalimnion.

\section{BOX 4.8: EARLY WARNING FOR THE FORMATION OF MICROCYSTIS SCUMS}

In the Netherlands, water managers use a scheme in which scums are classified as I (light scums/surface blooms) to 4 (severe scums) on the basis of an information sheet showing pictures and descriptions of these categories. For a number of Dutch lakes, observers took notes on the occurrence of scums on a daily basis and used these data to validate an early warning model (Ibelings et al., 2003) that predicts scum formation (time and location) from several factors, including the mid-term weather forecast.

This model estimates cyanobacterial biomass increase using a traditional water quality model, combining this with a fuzzy-logic model to estimate the buoyancy of the cells and to relate this to waterbody mixing or stability of stratification. Fuzzy-logic model allowed qualitative data (expert knowledge) about scum formation to be made available in a quantitative way. The model was first developed for the open water of the large Lake IJsselmeer and then expanded to be applicable to smaller lakes, taking also sheltered areas (harbours, etc.) into account, that is, places where scums are more persistent than in the open water of lakes. It provides lake managers with a weekly bulletin in which the risk of scum formation for the coming week is indicated. The model is continuously being updated and improved (work by Deltares; https://www.deltares.nl).

All models are intended to (i) identify physical conditions of the waterbody that allow for surface bloom formation in a specific lake and (ii) predict the occurrence of surface blooms and scums. Generally, they work satisfactorily 
for the waterbodies for which they were developed. For the application of scum-forecasting models to a specific waterbody, it is important to consult an expert for limnological modelling.

\subsection{WILL CLIMATE CHANGE AFFECT CYANOBACTERIAL BLOOMS?}

Evidence for an increase in cyanobacterial blooms in the wake of climate change is increasingly published (e.g., Mooij et al., 2005; Paerl \& Huisman, 2009), and there is widespread concern that cyanobacterial blooms will increase in warming waterbodies where these are sufficiently eutrophic to sustain blooms. However, the impact of climate change on growth conditions for cyanobacteria is not straightforward (De Senerpont Domis et al., 2013), and it is important not to confuse the effects of local - and possibly unusual - weather on plankton dynamics in a given lake with climate effects.

Climate change affects water temperatures directly, but also indirectly waterbodies through changes in the strength and duration of thermal stratification (see section 4.3.4), including the impact of (possibly more frequent) storm events, and warming can lead to earlier appearance of zooplankton, changing grazing pressure on phytoplankton (Winder \& Sommer, 2012). Elevated atmospheric $\mathrm{CO}_{2}$ concentrations may stimulate access to $\mathrm{CO}_{2}$ for surface blooms, which may be limited by inorganic carbon (see Huisman et al., 2018) - but elevated water temperatures simultaneously reduce the solubility of $\mathrm{CO}_{2}$ in water and thus lead to lower concentrations. Climate change may also impact on the patterns of rainfall and snowmelt and thus on inflow, turbidity and nutrient loading, and it may increase water residence times where periods of drought increase - or reduce water residence time where precipitation increases. Thus, the probable effects of a climate change include mechanisms that may be favourable for cyanobacterial growth as well as mechanisms which are not, and the balance between them will vary strongly between waterbodies and have different effects on different bloom-forming species.

For Microcystis, a direct mechanism proposed to cause an increase in its abundance is the more pronounced dependency of growth rates on elevated temperature as compared to most of their competitors among other phytoplankton, which would increase the chances of Microcystis to dominate in warmer water. Additionally, increased stability of thermal stratification resulting from enhanced energy input into the surface layer of waterbodies could provide a competitive advantage for species with a mode of active vertical positioning, like buoyant cyanobacteria. In contrast, however, increases in cloud cover and wind speed (as, e.g., predicted for North West Europe) or more frequent storms would weaken thermal stratification of waterbodies and thus reduce this competitive advantage. 
Analysis of surface blooms in IJsselmeer showed that scums are absent at wind speeds greater than $2-3 \mathrm{~m} / \mathrm{s}$ (Ibelings et al., 2003), and in this lake, they may therefore become less frequent in the predicted slightly more windy future (Cheng et al., 2002).

P. agardhii may also be affected by a warmer climate, especially in those hypertrophic lakes where this species forms more or less permanent (yearround) blooms. In Lake Veluwe, the Netherlands, a 15-year bloom of Planktothrix was broken by a combination of reduced P loading and flushing, but a series of cold winters with extended ice-cover was also important in reducing the overwintering biomass of this species and giving other species, particularly of planktonic algae, a chance to dominate in spring (Reeders et al., 1998). Jeppesen et al. (2003) suggest that climate warming may increase the probability of lakes to become locked in a turbid state. Heatwave summers have been shown to reduce, rather than expand, the proliferation of Planktothrix rubescens in deep lakes. Here, milder winters rather than warm summers promoted cyanobacterial development, an example of ecological memory carrying over environmental effects from one season to the next (Anneville et al., 2015).

The spreading of $R$. raciborskii - previously regarded as subtropical - into temperate regions has been tentatively linked to climate change. Wiedner et al. (2007) showed that this is also not attributable to overall higher summer temperatures but rather to the timing of higher temperatures: resting stages (akinetes) of $R$. raciborskii germinate at $15^{\circ} \mathrm{C}$, and in northern Germany, lake sediments reach this temperature earlier by 2 weeks, when less spring phytoplankton has developed and water is still clearer. The earlier $R$. raciborskii hatches from its resting stages, the more light is available for its rapid growth and the establishment of a large population.

A further aspect is that higher temperatures and higher stratification stability can trigger an increased release of phosphorus from sediments, thus fertilising cyanobacterial blooms. Vice versa, however, increased stratification stability can reduce the transport of released phosphorus into the euphotic zone, thus reducing its availability to cyanobacteria possibly resulting in a "climate warming-induced oligotrophication" (Salmaso et al., 2018). The specific conditions in a waterbody determine which of these two contrary processes determines phosphorus concentrations in the euphotic zone.

The concept of "carrying capacity" (section 4.3.5 and Figure 4.3) is helpful for assessing the impact of climate change versus the impact of trophic state: where there is not enough phosphorus and nitrogen to support substantial levels of phytoplankton biomass, warming is not likely to increase cyanobacterial proliferation. A number of modelling studies (reviewed by Elliott (2012)) show agreement that while cyanobacterial biomass is likely to increase in a warmer climate, the magnitude of this response will strongly depend on nutrient concentrations: where these are limiting, the annual amount of biomass is not likely to increase although the timing and proportional 
dominance of cyanobacteria may change. On the basis of data analysed from more than 1000 lakes, Rigosi et al. (2014) emphasise that the impacts of nutrients and climate are not synergistic; rather, "nutrients predominantly controlled cyanobacterial biovolume" and, although very eutrophic lakes are more sensitive to increased temperature, "ultimately nutrients are the more important predictor of cyanobacterial biovolume". Others, however, are convinced that a synergy between eutrophication and increased temperatures will produce even larger blooms in future (Moss et al., 2011; Havens \& Jeppesen, 2018).

A further concern in climate change scenarios for some situations is the possible reduction in available water in lakes and reservoirs due to reduced rainfall. Water scarcity combined with increasing cyanobacterial blooms would create challenges for waterbody management in general and specifically for providing safe drinking-water. Yet, also for this aspect, direct human impact, for example, through large-scale depletion of groundwater for irrigation, could outweigh the possible long-term impact of changes in precipitation patterns in the course of climate change.

In conclusion, it is highly probable that a significant change in climatic conditions will affect the ecology of waterbodies. In some waterbodies, this could cause an increase in the frequency and the scale of cyanobacterial blooms, while not in others. Preparing today for possible effects of climate change on cyanobacterial blooms in the future should not divert the focus from measures to reduce cyanobacterial blooms that can be taken today: reducing eutrophication to levels unlikely to support blooms is an effective component of preparing for climate change.

\subsection{WHICH FACTORS DETERMINE CYANOTOXIN CONCENTRATIONS?}

In natural waters, complete absence of cyanobacteria is unlikely given the capability of cyanobacteria to thrive in the most extreme environments, and therefore, cyanotoxins are likely found in most waterbodies - yet often at very low concentrations and detectable only with highly sensitive analytical methods. Therefore, the qualitative detection of cyanobacterial toxins, for example, in samples concentrated with a plankton net, is only of limited relevance for public health management.

For health risk assessment, not mere occurrence but rather the concentration of cyanotoxins in waterbodies is important, and the concentration is tightly linked to the biomass of potentially toxigenic taxa. The most important ones include Microcystis, Planktothrix, Dolichospermum, Raphidiopsis and Aphanizomenon in the plankton of lakes and reservoirs, benthic taxa like Phormidium or Microcoleus in streams, (tychoplanktonic) Tychonema in lakes, and Lyngbya or Nodularia 
in brackish and coastal waters. Other taxa that have been reported to form blooms, such as Limnothrix or Gomphosphaeria, have not been unambiguously reported to produce known toxins, while, on the other hand, some toxigenic taxa such as Hapalosiphon or Umezakia have not been reported to form blooms.

As discussed in Chapters 2 and 3, the current understanding of cyanotoxin occurrence is incomplete, as the identification of further taxa producing specific cyanotoxins (and potentially yet unknown ones) is ongoing, and for most types of cyanotoxins, new producing taxa may be found in future. In particular, while it is well recognised that cyanobacterial populations consist of a mixture of clones, some of which produce toxins and others which do not, differentiation between toxic and nontoxic clones cannot be done reliably by microscopic examination. It became possible only with the advent of molecular methods (Kurmayer et al., 2004; section 13.4) or highly sensitive analytical methods that allow the detection of toxins in single colonies or filaments (Akçaalan et al., 2006; Welker \& Erhard, 2007). Such methodology can characterise the clonal diversity of cyanobacterial communities, showing that a distinction between toxic and nontoxic clones is only a very rough classification (Janse et al., 2004). Rather, a multitude of genetically and metabolically distinct clones can be distinguished, with the production of cyanotoxins being one characteristic among others (Fastner et al., 2001a; Janse et al., 2003; Welker et al., 2004a).

Geographic variation in the genetic diversity of toxin-producing cyanobacteria is just beginning to be explored, and new insights into biogeographic patterns of toxin production are likely. Further surveys at a global scale will be particularly relevant for regions that have so far been poorly investigated.

\subsection{Composition of blooms and cyanotoxin types}

MCs appear to be the most widespread type of cyanotoxins occurring in health-relevant concentrations (Svirčev et al., 2019), and they are very likely to occur when species of Microcystis or Planktothrix are present. Field populations of these genera usually contain both clones with and without the genes for MC production (see below), yet it is very rare to find field populations of Microcystis without any MC-producing clones. In Europe, field populations of Planktothrix agardhii as well as of P. rubescens have never been observed without MC production (Kurmayer \& Gumpenberger, 2006), although within these, some nonproducing clones occur frequently (Welker et al., 2004b). A number of studies have highlighted patterns of occurrence of particular MC congeners with particular taxa (e.g., Fastner et al., 1999). While for Microcystis blooms MC-LR, MC-RR and MC-YR typically are the most abundant congeners, in $P$. agardhii dominated blooms demethylated $\left[\mathrm{Asp}^{3}\right]$ congeners dominate and in P. rubescens the 
$\left[\mathrm{Asp}^{3}, \mathrm{Dhb}^{7}\right]$ congeners are typical. For risk assessment, specific toxicological data for congeners other than MC-LR are sparse or lacking, so as default or conservative estimate, these are regarded as being similarly toxic as MC-LR (see sections 2.1, 5.1 and 5.2).

Occurrence of cylindrospermopsin was first only expected when $R$. raciborskii was present in the plankton, but the number of taxa reported to produce CYNs is increasing (currently including species of Aphanizomenon and Dolichospermum). Further, among strains of $R$. raciborskii, only those originating from Australia or South East Asia were found to produce CYNs (Li et al., 2001b; Neilan et al., 2003; Piccini et al., 2011). Most CYNproducing species known so far belong to the order Nostocales (sensu Anagnostidis \& Komárek (1985)) but evidence for CYN production in Stigonematales and Oscillatoriales indicates that the ability to produce CYN could be more widespread. However, CYN production appears to be more variable than $\mathrm{MC}$ production: while for MCs, occurrence can be reliably predicted when specific taxa are present with sufficiently high biomass (Microcystis, Planktothrix), no taxa have been reported which are almost always found together with CYNs. Thus, compared to MCs, for CYNs the frequency of nonproducing clones appears to be relatively high. This observation could, however, be biased to some degree by the poorly resolved taxonomy for some cyanobacteria (Chapter 3).

The same appears to apply to the cyanobacterial neurotoxins, although less data are available on their occurrence and producing strains. For neurotoxins, relationships between toxigenicity and taxonomy are less clear, as information on genes encoding their biosynthesis has become available later (see sections 2.3-2.5 and 13.4), but molecular methods are needed to unambiguously verify the potential to produce neurotoxins in large numbers of samples and strains (Wang et al., 2015). Like with MCs and CYNs, the ability to produce neurotoxins is not confined to a particular order of cyanobacteria, and within genera or even species, toxic and nontoxic clones exist (Beltran \& Neilan, 2000). There are also possible biogeographic differences in neurotoxin production: for example, while for Raphidiopsis exclusively Brazilian strains seem to produce saxitoxins (Haande et al., 2008), for D. circinale only Australian strains have been shown to produce saxitoxins (Fergusson \& Saint, 2000; Al-Tebrineh et al., 2010).

\subsubsection{Toxin content in biomass}

The term "concentration", according to IUPAC definitions, refers to an amount of toxin (generally expressed as mass or weight) per volume of water. This is best distinguished from toxin "content" referring to an amount of toxin per unit of cyanobacterial biomass, with the latter expressed as weight or as biovolume (Box 4.9). This distinction is not always made clear in the literature, rendering the comparison of data sometimes difficult. 


\section{BOX 4.9: UNITS TO REPORT CYANOTOXINS}

The occurrence of cyanobacterial toxins is reported in a variety of units that are not always easily transformed from one to another. The most commonly used units are given in this box together with exemplary values that can serve as reference data to judge the plausibility of measured values.

Cell quota: amount of toxin per cell, expressed either in gravimetric or in molar units; this is femtogram ( $\mathrm{fg}$ ) per cell or femto- or attomol (fmol or amol, respectively) per cell. Cell quota are used primarily in laboratory experiments on MC production but also sometimes in field studies and generally for unicellular taxa like Microcystis. In individual toxigenic Microcystis strains, cell quota have been found to vary by a factor of about three, and the maximum values reported are $165 \mathrm{fg} / \mathrm{cell}$ (Orr \& Jones, 1998; Long et al., 200I; Wiedner et al., 2003). From field samples, cell quota ranging from I to $144 \mathrm{fg} /$ cell have been calculated (Okello et al., 2010). For CYNs, cell quota of $60 \mathrm{fg} / \mathrm{cell}$ (Orr et al., 2010) and $191 \mathrm{fg} / \mathrm{cell}$ (Vasas et al., 20l3) have been reported for $R$. raciborskii and Chrysosporum ovalisporum, respectively. For saxitoxin, cell quota of I.3 picogram (pg) per cell in a Scytonema strain have been reported together with a toxin content of $119 \mu \mathrm{g} / \mathrm{g}$ DW (Smith et al., 20II). Cells of Scytonema have a volume about fifty times that of a Microcystis cell. Any numbers considerably beyond these ranges may be the result of a conversion error or inaccuracies in the quantification of the cell number or the toxin concentration (see Box 4.10).

Toxin content: amount of toxin per mass of cells, expressed in $\mu \mathrm{g}$ or $\mathrm{mg}$ per gram dry weight $(\mathrm{dw})$ in the older literature. A large number of values have been published for different cyanotoxins: in individual strains maximally $8 \mathrm{mg}$ MC/g DW and 4.6 mg CYN/g dw (Sivonen, 1990; Long et al., 200I) and in field samples from below detection limit to a few $\mathrm{mg} / \mathrm{g} \mathrm{dw}$. Toxin content may also be expressed as $\mu \mathrm{g}$ per $\mathrm{mm}^{3}$ biovolume. As $\mathrm{I} \mathrm{mm}^{3}$ equals $\sim \mathrm{mg}$ of fresh weight or about $\sim 0.25 \mathrm{mg} \mathrm{DW}$, and I $\mu$ g toxin $/ \mathrm{mm}^{3}$ corresponds to about $4 \mu \mathrm{g}$ toxin/mg dw. A third common unit for toxin content is $\mu \mathrm{g}$ toxin per $\mu \mathrm{g}$ chlorophyll-a, rarely exceeding a I:I ratio.

Toxin concentration: amount of toxin per volume of water, often expressed in $\mu \mathrm{g} / \mathrm{L}$ or if concentrations are very low, in $\mathrm{ng} / \mathrm{L}(=0.00 \mathrm{I} \mu \mathrm{g} / \mathrm{L})$. Two fractions need to be discriminated, particulate and dissolved. The particulate fraction comprises toxins contained in cells and adsorbed to particles or, from a practical point of view, the toxins that can be collected on a filter. Accordingly, the dissolved fraction is in the particle-free sample that passed the filter. Toxin concentration is the most important parameter for risk assessment. 
Dry weight: A wealth of (published) data exists on toxin contents of bloom samples or isolated strains on a weight-to-weight basis (e.g., $\mu \mathrm{g} \mathrm{MC}$ per $g$ dry weight). Analytical methods can detect most toxins in the ppb range, that is, a few tens of nanograms per gram dry weight (for units and scales, see Box 4.10). The highest reported toxin contents for cultured strains are around $1.5 \%$ of dry weight for MCs and CYNs, corresponding to $15 \mu \mathrm{g}$ toxin per mg dry weight (Chapter 2 ). The maximally achievable toxin contents of plankton net samples are thus reasonably expected in the same range. It follows that any reported toxin content exceeding $2 \%$ of dry weight is remarkably high and needs to be critically verified.

\section{BOX 4.10: SCALES AND MAGNITUDES OF MASS AND VOLUME}

"For thousands more years, the mighty ships tore across the empty wastes of space and finally dived screaming on the first planet they came across - which happened to be the earth - where due to a terrible miscalculation of scale the entire battle fleet was accidentally swallowed by a small dog"

Douglas Adams, The Hitchhiker's Guide to the Galaxy

What reads as funny side-kick in a novel conveys some deeper meaning: when dealing with masses and volumes in extremely low ranges, anyone who is not familiar with the units has to be very careful to avoid conversion errors that could lead to the reporting of false numbers.

For units of mass (often also termed "weight"), the relevant units for cyanotoxin research are gram $(\mathrm{g})$, milligram $(\mathrm{mg})$, microgram $(\mu \mathrm{g})$, nanogram $(\mathrm{ng})$, picogram $(\mathrm{pg})$ and femtogram $(\mathrm{fg})$. The conversion factor from one unit to the next is 1000 ; this means, for example, I $\mu \mathrm{g}$ equals $1,000,000,000 \mathrm{fg}=10^{9} \mathrm{fg}$.

For units of volumes, in the context of toxic cyanobacteria, the units litre $(\mathrm{L})$, millilitre $(\mathrm{mL})$, cubic millimetre $\left(\mathrm{mm}^{3}\right.$; to report phytoplankton population biovolume) and cubic micrometre $\left(\mu \mathrm{m}^{3}\right.$; to report individual cells' volumes) are relevant. While conversion of $L$ to $\mathrm{mL}$ to $\mu \mathrm{L}$ is done with respective factors of 1000, the conversion of $\mathrm{mm}^{3}$ to $\mu \mathrm{m}^{3}$ with a factor of I 000000000 $\left(10^{9}\right)$ requires particular attention. Conversion factors are summarised in the following table:

\begin{tabular}{lcccc}
\hline volume & $\mathrm{dm}^{3}$ & $\mathrm{~cm}^{3}$ & $\mathrm{~mm}^{3}$ & $\mu m^{3}$ \\
$\mathrm{dm}^{3}=\mathrm{L}$ & $\mathrm{I}$ & $\mathrm{I} .0 \mathrm{E}+03$ & $\mathrm{I} .0 \mathrm{E}+06$ & $\mathrm{I} .0 \mathrm{E}+\mathrm{I} 5$ \\
$\mathrm{~cm}^{3}=\mathrm{mL}$ & $\mathrm{I} .0 \mathrm{E}-03$ & $\mathrm{I}$ & $\mathrm{I} .0 \mathrm{E}+03$ & $\mathrm{I} .0 \mathrm{E}+12$ \\
$\mathrm{~mm}^{3}=\mu \mathrm{L}$ & $\mathrm{I} .0 \mathrm{E}-06$ & $\mathrm{I} .0 \mathrm{E}-03$ & $\mathrm{I}$ & $\mathrm{I} .0 \mathrm{E}+09$ \\
$\mu \mathrm{m}^{3}=\mathrm{fL}$ & $\mathrm{I} .0 \mathrm{E}-\mathrm{I} 5$ & $\mathrm{I} .0 \mathrm{E}-12$ & $\mathrm{I} .0 \mathrm{E}-09$ & $\mathrm{I}$ \\
\hline
\end{tabular}


Assuming a specific density of $\rho=\mathrm{I} g / \mathrm{mL}$ for fresh cyanobacterial cells - the density of water - biovolume converts to fresh weight ( $\mathrm{fw}$ ) as follows: I $\mathrm{mm}^{3}$ $\rightarrow \mathrm{I} \mathrm{mg}$ and I $\mu \mathrm{m}^{3} \rightarrow \mathrm{I} \mathrm{pg}$. For the conversion of fw to dry weight (dw), a factor of 0.25 is considered. Based on this and the assumptions of an MC content of $\mathrm{I} \%$ of $\mathrm{dw}$, the amount of toxin per cell can be computed like in the following table (with three exemplary size classes of Microcystis):

\begin{tabular}{lclll}
\hline & Dolichospermum & Microcystis & Microcystis & Microcystis \\
\hline $\begin{array}{l}\text { Cell diameter } \\
\begin{array}{c}\text { Cell volume } \\
\left(V==\pi / 6 \times \mathrm{d}^{3}\right)\end{array}\end{array}$ & $10 \mu \mathrm{m}$ & $4 \mu \mathrm{m}$ & $4.5 \mu \mathrm{m}$ & $5 \mu \mathrm{m}$ \\
$\begin{array}{l}\text { Cell mass (wet } \\
\text { weight) }\end{array}$ & $523 \mathrm{pg}$ & $34 \mathrm{pg}$ & $48 \mathrm{pg}$ & $65 \mathrm{pg}$ \\
$\begin{array}{l}\text { Cell dry weight } \\
(25 \%)\end{array}$ & $131 \mathrm{pg}$ & $8.5 \mathrm{pg}$ & $12 \mathrm{pg}$ & $16 \mathrm{pg}$ \\
$\begin{array}{l}\text { Calculated cell } \\
\text { quota }\end{array}$ & $1300 \mathrm{fg} / \mathrm{cell}$ & $85 \mathrm{fg} / \mathrm{cell}$ & $120 \mathrm{fg} / \mathrm{cell}$ & $160 \mathrm{fg} / \mathrm{cell}$ \\
\hline
\end{tabular}

For Microcystis, the computed cell quota are in the range of reported cell quota estimated from direct cell counts and MC analyses; hence, the estimates are consistent with reported values. In turn, any cell quota substantially exceeding these values have to be critically evaluated. For example, cell quota reported for Microcystis of I pg/cell correspond to an improbable MC content of some $10 \%$ of $\mathrm{dw}, 5 \mathrm{pg} / \mathrm{cell}$ to very unrealistic $50 \%$, and any value exceeding $10 \mathrm{pg} / \mathrm{cell}$ is close to the cells' dry weight or actually exceeds it - which is physically impossible.

It is thus highly advisable to perform basic plausibility tests based on known cell dimension, biovolumes, cell numbers, etc. to verify that calculated ratios are physically possible and in accordance with available data. Any value that is substantially beyond the values reported so far has to be carefully checked for possible errors in measurements and conversions - once erroneous data have been published, they can develop a life of their own through continuing citation.

Since most cyanobacterial blooms do not consist of a single clone with an extremely high toxin content, but comprise mixtures of clones with varying toxin contents, including nontoxigenic ones, field samples generally show toxin contents that are much lower than $1 \%$ of dry weight. A number of exemplary values for toxin contents of cultured strains are given in Chapter 2 . However, dry weight is not practical for estimating toxin concentrations 
from biomass because it requires collecting a sufficiently large amount of biomass from a defined volume of water with a plankton net for drying and weighing. Water volumes are poorly defined if the sample is collected by hauling the net through the water column. With more sensitive analytical methods, small sample sizes suffice for accurate toxin analysis. The more practical approach therefore is to relate toxin content to biovolume (see Chapter 13 for the determination of biovolume by microscopy.)

Biovolumes: Data from field samples and laboratory experiments suggest that, for example, for MCs, a ratio of $3 \mu \mathrm{g} \mathrm{MC} \mathrm{per} \mathrm{mm}^{3}$ biovolume is rarely exceeded in the mixture of clones or genotypes occurring in waterbodies (Fastner et al., 2001b; Hesse \& Kohl, 2001; Znachor et al., 2006) even though outliers of up to $13.8 \mu \mathrm{g} / \mathrm{mm}^{3}$ and $20.6 \mu \mathrm{g} / \mathrm{mm}^{3}$ have been found in cultured strains of Microcystis and Planktothrix, respectively (see Table 2.3). This small number of higher ratios reported in the literature should not be given too much weight unless the values have been verified with further values in the same range. One reason for outliers may partly be attributed to (unavoidable) inaccuracies in biovolume determination and analytical errors when the concentrations are close to the limit of quantification: any computing of ratios is sensitive to relative errors and errors in both values may potentiate the ratio's error (Chapter 13). For example, an underestimation of biovolume by setting the average cell diameter to $4 \mu \mathrm{m}$ while the true value is $4.5 \mu \mathrm{m}$ results in a biovolume with an error of $30 \%$. Together with an overestimation of toxin concentration as $1 \mu \mathrm{g} / \mathrm{L}$ instead of truly $0.7 \mu \mathrm{g} / \mathrm{L}$ (error of $30 \%$ ) already results in an overestimation of the toxin-to-biovolume ratio by a factor 2 . Therefore, based on the bulk of the reported data, a value of $3 \mu \mathrm{g} / \mathrm{mm}^{3}$ of biovolume serves as a conservative assumption.

Cell quota: Not very many data are available on toxin contents per cell (generally expressed in femtogram (fg) per cell). Exemplary values are compiled in Box 4.9 and for cultured strains in Chapter 2; these suggest, for example, for MCs, a content of $200 \mathrm{fg}$ per cell for Microcystis sp. is a conservative assumption. Again, outliers have to be critically verified before taken into consideration, for example, by rough estimates whether the cell quota are consistent with toxin contents per dry weight reported for specific toxins and taxa (Box 4.10). Based on assumed cell quota of $200 \mathrm{fg}$ per cell of Microcystis, one million $\left(10^{6}\right)$ cells in a bloom can account for maximally $0.2 \mu \mathrm{g}$ MC but expectedly, in typically multiclonal populations, average cell quota are lower and hence the amount of toxin, too. Therefore, for an in situ MC concentration of $1 \mu \mathrm{g} / \mathrm{L}$, Microcystis cell densities of at least $10^{7}$ cells/L are expected. For other toxins and taxa, only few values are available (Chapter 2), and unfortunately erroneous toxin contents (even exceeding the cell's dry weight) have been published. Box 4.10 gives factors and an example for converting weights, biovolumes and cell quota to support checking for plausibility of values for toxin contents. 


\subsubsection{Toxin concentrations in water}

The dynamic fluctuations in cyanobacterial occurrence discussed above impact on cyanotoxin concentrations. Studies of seasonal dynamics of cyanotoxin concentrations in relation to trophic and geographic gradients have mainly focused on MCs and cover a number of different types of waterbodies. A number of publications report significant correlations between MC concentrations and environmental variables - particularly total phosphorus (TP) (Kotak et al., 2000; Graham et al., 2006), N:P ratio (Kotak et al., 2000; Welker et al., 2003), dissolved inorganic and total nitrogen (TN) (Giani et al., 2005) or temperature (Albay et al., 2005). However, all of these conditions typically directly affect cyanobacterial proliferation and dominance (section 4.4), and the chief biological mechanism behind these correlations is the wax and wane of cyanobacterial populations rather than effects on toxin production by individual clones in these populations. Generally, the results show correlations of cyanotoxin concentration to a measure of phytoplankton biomass such as chlorophyll- $a$ or - more specifically - biovolumes of potentially toxigenic cyanobacterial taxa (Znachor et al., 2006; Sitoki et al., 2012; Salmaso et al., 2014). The data in all of these studies show upper boundaries and below these a broad residual scatter, indicating that further variables, other than biomass, also influence cyanotoxin concentrations.

A key explanation for highly variable ratios of cyanotoxin to cyanobacterial biomass (e.g., expressed as biovolume) is shifts in clonal composition, that is, between clones of different toxin content (including nonproducers) which would influence the average cyanotoxin content of the cyanobacterial population and hence of the entire phytoplankton community (Kardinaal et al., 2007; Welker et al., 2007; Yepremian et al., 2007; Agha et al., 2014; Haruštiaková \& Welker, 2017; Otten et al., 2017). Figure 4.8 illustrates this schematically: in (the improbable) scenario 1, all clones, each of which with a different toxin content, show homogenous dynamics and the relative clonal composition is stable. This would result in an equally stable average toxin content and a toxin concentration tightly following the total cell number. In scenario 2, individual clones show diverging dynamics. As a consequence, the average toxin content varies strongly, and the toxin concentration is partly uncoupled from the total cell number. In natural waters, dynamics of cyanobacterial populations are likely closer to scenario 2 than to scenario 1, although the number of respective studies is still limited. Coexisting toxigenic clones can also vary considerably in their toxin composition (i.e., in individual congeners produced) and in their (average) toxin content or toxin cell quota (Chapter 2 and Box 4.9) that may span ranges exceeding two orders of magnitude (Wilson et al., 2006b; Yepremian et al., 2007). The fact that cyanobacterial blooms and populations are generally composed of mixtures of toxin-producing and 

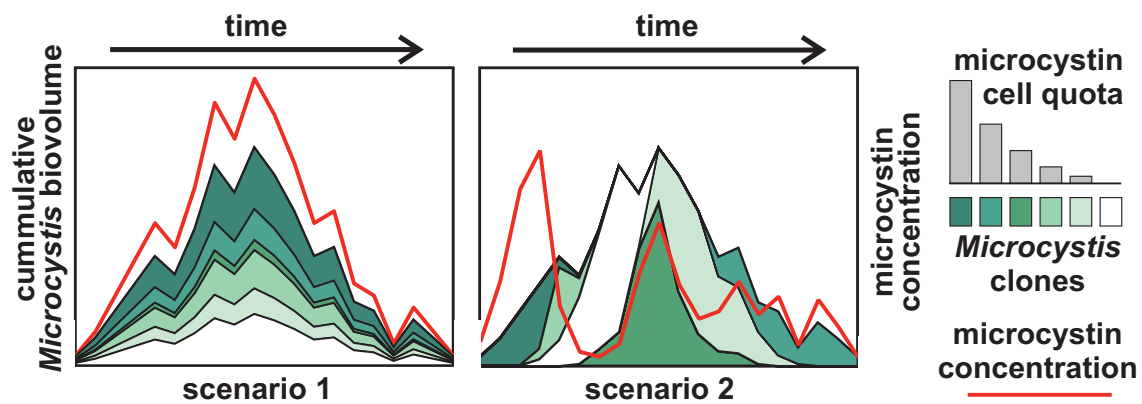

Figure 4.8 Schematic illustration of dynamics of Microcystis spp. clones with varying microcystin (MC) content (or cell quota) and the resulting MC concentration. In (unlikely) scenario I, the temporal dynamic of all clones is homogeneous: that is, clone composition does not change over time, and the MC concentration follows Microcystis total biovolume. In scenario 2, the individual clones show variable dynamics resulting partly in a decoupling of Microcystis biovolume and $\mathrm{MC}$ concentration. For further explanations, see text.

nonproducing clones has also been demonstrated for CYN and for neurotoxins (Carmichael \& Gorham, 1981; Fastner et al., 2001a; Wood \& Puddick, 2017).

In some waterbodies, Planktothrix- and Microcystis-dominated cyanobacterial communities show seasonal patterns with the MC content of cyanobacterial biomass declining from a maximum at the onset of the bloom to lower values later in the season, coinciding with shifts in relative abundance of MC-producing clones (Kardinaal \& Visser, 2005; Kardinaal et al., 2007; Welker et al., 2007; Davis et al., 2009), while in other waterbodies a reverse pattern was observed (see Chapter 5, Figure 5.1). In other waterbodies, the proportion of toxigenic cells in relation to total cell numbers proved rather stable for extended periods of time (Kurmayer et al., 2003; Salmaso et al., 2014). Also, MC concentrations may reach their maximum even at times when toxin content per cell or unit biovolume is relatively low if the total abundance of potentially toxigenic cyanobacteria is high.

In contrast to the decisive role of cyanobacterial biomass and clonal composition for toxin concentrations, laboratory studies showed that for a given clone, ratios of toxin per cell rarely change by more than a factor of $2-4$. Moreover, the striking differences between laboratory studies addressing the impact of environmental conditions on toxin production are likely partially due to differences in study design (see Box 4.11). Compared to shifts in cyanobacterial biomass and/or clone composition, such shifts in toxin cell quota in individual clones have a relatively minor impact on toxin contents of field populations (Chapter 2). 


\section{BOX 4.II: PITFALLS WHEN DETERMINING CELLULAR CYANOTOXIN CONTENTS IN THE LABORATORY \\ Gary Jones}

The literature is replete with laboratory studies attempting to correlate cellular cyanotoxin content with growth-limiting resources such as nitrogen, phosphorus, iron, light or temperature. Some of their apparently contradictory results may be due to inadequate experimental controls over the limiting resource and of how it regulates cyanobacterial growth rate and yield, if unequivocal single-resource limitation was not given. This is especially the case for batch cultures, where in vitro conditions (e.g., $\mathrm{pH}$, light, nutrient concentration) and growth rate change continuously as the cells multiply (especially towards the end of exponential phase). Some of these batch cultures problems can be overcome through very carefully controlled design and sampling or, better still, by using continuous culture systems. An important consideration, often not fully accounted for, is that both batch and continuous culture experiments can be designed (intentionally or unintentionally!) so that the limiting resource reduces either one or both of (i) exponential growth rate and (ii) the cell concentration achieved in the plateau phase of a batch culture or the steady state of a continuous culture. Also often overlooked is the need for culture media which are chemically well defined, especially in the case of nutrients that have complex aqueous chemistry and speciation like phosphorus or iron.

Planning of experiments and interpretation of data requires proper training in microalgal culturing techniques, as well as a full understanding of the key theories behind resource limitation and growth (most notably the Monod and Droop equations), as well as the basic aqueous chemistry of common nutrient ions. Indeed, many of these considerations apply equally to the interpretation of field data as well.

Some excellent reference books to begin with are, for example, Stein et al. (1980) and Andersen (2005) on culture techniques and theory and Stumm \& Morgan (1996) on water chemistry.

In conclusion, the average cyanotoxin concentration in a waterbody depends on

1. the combined biomass of potentially toxic cyanobacteria;

2. the clonal composition of populations and, in particular, on clonespecific toxin contents;

3. the physiological regulation of toxin biosynthesis in toxigenic clones. 
While the clonal composition is crucial for the toxin concentration in the water, a distinction between only two types - toxigenic and nontoxigenic - is an undue simplification that may lead to invalid conclusions because both types likely are represented by multiple individual clones (Meyer et al., 2017). Other metabolites and physiological traits of individual clones may be decisive for the outcome of selection between clones. However, the driving forces regulating clonal composition of cyanobacterial populations are still poorly understood. For example, $\mathrm{N}$ limitation may play a role in selecting clones of Microcystis or Planktothrix that do not produce MCs (or other peptides) (Gobler et al., 2016), or parasite and phage infection may cause clone-specific mortality in cyanobacterial populations (Honjo et al., 2006; Rohrlack et al., 2013; Van Wichelen et al., 2016; Stough et al., 2017; Box 4.3).

Therefore, accurate predictions of cyanotoxin concentrations from cyanobacterial biomass are limited, even in an intensively studied waterbody. As an approximative approach, upper boundaries of possible toxin concentrations, based on conservative assumptions for toxin-to-biomass ratios, are used in the Alert Levels Frameworks in sections 5.1 and 5.2. As discussed in section 4.5, modelling is still struggling to predict cyanobacterial abundance as such, and forecasting cyanotoxin concentration adds a further dimension of complexity. However, some examples show that statistical models based on empirical data can predict cyanotoxin concentrations for a given waterbody with reasonable accuracy with respect to their timing as well as the magnitude of toxin occurrence (Jacoby et al., 2015; Recknagel et al., 2017). Although models cannot replace monitoring for the purpose of assessing cyanotoxin risks to human health, they can be used to streamline and focus monitoring, for example, by adjusting sampling frequency to expected bloom and toxin dynamics (Chapter 11). By using a default assumption for a ratio of toxin to cyanobacterial biomass, models to estimate cyanobacterial biomass can be expanded for a first, conservative estimate of toxin concentration. Such an approach likely results in an overestimation of the actual toxin concentration (Chapter 5 and section 4.6.5).

\subsubsection{Spatial heterogeneity of toxin concentrations}

As cyanobacterial biomass can show pronounced spatial variability, so do cyanotoxins: detectable cyanotoxin concentrations, reported as average concentrations from depth-integrated samples, generally range from just above detection limit to a few tens of $\mu \mathrm{g} / \mathrm{L}$. However, in individual samples taken in the same waterbodies on the same date, the toxin concentration can vary by several orders of magnitude, depending on where and how the sample is taken: surface layer versus hypolimnion or a central site versus the shoreline (see Figure 4.1, Figure 4.2, Box 4.8). In scums of Microcystis, for example, 
concentrations of MCs can reach several tens of $\mathrm{mg} / \mathrm{L}$ (see section 2.1). In several multilake surveys, MC concentrations exceeding $50 \mu \mathrm{g} / \mathrm{L}$ were only found in scums where concentrations regularly reached the $\mathrm{mg} / \mathrm{L}$ range, but not in integrated, averaged samples when cyanobacterial populations are suspended more or less homogeneously in the water column (Cook et al., 2004; Loftin et al., 2016). As concentrations of cyanotoxins can show pronounced horizontal gradients, data from a water sample taken at one site are unlikely to represent a lake-wide average (Welker et al., 2003; Ozawa et al., 2005; Dyble et al., 2008). It is thus of utmost importance to clearly define the objective and corresponding sampling strategy when designing monitoring programmes (Chapter 11).

Horizontal variability is mainly caused by two factors. One is differences in growth conditions that may occur between different parts of a lake, particularly in large lakes or reservoirs with complex morphology (e.g., Michalak et al., 2013; Chung et al., 2014). The other - often more important one - is the combination of surface bloom formation and horizontal dislocation by which cyanobacterial cells are generally concentrated at nearshore, downwind sites of a waterbody (section 4.5). However, the short-term fluctuations are not restricted to near-shore sites. Cyanotoxin concentrations in samples taken at high frequency at a fixed station showed fluctuations of several $\mu \mathrm{g} / \mathrm{L}$ over the 6-h sampling interval (Miller et al., 2019).

Vertical variability in toxin concentration occurs mainly due to buoyancy regulation of the toxic cyanobacteria (section 4.2). Higher concentrations of cyanotoxins occur either in the topmost water layers, especially when buoyant taxa like Microcystis are dominant (Naselli-Flores et al., 2007), or in a metalimnetic layer in the case of Planktothrix rubescens (Ernst et al., 2009).

Since vertical and horizontal distributions depend to a large degree on current weather conditions such as wind direction and speed, dense cyanobacterial accumulations can occur within hours at one site of a lake and a few hours later at others. For approaches to early warning for surface bloom and scum occurrence, it is therefore effective to include the use of satellite images or continuous measurement of fluorescence, combined with numerical modelling (Ibelings et al., 2003; Chapter 11).

Two consequences are equally important for assessing the risk of cyanotoxin occurrence:

1. A cyanotoxin concentration of a few microgram per litre (that might be considered a low risk) at a central site in a waterbody can lead to cyanotoxin concentrations several orders of magnitude higher at downwind "hot spot" sites.

2. The timescales in which toxin concentrations can dramatically change at a particular (near-shore) site can be only a few hours. 


\subsubsection{Estimating cyanotoxin concentration from other limnological parameters}

Where toxin data are not (or not readily) available for assessing and managing the health risks caused by cyanobacteria, measurements of cyanobacterial biomass are a useful point of departure for conservative estimates of potential maximum cyanotoxin concentrations in a waterbody. For practical purposes, such as the Alert Level Frameworks in sections 5.1 and 5.2, estimates therefore best use the maximum expectable concentrations. These will show where toxin analyses for the specific site are important in order to obtain more precise information to appropriately guide management responses, with significantly lower toxin concentrations being a likely outcome.

The limnological parameters allowing an estimation of cyanotoxin concentrations are primarily (cyanobacterial) biovolumes, cell counts, chlorophyll- $a$ concentrations, water transparency (i.e., Secchi depth) and nutrient concentrations, in particular total phosphorus (TP). The uncertainty of cyanotoxin estimates increases in the same order. It is important to understand that estimates of maximum cyanotoxin concentrations based on these parameters will not be accurate; they merely serve as indicators to support decisions on where to focus efforts for monitoring and for further analyses, for example, of cyanotoxins (Chapters 13 and 14). In particular, it is important to realise that these indicators give conservative estimates gleaned from maximum likely ratios of toxin to the respective indicator. Due to their variability over time and between waterbodies, using any of them as an estimate for cyanotoxin concentration implies that follow-up by toxin analysis is most likely to result in a considerably lower rather than a higher human health risk.

While the ratios of toxin to indicator proposed here are primarily derived from data published for MCs, for other cyanotoxins, content per unit biomass does not appear higher than these maxima known for MCs (see Chapter 2); thus, the ratios of toxin to the concentration of the indicators discussed here may also be assumed as proxy for risk assessment. However - in contrast to MCs which largely occur cell-bound - applying this to CYNs may miss the higher dissolved fraction of this toxin.

Biovolumes can give a fairly accurate estimate of the maximum expectable cell-bound cyanotoxin concentrations, but yet bear uncertainty spanning more than an order of magnitude due to the variability of the toxin content of different clones of potentially toxigenic taxa, even within an individual waterbody and a single season. A key advantage of using biovolumes identified by microscopy as point of departure for risk assessment is that they include information on taxonomic composition, which provides a basis for understanding the potential further development of a bloom and thus of toxin occurrence. As discussed above in section 4.6.2, a ratio of $3 \mu \mathrm{g}$ 
toxin per $\mathrm{mm}^{3}$ biovolume serves as conservative estimate that is not likely to be exceeded in field samples.

Cell counts of potentially toxigenic cyanobacteria may likewise be used in combination with reported toxin cell quota of these taxa to estimate toxin concentrations. However, since reliable values for taxon and toxinspecific cell quota are scarce, this approach is limited to taxa for which cell quota estimates are available (see section 4.6.2). Furthermore, estimates based on cell counts and toxin cell quota are subject to the same limitations as estimates from biovolume.

Chlorophyll- $a$ concentrations as a measure of biomass also include phytoplankton organisms other than cyanobacteria. Using them as indicator therefore requires a brief qualitative assessment by microscopy of whether or not the phytoplankton consists chiefly of cyanobacteria. While fluorescence methods, which include the cyanobacteria-specific pigment phycocyanin, can overcome this, they introduce a further dimension of variability (see section 13.5). Furthermore, the chlorophyll- $a$ content of phytoplankton may vary in response to light and nutrient availability by a factor of up to 10 (Kruskopf \& Flynn, 2006; Kasprzak et al., 2008). Also, if photometric analysis of chlorophyll- $a$ includes a correction for phaeophytin, this may result in an underestimation of the concentration of chlorophyll- $a$, particularly in the low concentration range (Chapter 13.5), and thus in an overestimation of the toxin-to-chlorophyll-a ratio.

A number of reports on cyanotoxin concentrations (mainly MCs) suggest that the cell-bound toxin concentration (in $\mu \mathrm{g} / \mathrm{L}$ ) only very rarely exceeds the concentration of chlorophyll- $a$ (also in $\mu \mathrm{g} / \mathrm{L}$ ) and if so, not by more than a factor of three (e.g., Fastner et al., 2001b; Carrasco et al., 2006; Sinang et al., 2013; Loftin et al., 2016; Mantzouki et al., 2018). For example, in Figure 4.9 , the MC/chl- $a$ ratio exceeded 1 only in a small share of samples, while the ratio for the majority of samples ranges between 0.1 and 0.5 . An assumption of a maximum ratio of $\mathbf{1} \boldsymbol{\mu g}$ MC per $\boldsymbol{\mu g}$ chl- $a$ is hence a conservative approach, and in most cases, measured $\mathrm{MC}$ concentrations will be considerably lower than thus estimated.

Secchi depth is a parameter for water transparency which is easily measured on site. In many waterbodies, it correlates directly and inversely with phytoplankton abundance and chlorophyll-a concentration. However, respective correlations generally show considerable scatter because other water constituents (inorganic sediments suspended in the water, humic substances) and differences in optical properties of phytoplankton species affect water transparency. Nonetheless, waterbodies with consistently high Secchi depths are rarely dominated by cyanobacteria, and thus, high transparency indicates that potentially health-relevant cyanotoxin concentrations are unlikely. The transparency threshold value indicating cyanobacterial blooms is best established individually for a given waterbody or a region with a number of similar waterbodies, based on seasonal data for Secchi 

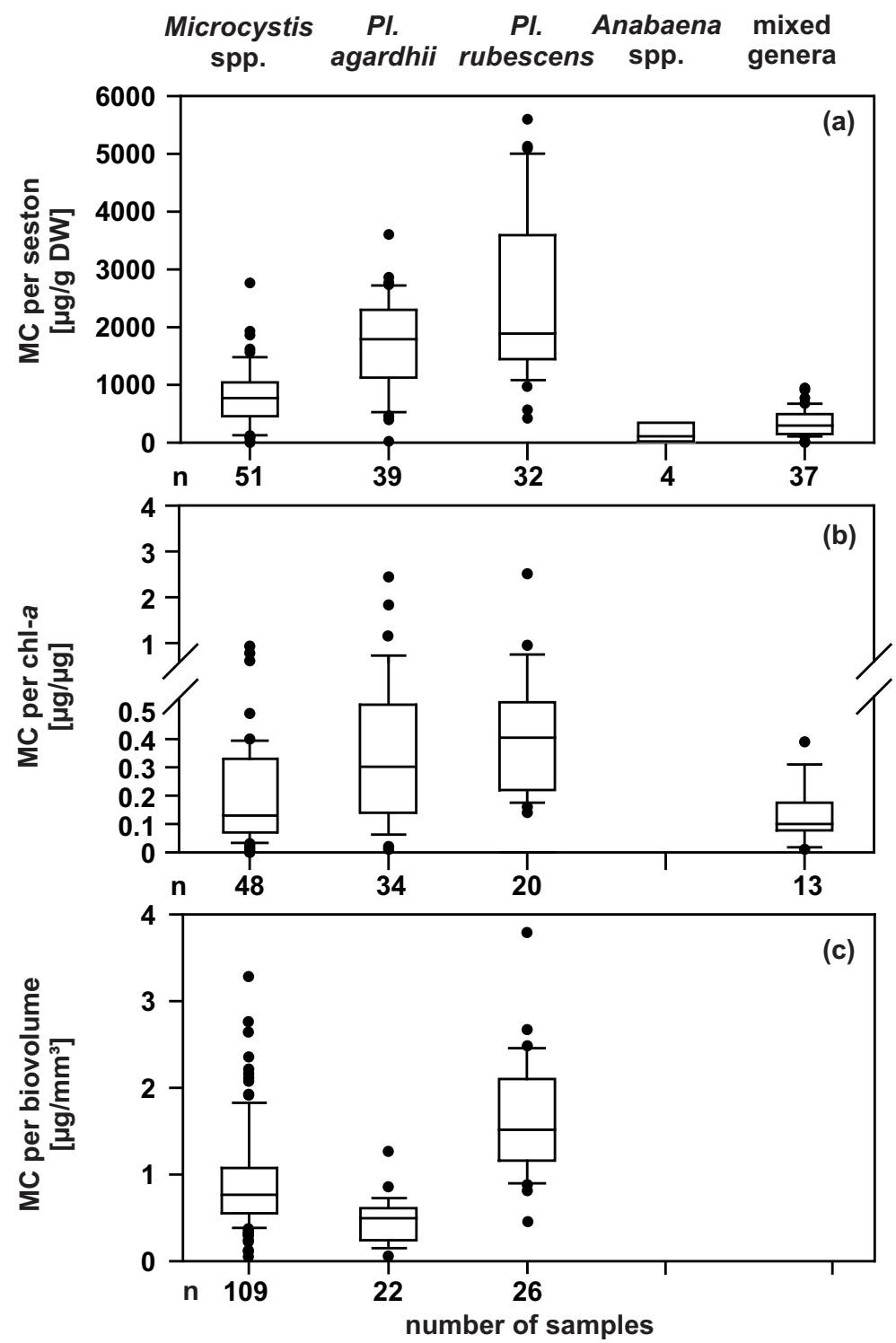

Figure 4.9 Distribution of microcystin (MCs) ratios in samples from German lakes: MC per dry weight of seston (a), MC per chlorophyll-a (b) and MC per biovolume (c). The samples are classified by types of dominance: that is, more than $50 \%$ of biovolume in a sample was due to a particular taxon. (Adapted by permission from Springer Nature, in: Cyanotoxins: occurrence, causes, consequences. Cyanotoxin occurrence in Germany: Microcystins and hepatocyte toxicity. Fastner J, Wirsing B, Wiedner C, Heinze R, Neumann U, Chorus I (200lb). Copyright 200I Springer Nature. www.springernature.com/gp.) 
depths and cyanobacterial biovolumes (or chlorophyll- $a$ together with a semiquantitative check via microscopy as to whether cyanobacteria dominate). For small lakes of less than 50-100 ha, it may well be in the range of 2-3 m, while for larger waterbodies (due to the possibility of surface bloom recruitment from a large water volume; Figure 4.2), it may be higher, and scums may yet accumulate in a bay, while the Secchi disc reading taken at a central site may show several metres. Furthermore, Secchi disc readings cannot serve for assessing risks from benthic or tychoplanktonic cyanobacteria. Also, high Secchi depth readings will not indicate a cyanotoxin risk from Planktothrix rubescens in the metalimnion: these will not diminish transparency in the epilimnion (and may yet cause elevated toxin concentrations at drinking-water offtake depths).

In summary, while Secchi depth readings may be a very useful indicator of cyanotoxin risks, as for many other parameters their reliability depends on a sound understanding of the given waterbody.

Nutrient concentrations - primarily TP and total nitrogen (TN) - determine carrying capacity and hence the maximally achievable phytoplankton biomass (measured as biovolumes or chlorophyll- $a$ concentrations) and hence the maximally achievable (average) cyanotoxin concentration (Dolman et al., 2012). Nutrient concentrations are useful as longer-term predictors whether blooms of cyanobacteria - and hence cyanotoxin concentrations at critical levels - are to be expected (Beaver et al., 2014; section 4.4 and Chapter 8).

\section{REFERENCES}

Abell JM, Özkundakci D, Hamilton DP (2010). Nitrogen and phosphorus limitation of phytoplankton growth in New Zealand lakes: implications for eutrophication control. Ecosystems. 13:966-977.

Agha R, Gross A, Gerphagnon M, Rohrlack T, Wolinska J (2018). Fitness and eco-physiological response of a chytrid fungal parasite infecting planktonic cya nobacteria to thermal and host genotype variation. Parasitology 145:1279-1286.

Agha R, Lezcano MA, del Mar Labrador M, Cirés S, Quesada A (2014). Seasonal dynamics and sedimentation patterns of Microcystis oligopeptide-based chemotypes reveal subpopulations with different ecological traits. Limnol Oceanogr 59:861-871.

Akçaalan R, Young FM, Metcalf JS, Morrison LF, Albay M, Codd GA (2006). Microcystin analysis in single filaments of Planktothrix spp. in laboratory cultures and environmental samples. Water Res. 40:1583-1590.

Al-Tebrineh J, Mihali TK, Pomati F, Neilan BA (2010). Detection of saxitoxinproducing cyanobacteria and Anabaena circinalis in environmental water blooms by quantitative PCR. Appl Environ Microbiol. 76:7836-7842.

Albay M, Matthiensen A, Codd GA (2005). Occurrence of toxic blue-green algae in the Kucukcekmece Lagoon (Istanbul, Turkey). Environ Toxicol. 20:277-284. 
Anagnostidis K, Komárek J (1985). Modern approach to the classification system of Cyanophytes. 1-Introduction. Arch Hydrobiol Algol Stud. 38-39:291-302.

Andersen RA (2005). Algal culturing techniques. Amsterdam. Elsevier Academic Press:578 pp.

Anderson L, Sarmiento J (1994). Redfield ratios of remineralization determined by nutrient data analysis. Global Biogeochem Cy. 8:65-80.

Anneville O, Domaizon I, Kerimoglu O, Rimet F, Jacquet S (2015). Blue-green algae in a "Greenhouse Century"? New insights from field data on climate change impacts on cyanobacteria abundance. Ecosystems. 18:441-458.

Antunes JT, Leão PN, Vasconcelos VM (2015). Cylindrospermopsis raciborskii: review of the distribution, phylogeography, and ecophysiology of a global invasive species. Front Microbiol. 6:473.

Baker P, Humpage A (1994). Toxicity associated with commonly occurring cyanobacteria in surface waters of the Murray-Darling Basin, Australia. Mar Freshwater Res. 45:773-786.

Baker SM, Levinton JS, Kurdziel JP, Shumway SE (1998). Selective feeding and biodeposition by zebra mussels and their relation to changes in phytoplankton composition and seston load. J Shellfish Res. 17:1207-1213.

Barco M, Flores C, Rivera J, Caixach J (2004). Determination of microcystin variants and related peptides present in a water bloom of Planktothrix (Oscillatoria) rubescens in a Spanish drinking water reservoir by LC/ESI-MS. Toxicon. 44:881-886.

Barker GL, Konopka A, Handley BA, Hayes PK (2000). Genetic variation in Aphanizomenon (cyanobacteria) colonies from the Baltic Sea and North America. J Phycol. 36:947-950.

Beattie KA, Kaya K, Codd GA (2000). The cyanobacterium Nodularia in PCC 7804, of freshwater origin, produces [L-Har(2)]nodularin. Phytochemistry. 54:57-61.

Beaver JR, Manis EE, Loftin KA, Graham JL, Pollard AI, Mitchell RM (2014). Land use patterns, ecoregion, and microcystin relationships in US lakes and reservoirs: a preliminary evaluation. Harmful Algae. 36:57-62.

Begon M, Harper JL, Townsend CR (1996). Ecology: individuals, populations and communities, fourth edition. Oxford: Blackwell Scientific Publications.

Beltran EC, Neilan BA (2000). Geographical segregation of the neurotoxinproducing cyanobacterium Anabaena circinalis. Appl Environ Microbiol. 66:4468-4474.

Bianchi TS, Engelhaupt E, Westman P, Andren T, Rolff C, Elmgren R (2000). Cyanobacterial blooms in the Baltic Sea: Natural or human-induced? Limnol Oceanogr. 45:716-726.

Bolch CJS, Orr PT, Jones GJ, Blackburn SI (1999). Genetic, morphological, and toxicological variation among globally distributed strains of Nodularia (Cyanobacteria). J Phycol. 35:339-355.

Boström B, Pettersson A-K, Ahlgren I (1989). Seasonal dynamics of a cyanobacteriadominated microbial community in surface sediments of a shallow, eutrophic lake. Aquat Sci. 51:153-178.

Bouma-Gregson K, Olm MR, Probst AJ, Anantharaman K, Power ME, Banfield JF (2019). Impacts of microbial assemblage and environmental conditions on the distribution of anatoxin-a producing cyanobacteria within a river network. ISME J. 13: 1618-1634. 
Briand JF,Leboulanger C,HumbertJF,Bernard C,DufourP(2004). Cylindrospermopsis raciborskii (Cyanobacteria) invasion at mid-latitudes: Selection, wide physiological tolerance, or global warming? J Phycol. 40:231-238.

Bright DI, Walsby AE (2000). The daily integral of growth by Planktothrix rubescens calculated from growth rate in culture and irradiance in Lake Zürich. New Phytol. 146:301-316.

Bulgakov N, Levich A (1999). The nitrogen: phosphorus ratio as a factor regulating phytoplankton community structure: nutrient ratios. Arch Hydrobiol. 146:3-22.

Burian A, Kainz MJ, Schagerl M, Yasindi A (2014). Species-specific separation of lake plankton reveals divergent food assimilation patterns in rotifers. Freshwat Biol. 59:1257-1265.

Cadel-Six S, Peyraud-Thomas C, Brient L, de Marsac NT, Rippka R, Méjean A (2007). Different genotypes of anatoxin-producing cyanobacteria coexist in the Tarn River, France. Appl Environ Microbiol. 73:7605-7614.

Cantoral Uriza E, Asencio A, Aboal M (2017). Are we underestimating benthic cyanotoxins? extensive sampling results from Spain. Toxins. 9:385.

Capone DG, Burns JA, Montoya JP, Subramaniam A, Mahaffey C, Gunderson T et al. (2005). Nitrogen fixation by Trichodesmium spp.: an important source of new nitrogen to the tropical and subtropical North Atlantic Ocean. Global Biogeochem Cy. 19.1-17.

Carey CC, Ibelings BW, Hoffmann EP, Hamilton DP, Brookes JD (2012). Ecophysiological adaptations that favour freshwater cyanobacteria in a changing climate. Water Res. 46:1394-1407.

Carlson RE (1977). A trophic state index for lakes. Limnol Oceanogr. 22:361-369.

Carmichael WW, Eschedor JT, Patterson GML, Moore RE (1988). Toxicity and partial structure of a hepatotoxic peptide produced by the cyanobacterium Nodularia spumigena Mertens emend. L575 from New Zealand. Appl Environ Microbiol. 54:2257-2263.

Carmichael WW, Gorham PR (1981). The mosaic nature of toxic blooms of cyanobacteria. In: Carmichael WW, editors: The water environment: algal toxins and health. New York: Plenum Press:161-172.

Carpenter SR, Ludwig D, Brock WA (1999). Management of eutrophication for lakes subject to potentially irreversible change. Ecol Appl. 9:751-771.

Carrasco D, Moreno E, Sanchis D, Wörmer L, Paniagua T, Del Cueto A et al. (2006). Cyanobacterial abundance and microcystin occurrence in Mediterranean water reservoirs in Central Spain: microcystins in the Madrid area. Europ J Phycol. 41:281-291.

Carvalho L, McDonald C, de Hoyos C, Mischke U, Phillips G, Borics G et al. (2013). Sustaining recreational quality of European lakes: minimizing the health risks from algal blooms through phosphorus control. J Appl Ecol. 50:315-323.

Chapman EJ, Byron CJ (2018). The flexible application of carrying capacity in ecology. Global Ecol Conserv. 13:e00365.

Cheng Y, Canuto V, Howard A (2002). An improved model for the turbulent PBL. J Atmos Sci. 59:1550-1565.

Chonudomkul D, Yongmanitchai W, Theeragool G, Kawachi M, Kasai F, Kaya K et al. (2004). Morphology, genetic diversity, temperature tolerance and toxicity of Cylindrospermopsis raciborskii (Nostocales, Cyanobacteria) strains from Thailand and Japan. FEMS Microbiol Ecol 48:345-355. 
Chorus I, Dokulil M, Lammens E, Manca M, Naselli-Flores L, Nixdorf B et al (2011). Restoration responses of 19 lakes: are TP thresholds common? In: Chorus I, Schauser I, editors. Oligotrophication of Lake Tegel and Schlachtensee, Berlin Analysis of system components, causalities and response thresholds compared to responses of other waterbodies. Dessau: Umweltbundesamt:84-102.

Chorus I, Niesel V (2011). Steps towards a statistical model to predict phytoplankton responses to changes in trophic state. In: Chorus I, Schauser I, editors. Oligotrophication of Lake Tegel and Schlachtensee, Berlin Analysis of system components, causalities and response thresholds compared to responses of other waterbodies. Dessau: Umweltbundesamt:109-139.

Chorus I, Spijkerman E (2020). What Colin Reynolds could tell us about nutrient limitation, N:P ratios and eutrophication control. Hydrobiologia, in press

Chung S, Imberger J, Hipsey M, Lee H (2014). The influence of physical and physiological processes on the spatial heterogeneity of a Microcystis bloom in a stratified reservoir. Ecol Model. 289:133-149.

Cirés S, Wörmer L, Agha R, Quesada A (2013). Overwintering populations of Anabaena, Aphanizomenon and Microcystis as potential inocula for summer blooms. J Plankton Res. 35:1254-1266.

Conley DJ, Paerl HW, Howarth RW, Boesch DF, Seitzinger SP, Karl E et al. (2009). Controlling eutrophication: nitrogen and phosphorus. Science. 123:1014-1015.

Cook CM, Vardaka E, Lanaras T (2004). Toxic cyanobacteria in Greek freshwaters, 1987-2000: Occurrence, toxicity, and impacts in the Mediterranean region. Acta Hydrochim Hydrobiol. 32:107-124.

Cuypers Y, Vincon-Leite B, Groleau A, Tassin B, Humbert JF (2011). Impact of internal waves on the spatial distribution of Planktothrix rubescens (cyanobacteria) in an alpine lake. ISME J. 5:580-589.

Davis TW, Berry DL, Boyer GL, Gobler CJ (2009). The effects of temperature and nutrients on the growth and dynamics of toxic and non-toxic strains of Microcystis during cyanobacteria blooms. Harmful Algae. 8:715-725.

De Senerpont Domis LN, Elser JJ, Gsell AS, Huszar VL, Ibelings BW, Jeppesen E et al. (2013). Plankton dynamics under different climatic conditions in space and time. Freshwater Biol. 58:463-482.

Diaz M, Pedrozo F, Reynolds C, Temporetti P (2007). Chemical composition and the nitrogen-regulated trophic state of Patagonian lakes. Limnologica. $37: 17-27$.

Dionisio Pires LM, Bontes BM, van Donk E, Ibelings BW (2005). Grazing on colonial and filamentous, toxic and non-toxic cyanobacteria by the zebra mussel Dreissena polymorpha. J Plankton Res. 27:331-339.

Dokulil MT, Mayer J (1996). Population dynamics and photosynthetic rates of a Cylindrospermopsis-Limnothrix association in a highly eutrophic urban lake, Alte Donau, Vienna, Austria. Arch Hydrobiol Algol Stud. 83:179-195

Dokulil MT, Teubner K (2000). Cyanobacterial dominance in lakes. Hydrobiologia. 438:1-12.

Dolman AM, Rücker J, Pick FR, Fastner J, Rohrlack T, Mischke U et al. (2012). Cyanobacteria and cyanotoxins: the influence of nitrogen versus phosphorus. PLoS One. 7:e38757.

Downing JA, Watson SB, McCauley E (2001). Predicting Cyanobacteria dominance in lakes. Can J Fish Aquat Sci. 58:1905-1908. 
Dyble J, Fahnenstiel GL, Litaker RW, Millie DF, Tester PA (2008). Microcystin concentrations and genetic diversity of Microcystis in the lower Great Lakes. Environ Toxicol. 23:507-516.

Dyble J, Paerl HW, Neilan BA (2002). Genetic characterization of Cylindrospermopsis raciborskii (Cyanobacteria) isolates from diverse geographic origins based on nifH and cpcBA-IGS nucleotide sequence analysis. Appl Environ Microbiol. 68:2567-2571.

Edmondson W, Litt AH (1982). Daphnia in lake Washington. Limnol Oceanogr. 27:272-293.

Elliott JA (2012). Is the future blue-green? A review of the current model predictions of how climate change could affect pelagic freshwater cyanobacteria. Water Res. 46:1364-1371.

Elser JJ, Bracken ME, Cleland EE, Gruner DS, Harpole WS, Hillebrand H et al. (2007). Global analysis of nitrogen and phosphorus limitation of primary producers in freshwater, marine and terrestrial ecosystems. Ecol Lett. 10:1135-1142.

Elser JJ, Urabe J (1999). The stoichiometry of consumer-driven nutrient recycling: Theory, observations, and consequences. Ecology. 80:735-751.

Ernst B, Hoeger SJ, O‘brien E, Dietrich DR (2009). Abundance and toxicity of Planktothrix rubescens in the pre-alpine Lake Ammersee, Germany. Harmful Algae. 8:329-342.

Fastner J, Abella S, Litt A, Morabito G, Vörös L, Pálffy K et al. (2016). Combating cyanobacterial proliferation by avoiding or treating inflows with high P load experiences from eight case studies. Aquat Ecol. 50:367-383.

Fastner J, Beulker C, Geiser B, Hoffmann A, Kröger R, Teske K et al. (2018). Fatal neurotoxicosis in dogs associated with tychoplanktic, anatoxin-a producing Tychonema sp. in mesotrophic Lake Tegel, Berlin. Toxins. 10:60.

Fastner J, Erhard M, Carmichael WW, Sun F, Rinehart KL, Rönicke H et al. (1999). Characterization and diversity of microcystins in natural blooms and strains of the genera Microcystis and Planktothrix from German freshwaters. Arch Hydrobiol. 145:147-163.

Fastner J, Erhard M, von Döhren H (2001a). Determination of oligopeptide diversity within a natural population of Microcystis spp. (Cyanobacteria) by typing single colonies by matrix-assisted laser desorption ionization-time of flight mass spectrometry. Appl Environ Microbiol. 67:5069-5076.

Fastner J, Wirsing B, Wiedner C, Heinze R, Neumann U, Chorus I (2001b). Cyanotoxin occurrence in Germany: microcystins and hepatocyte toxicity. In: Chorus I, editors: Cyanotoxins: occurrence, causes, consequences. Berlin: Springer:22-37.

Fergusson KM, Saint CP (2000). Molecular phylogeny of Anabaena circinalis and its identification in environmental samples by PCR. Appl Environ Microbiol. 66:4145-4148.

Fetscher AE, Howard MDA, Stancheva R, Kudela RM, Stein ED, Sutula MA et al. (2015). Wadeable streams as widespread sources of benthic cyanotoxins in California, USA. Harmful Algae. 49:105-116.

Feuillade J (1994). The cyanobacterium (blue-green alga) Oscillatoria rubescens D. C. Adv Limnol. 41:77-93.

Finlay BJ (2002). Global dispersal of free-living microbial eukaryote species. Science. 296:1061-1063. 
Foy R, Gibson C, Smith R (1976). The influence of daylength, light intensity and temperature on the growth rates of planktonic blue-green algae. Brit Phycol J. 11:151-163.

Francis G (1878). Poisonous Australian lake. Nature. 18:11-12.

Frenken T, Wierenga J, Gsell AS, van Donk E, Rohrlack T, Van de Waal DB (2017). Changes in N: P supply ratios affect the ecological stoichiometry of a toxic cyanobacterium and its fungal parasite. Front Microbiol. 8:1015.

Gabriel J-P, Saucy F, Bersier L-F (2005). Paradoxes in the logistic equation? Ecol Model. 185:147-151.

Gallina N, Beniston M, Jacquet S (2017). Estimating future cyanobacterial occurrence and importance in lakes: a case study with Planktothrix rubescens in Lake Geneva. Aquat Sci. 79:249-263.

Gallon JR (2004). N-2 fixation by non-heterocystous cyanobacteria. In: Klipp W, Masepohl B, Gallon JR et al., editors: Genetics and regulation of nitrogen fixation in free-living bacteria. Dordrecht: Springer:111-139.

Gammeter S, Zimmermann U (2001). Changes in phytoplankton productivity and composition during re-oligotrophication in two Swiss lakes. Verh Int Verein Limnol. 27:2190-2193.

Garcia-Pichel F, Belnap J, Neuer S, Schanz F (2003). Estimates of global cyanobacterial biomass and its distribution. Algological Studies. 109:213-227.

Ger KA, Urrutia-Cordero P, Frost PC, Hansson L-A, Sarnelle O, Wilson AE et al. (2016). The interaction between cyanobacteria and zooplankton in a more eutrophic world. Harmful Algae. 54:128-144.

Giani A, Bird DF, Prairie YT, Lawrence JF (2005). Empirical study of cyanobacterial toxicity along a trophic gradient of lakes. Can J Fish Aquat Sci. 62:2100-2109.

Gobler CJ, Burkholder JM, Davis TW, Harke MJ, Johengen T, Stow CA et al. (2016). The dual role of nitrogen supply in controlling the growth and toxicity of cyanobacterial blooms. Harmful Algae. 54:87-97.

Gragnani A, Scheffer M, Rinaldi S (1999). Top-down control of cyanobacteria: a theoretical analysis. Am Nat. 153:59-72.

Graham JL, Jones JR, Jones SB, Clevenger TE (2006). Spatial and temporal dynamics of microcystin in a Missouri reservoir. Lake Reserv Manage. 22:59-68.

Gugger MF, Lenoir S, Berger C, Ledreux A, Druart JC, Humbert JF et al. (2005a). First report in a river in France of the benthic cyanobacterium Phormidium favosum producing anatoxin-a associated with dog neurotoxicosis. Toxicon. 45:919-928.

Gugger MF, Molica R, Le Berre B, Dufour P, Bernard C, Humbert JF (2005b). Genetic diversity of Cylindrospermopsis strains (Cyanobacteria) isolated from four continents. Appl Environ Microbiol. 71:1097-1100.

Haande S, Rohrlack T, Ballot A, Roberg K, Skulberg R, Beck M et al. (2008). Genetic characterisation of Cylindrospermopsis raciborskii (Nostocales, Cyanobacteria) isolates from Africa and Europe. Harmful Algae. 7:692-701.

Harris TD, Wilhelm FM, Graham JL, Loftin KA (2014). Experimental manipulation of TN:TP ratios suppress cyanobacterial biovolume and microcystin concentration in large-scale in situ mesocosms. Lake Reserv Manage. 30:72-83.

Haruštiaková D, Welker M (2017). Chemotype diversity in Planktothrix rubescens (cyanobacteria) populations is correlated to lake depth. Environ Microbiol Rep. 9:158-168. 
Havens K, Jeppesen E (2018). Ecological responses of lakes to climate change. Water. 10:917.

Hesse K, Kohl J-G (2001). Effects of light and nutrients supply on growth and microcystin content of different strains of Microcystis aeruginosa. In: Chorus I, editors: Cyanotoxins: occurrence, causes, consequences. Berlin: Springer:104-115.

Higgins SN, Paterson MJ, Hecky RE, Schindler DW, Venkiteswaran JJ, Findlay DL (2018). Biological nitrogen fixation prevents the response of a eutrophic lake to reduced loading of nitrogen: evidence from a 46-year whole-lake experiment. Ecosystems. 21:1088-1100.

Honjo M, Matsui K, Ueki M, Nakamura R, Fuhrman JA, Kawabata Z (2006). Diversity of virus-like agents killing Microcystis aeruginosa in a hyper-eutrophic pond. J Plankton Res. 28:407-412.

Huber V, Wagner C, Gerten D, Adrian R (2012). To bloom or not to bloom: contrasting responses of cyanobacteria to recent heat waves explained by critical thresholds of abiotic drivers. Oecologia. 169:245-256.

Huisman J, Codd GA, Paerl HW, Ibelings BW, Verspagen JM, Visser PM (2018). Cyanobacterial blooms. Nat Rev Microbiol. 16:471.

Huisman J, Sharples J, Stroom JM, Visser PM, Kardinaal WEA, Verspagen JM et al. (2004). Changes in turbulent mixing shift competition for light between phytoplankton species. Ecology. 85:2960-2970.

Humphries SE, Lyne VD (1988). Cyanophyte blooms: the role of cell buoyancy. Limnol Oceanogr. 33:79-91.

Huszar V, Caraco N, Roland F, Cole J (2006). Nutrient-chlorophyll relationships in tropical-subtropical lakes: do temperate models fit? In: Martinelli LA, Howarth RW, editors: Nitrogen cycling in the Americas: natural and anthropogenic influences and controls. Netherlands: Springer:239-250.

Hutchinson PA, Webster IT (1994). On the distribution of blue-green algae in lakes: wind-tunnel tank experiments. Limnol Oceanogr. 39:374-382.

Ibelings B, Kroon BM, Mur L (1994). Acclimation of Photosystem II in a cyanobacterium and a eukaryotic green alga to high and fluctuating photosynthetic photon flux densities, simulating light regimes induced by mixing in lakes. New Phytol. 128:407-424.

Ibelings BW, Maberly SC (1998). Photoinhibition and the availability of inorganic carybon restrict photosynthesis by surface blooms of cyanobacteria. Limnol Oceanogr. 43:408-419.

Ibelings BW, Mur LR, Kinsman R, Walsby AE (1991). Microcystis changes its buoyancy in response to the average irradiance in the surface mixed layer. Arch Hydrobiol. 120:385-401.

Ibelings BW, Portielje R, Lammens EH, Noordhuis R, van den Berg MS, Joosse W et al. (2007). Resilience of alternative stable states during the recovery of shallow lakes from eutrophication: Lake Veluwe as a case study. Ecosystems. 10:4-16.

Ibelings BW, Vonk M, Los HFJ, van der Molen DT, Mooij WM (2003). Fuzzy modeling of cyanobacterial surface waterblooms: validation with NOAA-AVHRR satellite images. Ecol Appl. 13:1456-1472.

Ihle T, Jähnichen S, Benndorf J (2005). Wax and wane of Microcystis (cyanophyceae) and microcystins in lake sediments: a case study in Quitzdorf reservoir (Germany). J Phycol. 41:479-488. 
Imai H, Chang K-H, Nakano S-I (2009). Growth responses of harmful algal species Microcystis (Cyanophyceae) under various environmental conditions. In: Obayashi Y, Isobe T, Subramanian A et al., editors: Interdisciplinary studies on environmental chemistry-environmental research in Asia. Tokyo: Terrapub:269-275.

Jacoby JM, Burghdoff M, Williams G, Read L, Hardy J (2015). Dominant factors associated with microcystins in nine midlatitude, maritime lakes. Inland Waters. 5:187-202.

Jacquet S, Kerimoglu O, Rimet F, Paolini G, Anneville O (2014). Cyanobacterial bloom termination: the disappearance of Planktothrix rubescens from Lake Bourget (France) after restoration. Freshwater Biol. 59:2472-2487.

Janse I, Kardinaal WEA, Meima M, Fastner J, Visser PM, Zwart G (2004). Toxic and nontoxic Microcystis colonies in natural populations can be differentiated on the basis of rRNA gene internal transcribed spacer. Appl Environ Microbiol. 70:3979-3987.

Janse I, Meima M, Kardinaal WEA, Zwart G (2003). High-resolution differentiation of cyanobacteria by using rRNA-internal transcribed spacer denaturing gradient gel electrophoresis. Appl Environ Microbiol. 69:6634-6643.

Jensen J, Jeppesen E, Olrik K, Kristensen P (1994). Impact of nutrients and physical factors on the shift from cyanobacterial to chlorophyte dominance in shallow Danish lakes. Can J Fish Aquat Sci. 51:1692-1699.

Jeppesen E, Kristensen P, Jensen JP, Søndergaard M, Mortensen E, Lauridsen T (1991). Recovery resilience following a reduction in external phosphorus loading of shallow, eutrophic Danish lakes: duration, regulating factors and methods for overcoming resilience. Mem Ist Ital Idrobiol. 48:127-148.

Jeppesen E, Meerhoff M, Jacobsen B, Hansen R, Søndergaard M, Jensen J et al. (2007). Restoration of shallow lakes by nutrient control and biomanipulation-the successful strategy varies with lake size and climate. Hydrobiologia. 581:269-285.

Jeppesen E, Søndergaard M, Jensen JP (2003). Climatic warming and regime shifts in lake food webs—some comments. Limnol Oceanogr 48:1346-1349.

Jeppesen E, Søndergaard M, Jensen JP, Havens KE, Anneville O, Carvalho L et al. (2005). Lake responses to reduced nutrient loading-an analysis of contemporary long-term data from 35 case studies. Freshwater Biol. 50:1747-1771.

Jöhnk K, Huisman J, Sharples J, Sommeijer B, Visser P, Stroom J (2008). Summer heatwaves promote blooms of harmful cyanobacteria. Global Change Biol. 14:495-512.

Jones GJ, Blackburn SI, Parker NS (1994). A toxic bloom of Nodularia spumigena MERTENS in Orielton Lagoon, Tasmania. Aust J Mar Freshwater Res. 45:787-800.

Kardinaal WEA, Janse I, Kamst-van Agterveld MP, Meima M, Snoek J, Mur LR et al. (2007). Microcystis genotype succession in relation to microcystin concentrations in freshwater lakes. Aquat Microb Ecol. 48:1-12.

Kardinaal WEA, Visser PM (2005). Dynamics of cyanobacterial toxins: sources of variability in microcystin concentrations. In: Huisman J, Matthijs HCP, Visser PM, editors. Harmful cyanobacteria. Berlin: Springer:41-63.

Karlsson-Elfgren I, Rengefors K, Gustafsson S (2004). Factors regulating recruitment from the sediment to the water column in the bloom-forming cyanobacterium Gloeotrichia echinulata. Freshwater Biol. 49:265-273. 
Karlsson-Elfgren I, Rydin E, Hyenstrand P, Pettersson K (2003). Recruitment and pelagic growth of Gloeotrichia echinulata (Cyanophyceae) in Lake Erken. J Phycol. 39:1050-1056.

Kasprzak P, Padisák J, Koschel R, Krienitz L, Gervais F (2008). Chlorophyll a concentration across a trophic gradient of lakes: An estimator of phytoplankton biomass? Limnologica. 38:327-338.

Kinsman R, Ibelings BW, Walsby A (1991). Gas vesicle collapse by turgor pressure and its role in buoyancy regulation by Anabaena flos-aquae. Microbiology. 137:1171-1178.

Kirk JTO (1994). Light and photosynthesis in aquatic ecosystems. Cambridge, UK: Cambridge University Press.

Klemer A, Feuillade J, Feuillade M (1982). Cyanobacterial blooms: carbon and nitrogen limitation have opposite effects on the buoyancy of Oscillatoria. Science. 215:1629-1631.

Kolzau S, Wiedner C, Rücker J, Köhler J, Köhler A, Dolman AM (2014). Seasonal patterns of nitrogen and phosphorus limitation in four German lakes and the predictability of limitation status from ambient nutrient concentrations. PLoS One. 9:e96065.

Konopka A (1989). Metalimnetic cyanobacteria in hard-water lakes: Buoyancy regulation and physiological state. Limnol Oceanogr. 34:1174-1184.

Konopka A, Kromkamp JC, Mur LR (1987). Buoyancy regulation in phosphatelimited cultures of Microcystis aeruginosa. FEMS Microbiol Lett. 45:135-142.

Kosten S, Huszar VL, Bécares E, Costa LS, Donk E, Hansson LA et al. (2012). Warmer climates boost cyanobacterial dominance in shallow lakes. Global Change Biol. 18:118-126.

Kosten S, Huszar VL, Mazzeo N, Scheffer M, da SL Sternberg L, Jeppesen E (2009). Lake and watershed characteristics rather than climate influence nutrient limitation in shallow lakes. Ecol App. 19:1791-1804.

Kotak BG, Lam AKY, Prepas EE, Hrudey SE (2000). Role of chemical and physical variables in regulating microcystin-LR concentration in phytoplankton of eutrophic lakes. Can J Fish Aquat Sci. 57:1584-1593.

Kromkamp J, Walsby AE (1990). A computer model of buoyancy and vertical migration in cyanobacteria. J Plankton Res. 12:161-183.

Kruk C, Mazzeo N, Lacerot G, Reynolds C (2002). Classification schemes for phytoplankton: a local validation of a functional approach to the analysis of species temporal replacement. J Plankton Res. 24:901-912.

Kruskopf M, Flynn KJ (2006). Chlorophyll content and fluorescence responses cannot be used to gauge reliably phytoplankton biomass, nutrient status or growth rate. New Phytol. 169:525-536.

Kuno S, Yoshida T, Kaneko T, Sako Y (2012). Intricate interactions between the bloomforming cyanobacterium Microcystis aeruginosa and foreign genetic elements, revealed by diversified clustered regularly interspaced short palindromic repeat (CRISPR) signatures. Appl Environ Microbiol. 78:5353-5360.

Kurmayer R, Christiansen G, Chorus I (2003). The abundance of microcystinproducing genotypes correlates positively with colony size in Microcystis sp and determines its microcystin net production in Lake Wannsee. Appl Environ Microbiol. 69:787-795. 
Kurmayer R, Christiansen G, Fastner J, Börner T (2004). Abundance of active and inactive microcystin genotypes in populations of the toxic cyanobacterium Planktothrix spp. Environ Microbiol. 6:831-841.

Kurmayer R, Gumpenberger M (2006). Diversity of microcystin genotypes among populations of the filamentous cyanobacteria Planktothrix rubescens and Planktothrix agardhii. Mol Ecol. 15:3849-3861.

Kurmayer R, Jüttner F (1999). Strategies for the co-existence of zooplankton with the toxic cyanobacterium Planktothrix rubescens in Lake Zurich. J Plankton Res. 21:659-683.

Lampert W, Fleckner W, Rai H, Taylor BE (1986). Phytoplankton control by grazing zooplankton: A study on the spring clear-water phase. Limnol Oceanogr. 31:478-490.

Lampert W, Sommer U (2007). Limnoecology: the ecology of lakes and streams. New York: Oxford University Press:336 pp.

Lemaire V, Brusciotti S, van Gremberghe I, Vyverman W, Vanoverbeke J, De Meester L (2012). Genotypexgenotype interactions between the toxic cyanobacterium Microcystis and its grazer, the waterflea Daphnia. Evol Appl. 5:168-182.

Li H, Sherman DM, Bao SL, Sherman LA (2001a). Pattern of cyanophycin accumulation in nitrogen-fixing and non-nitrogen-fixing cyanobacteria. Arch Microbiol. 176:9-18.

Li J, Dittrich M (2019). Dynamic polyphosphate metabolism in cyanobacteria responding to phosphorus availability. Environ Microbiol. 21:572-583.

Li R, Carmichael WW, Brittain S, Eaglesham GK, Shaw GR, Mahakahant A et al. (2001b). Isolation and identification of the cyanotoxin cylindrospermopsin and deoxy-cylindrospermopsin from a Thailand strain of Cylindrospermopsis raciborskii (Cyanobacteria). Toxicon. 39:973-980.

Livingstone DM (2003). Impact of secular climate change on the thermal structure of a large temperate central European lake. Climatic Change. 57:205-225.

Loftin KA, Graham JL, Hilborn ED, Lehmann SC, Meyer MT, Dietze JE et al. (2016). Cyanotoxins in inland lakes of the United States: Occurrence and potential recreational health risks in the EPA National Lakes Assessment 2007. Harmful Algae. 56:77-90.

Loiselle SA, Cozar A, Dattilo A, Bracchini L, Galvez JA (2007). Light limitations to algal growth in tropical ecosystems. Freshwater Biol. 52:305-312.

Long BM, Jones GJ, Orr PT (2001). Cellular microcystin content in N-limited Microcystis aeruginosa can be predicted from growth rate. Appl Environ Microbiol. 67:278-283.

Lürling M, Eshetu F, Faassen EJ, Kosten S, Huszar VLM (2013). Comparison of cyanobacterial and green algal growth rates at different temperatures. Freshwater Biol. 58:552-559.

Mallet J (2012). The struggle for existence. how the notion of carrying capacity, K, obscures the links between demography, Darwinian evolution and speciation. Evol Ecol Res. 14:627-665.

Mamun M, An K-G (2017). Major nutrients and chlorophyll dynamics in Korean agricultural reservoirs along with an analysis of trophic state index deviation. J Asia-Pacific Biodiversity. 10:183-191.

Mantzouki E, Lürling M, Fastner J, de Senerpont Domis L, Wilk-Woźniak E, Koreivienė J et al. (2018). Temperature effects explain continental scale distribution of cyanobacterial toxins. Toxins. 10:156. 
Mantzouki E, Visser PM, Bormans M, Ibelings BW (2016). Understanding the key ecological traits of cyanobacteria as a basis for their management and control in changing lakes. Aquat Ecol. 50:333-350.

Martiny JB, Bohannan BJ, Brown JH, Colwell RK, Fuhrman JA, Green JL et al. (2006). Microbial biogeography: putting microorganisms on the map. Nat Rev Microbiol. 4:102-112.

Matveev V, Matveeva L, Jones GJ (1994). Study of the ability of Daphnia carinata (King) to control phytoplankton and resist cyanobacterial toxicity: implications for biomanipulation in Australia. Mar Freshwater Res. 45:889-904.

McAllister TG, Wood SA, Hawes I (2016). The rise of toxic benthic Phormidium proliferations: a review of their taxonomy, distribution, toxin content and factors regulating prevalence and increased severity. Harmful Algae. 55:282-294.

Medrano EA, Uittenbogaard R, Pires LD, Van De Wiel B, Clercx H (2013). Coupling hydrodynamics and buoyancy regulation in Microcystis aeruginosa for its vertical distribution in lakes. Ecol Model. 248:41-56.

Mehnert G, Leunert F, Cirés S, Jöhnk KD, Rücker J, Nixdorf B et al. (2010). Competitiveness of invasive and native cyanobacteria from temperate freshwaters under various light and temperature conditions. J Plankton Res. 32:1009-1021.

Meyer KA, Davis TW, Watson SB, Denef VJ, Berry MA, Dick GJ (2017). Genome sequences of lower Great Lakes Microcystis sp. reveal strain-specific genes that are present and expressed in western Lake Erie blooms. PLoS One. 12. e0183859.

Michalak AM, Anderson EJ, Beletsky D, Boland S, Bosch NS, Bridgeman TB et al. (2013). Record-setting algal bloom in Lake Erie caused by agricultural and meteorological trends consistent with expected future conditions. Proc Natl Acad Sci USA. 110:6448-6452.

Miller TR, Bartlett S, Weirich CA, Hernandez J (2019). Automated sub-daily sampling of cyanobacterial toxins on a buoy reveals new temporal patterns in toxin dynamics. Environ Sci Technol. 53:5661-5670.

Mohamed ZA (2001). Accumulation of cyanobacterial hepatotoxins by Daphnia in some Egyptian irrigation canals. Ecotoxicol Environ Safety. 50:4-8.

Mooij WM, Hülsmann S, De Senerpont Domis LN, Nolet BA, Bodelier PL, Boers PC et al. (2005). The impact of climate change on lakes in the Netherlands: a review. Aquat Ecol. 39:381-400.

Mooij WM, Trolle D, Jeppesen E, Arhonditsis G, Belolipetsky PV, Chitamwebwa DB et al. (2010). Challenges and opportunities for integrating lake ecosystem modelling approaches. Aquat Ecol. 44:633-667.

Moss B, Jeppesen E, Søndergaard M, Lauridsen TL, Liu Z (2013). Nitrogen, macrophytes, shallow lakes and nutrient limitation: resolution of a current controversy? Hydrobiologia. 710:3-21.

Moss B, Kosten S, Meerhoff M, Battarbee RW, Jeppesen E, Mazzeo N et al. (2011). Allied attack: climate change and eutrophication. Inland Waters. 1:101-105.

Mur L (1983). Some aspects of the ecophysiology of cyanobacteria. Annales de l'Institut Pasteur/Microbiologie. 134B:61-72.

Nalewajko C, Murphy TP (2001). Effects of temperature, and availability of nitrogen and phosphorus on the abundance of Anabaena and Microcystis in Lake Biwa, Japan: an experimental approach. Limnology. 2:45-48. 
Naselli-Flores L, Barone R, Chorus I, Kurmayer R (2007). Toxic cyanobacterial blooms in reservoirs under a semiarid mediterranean climate: the magnification of a problem. Environ Toxicol. 22:399-404.

Nehring S (1993). Mortality of dogs associated with a mass development of Nodularia spumigena (Cyanophyceae) in a brackish lake at the German North Sea coast. J Plankton Res. 15:867-872.

Neilan BA, Saker ML, Fastner J, Törökné AK, Burns BP (2003). Phylogeography of the invasive cyanobacterium Cylindrospermopsis raciborskii. Mol Ecol. 12:133-140.

Novak JT, Brune DE (1985). Inorganic carbon limited growth kinetics of some freshwater algae. Water Res. 19:215-225.

Nürnberg GK (1996). Trophic state of clear and colored, soft-and hardwater lakes with special consideration of nutrients, anoxia, phytoplankton and fish. Lake Reserv Manage. 12:432-447.

Nürnberg GK, LaZerte BD, Olding DD (2003). An artificially induced Planktothrix rubescens surface bloom in a small kettle lake in Southern Ontario compared to blooms world-wide. Lake Reserv Manage. 19:307-322.

Oberhaus L, Briand JF, Leboulanger C, Jacquet S, Humbert JF (2007). Comparative effects of the quality and quantity of light and temperature on the growth of Planktothrix agardhii and P. rubescens. J Phycol. 43:1191-1199.

Odum EP (1953). Fundamentals of ecology, first edition. Philadelphia (PA): WB Saunders.

Okello W, Ostermaier V, Portmann C, Gademann K, Kurmayer R (2010). Spatial isolation favours the divergence in microcystin net production by Microcystis in Ugandan freshwater lakes. Water Res. 44:2803-2814.

Oliver R, Ganf G (2000). Freshwater blooms. In: Whitton BA, Potts M, editors: The ecology of cyanobacteria: their diversity in time and space. Dordrecht: Springer:150-194.

Orr PT, Jones GJ (1998). Relationship between microcystin production and cell division rates in nitrogen-limited Microcystis aeruginosa cultures. Limnol Oceanogr. 43:1604-1614.

Orr PT, Rasmussen JP, Burford MA, Eaglesham GK, Lennox SM (2010). Evaluation of quantitative real-time PCR to characterise spatial and temporal variations in cyanobacteria, Cylindrospermopsis raciborskii (Woloszynska) Seenaya et Subba Raju and cylindrospermopsin concentrations in three subtropical Australian reservoirs. Harmful Algae. 9:243-254.

Otsuka S, Suda S, Li R, Watanabe M, Oyaizu H, Matsumoto S et al. (1999). Characterization of morphospecies and strains of the genus Microcystis (Cyanobacteria) for a reconsideration of species classification. Phycol Res. 47:189-197.

Otten TG, Paerl HW, Dreher TW, Kimmerer WJ, Parker AE (2017). The molecular ecology of Microcystis sp. blooms in the San Francisco Estuary. Environ Microbiol. 19:3619-3637.

Ozawa K, Fujioka H, Muranaka M, Yokoyama A, Katagami Y, Homma T et al. (2005). Spatial distribution and temporal variation of Microcystis species composition and microcystin concentration in Lake Biwa. Environ Toxicol. 20:270-276.

Padisák J (1997). Cylindrospermopsis raciborskii (Woloszynska) Seenayya et Stubba Raju, an expanding, highly adaptive cyanobacterium: worldwide distribution and review of its ecology. Arch Hydrobiol Suppl. 107:563-593. 
Padisák J, Crossetti LO, Naselli-Flores L (2009). Use and misuse in the application of the phytoplankton functional classification: a critical review with updates. Hydrobiologia. 621:1-19.

Paerl HW, Huisman J (2009). Climate change: a catalyst for global expansion of harmful cyanobacterial blooms. Environ Microbiol Rep. 1:27-37.

Paerl HW, Scott JT, McCarthy MJ, Newell SE, Gardner WS, Havens KE et al. (2016). It takes two to tango: when and where dual nutrient $(\mathrm{N} \& \mathrm{P})$ reductions are needed to protect lakes and downstream ecosystems. Environ Sci Technol. 50:10805-10813.

Paterson M, Schindler D, Hecky R, Findlay D, Rondeau K (2011). Comment: Lake 227 shows clearly that controlling inputs of nitrogen will not reduce or prevent eutrophication of lakes. Limnol Oceanogr. 56:1545-1547.

Phillips G, Pietiläinen O-P, Carvalho L, Solimini A, Solheim AL, Cardoso A (2008). Chlorophyll-nutrient relationships of different lake types using a large European dataset. Aquat Ecol. 42:213-226.

Piccini C, Aubriot L, Fabre A, Amaral V, González-Piana M, Giani A et al. (2011). Genetic and eco-physiological differences of South American Cylindrospermopsis raciborskii isolates support the hypothesis of multiple ecotypes. Harmful Algae. 10:644-653.

Porat R, Teltsch B, Perelman A, Dubinsky Z (2001). Diel buoyancy changes by the cyanobacterium Aphanizomenon ovalisporum from a shallow reservoir. J Plankton Res. 23:753-763.

Posch T, Köster O, Salcher MM, Pernthaler J (2012). Harmful filamentous cyanobacteria favoured by reduced water turnover with lake warming. Nat Clim Change. 2:809.

Preston T, Stewart WDP, Reynolds CS (1980). Bloom-forming cyanobacterium Microcystis aeruginosa overwinters on sediment surface. Nature. 288:365-367.

Price GD, Badger MR, Woodger FJ, Long BM (2007). Advances in understanding the cyanobacterial CO2-concentrating-mechanism (CCM): functional components, $\mathrm{Ci}$ transporters, diversity, genetic regulation and prospects for engineering into plants. J Exp Bot. 59:1441-1461.

Pridmore RD, Etheredge MK (1987). Planktonic cyanobacteria in New Zealand inland waters: distribution and population dynamics. New Zeal J Mar Freshwater Res. 21:491-502.

Ptacnik R, Lepistö L, Willén E, Brettum P, Andersen T, Rekolainen S et al. (2008). Quantitative responses of lake phytoplankton to eutrophication in Northern Europe. Aquat Ecol. 42:227-236.

Quiblier C, Wood SA, Echenique-Subiabre I, Heath M, Villeneuve A, Humbert JF (2013). A review of current knowledge on toxic benthic freshwater cyanobacteriaecology, toxin production and risk management. Water Res. 47:5464-5479.

Rabouille S, Salençon M-J (2005). Functional analysis of Microcystis vertical migration: a dynamic model as a prospecting tool. II. Influence of mixing, thermal stratification and colony diameter on biomass production. Aquat Microb Ecol. 39:281-292.

Raikow DF, Sarnelle O, Wilson AE, Hamilton SK (2004). Dominance of the noxious cyanobacterium Microcystis aeruginosa in low-nutrient lakes is associated with exotic zebra mussels. Limnol Oceanogr. 49:482-487. 
Recknagel F, Orr PT, Bartkow M, Swanepoel A, Cao H (2017). Early warning of limit-exceeding concentrations of cyanobacteria and cyanotoxins in drinking water reservoirs by inferential modelling. Harmful Algae. 69:18-27.

Redfield A (1934). On the proportions of organic derivations in seawater and their relation to the composition of plankton (reprint). In: Daniel R, editors: James Johnstone memorial volume. Liverpool: University Press of Liverpool: 176-192.

Reeders H, Boers P, Van der Molen D, Helmerhorst T (1998). Cyanobacterial dominance in the lakes Veluwemeer and Wolderwijd, The Netherlands. Wat Sci Technol. 37:85-92.

Reynolds C (1994). The ecological basis for the successful biomanipulation of aquatic communities. Arch Hydrobiol. 130:1-33.

Reynolds C (1999a). Modelling phytoplankton dynamics and its application to lake management. Hydrobiologia. 395:123-131.

Reynolds C, Maberly S (2002). A simple method for approximating the supportive capacities and metabolic constraints in lakes and reservoirs. Freshwater Biol. 47:1183-1188.

Reynolds CS (1984). The ecology of freshwater phytoplankton. Cambridge, UK: Cambridge University Press:396 pp.

Reynolds CS (1997). Vegetation processes in the pelagic: a model for ecosystem theory. Oldendorf/Luhe: Ecology Institute:371 pp.

Reynolds CS (1999b). Non-determinism to probability, or N: P in the community ecology of phytoplankton: nutrient ratios. Arch Hydrobiol. 146:23-35.

Reynolds CS (2006). The ecology of phytoplankton. Cambridge, UK: Cambridge University Press:552 pp.

Reynolds CS, Huszar V, Kruk C, Naselli-Flores L, Melo S (2002). Towards a functional classification of the freshwater phytoplankton. J Plankton Res. 24:417-428.

Reynolds CS, Jaworsky GHM, Cmiech HA, Leedale GF (1981). On the annual cycle of Microcystis aeruginosa Kütz emend. Elenkin. Philos Trans R Soc Lond B. 293:419-477.

Reynolds CS, Maberly SC, Parker JE, De Ville MM (2012). Forty years of monitoring water quality in Grasmere (English Lake District): separating the effects of enrichment by treated sewage and hydraulic flushing on phytoplankton ecology. Freshwater Biol. 57:384-399.

Rigosi A, Carey CC, Ibelings BW, Brookes JD (2014). The interaction between climate warming and eutrophication to promote cyanobacteria is dependent on trophic state and varies among taxa. Limnol Oceanogr. 59:99-114.

Rohrlack T (2018). Low temperatures can promote cyanobacterial bloom formation by providing refuge from microbial antagonists. AIMS Microbiol. 4:304-318.

Rohrlack T, Christiansen G, Kurmayer R (2013). Putative antiparasite defensive system involving ribosomal and nonribosomal oligopeptides in cyanobacteria of the genus Planktothrix. Appl Environ Microbiol. 79:2642-2647.

Romo S, Soria J, Fernandez F, Ouahid Y, Barón-Solá Á (2013). Water residence time and the dynamics of toxic cyanobacteria. Freshwater Biol. 58:513-522.

Rücker J, Wiedner C, Zippel P (1997). Factors controlling the dominance of Planktothrix agardhii and Limnothrix redekei in eutrophic shallow lakes. Hydrobiologia. 342/343:107-115. 
Saker ML, Griffiths DJ (2000). The effect of temperature on growth and cylindrospermopsin content of seven isolates of Cylindrospermopsis raciborskii (Nostocales, Cyanophyceae) from water bodies in northern Australia. Phycologia. 39:349-354.

Salas HJ, Martino P (1991). A simplified phosphorus trophic state model for warmwater tropical lakes. Water Res. 25:341-350.

Salk KR, Bullerjahn GS, McKay RML, Chaffin JD, Ostrom NE (2018). Nitrogen cycling in Sandusky Bay, Lake Erie: oscillations between strong and weak export and implications for harmful algal blooms. Biogeosciences. 15:2891-2907.

Salmaso N, Boscaini A, Capelli C, Cerasino L (2018). Ongoing ecological shifts in a large lake are driven by climate change and eutrophication: evidences from a three-decade study in Lake Garda. Hydrobiologia. 824:177-195.

Salmaso N, Capelli C, Shams S, Cerasino L (2015). Expansion of bloom-forming Dolichospermum lemmermannii (Nostocales, Cyanobacteria) to the deep lakes south of the Alps: colonization patterns, driving forces and implications for water use. Harmful Algae. 50:76-87.

Salmaso N, Cerasino L, Boscaini A, Capelli C (2016). Planktic Tychonema (Cyanobacteria) in the large lakes south of the Alps: phylogenetic assessment and toxigenic potential. FEMS Microbiol Ecol. 92:fiw155.

Salmaso N, Copetti D, Cerasino L, Shams S, Capelli C, Boscaini A et al. (2014). Variability of microcystin cell quota in metapopulations of Planktothrix rubescens: causes and implications for water management. Toxicon. 90:82-96.

Sandrini G, Matthijs HC, Verspagen JM, Muyzer G, Huisman J (2014). Genetic diversity of inorganic carbon uptake systems causes variation in $\mathrm{CO}_{2}$ response of the cyanobacterium Microcystis. ISME J. 8:589.

Sarnelle O (1993). Herbivore effects on phytoplankton succession in a eutrophic lake. Ecol Monogr. 63:129-149.

Sayre NF (2008). The genesis, history, and limits of carrying capacity. Ann Assoc Am Geogr. 98:120-134.

Schanz F (1994). Oligotrophication of Lake Zürich as reflected in Secchi depth measurements. Ann Limnol. 30:57-65.

Scheffer M, Rinaldi S, Gragnani A, Mur LR, van Nes EH (1997). On the dominance of filamentous cyanobacteria in shallow, turbid lakes. Ecology. 78:272-282.

Schindler DW (2006). Recent advances in the understanding and management of eutrophication. Limnol Oceanogr. 51:356-363.

Schindler DW, Carpenter SR, Chapra SC, Hecky RE, Orihel DM (2016). Reducing phosphorus to curb lake eutrophication is a success. Environ Sci Technol. 50:8923-8929.

Schindler DW, Hecky R, Findlay D, Stainton M, Parker B, Paterson M et al. (2008). Eutrophication of lakes cannot be controlled by reducing nitrogen input: results of a 37-year whole-ecosystem experiment. Proc Natl Acad Sci USA. 105:11254-11258.

Scott JT, Marcarelli AM (2012). Cyanobacteria in freshwater benthic environments. In: Whitton BA, editors: Ecology of Cyanobacteria II, second edition. Dordrecht: Springer:271-289.

Scott JT, McCarthy MJ (2010). Nitrogen fixation may not balance the nitrogen pool in lakes over timescales relevant to eutrophication management. Limnol Oceanogr. 55:1265-1270. 
Scott JT, McCarthy MJ (2011). Response to comment: nitrogen fixation has not offset declines in the Lake 227 nitrogen pool and shows that nitrogen control deserves consideration in aquatic ecosystems. Limnol Oceanogr. 56:1548-1550.

Shams S, Capelli C, Cerasino L, Ballot A, Dietrich DR, Sivonen K et al. (2015). Anatoxin-a producing Tychonema (Cyanobacteria) in European waterbodies. Water Res 69:68-79.

Shapiro J (1997). The role of carbon dioxide in the initiation and maintenance of blue-green dominance in lakes. Freshwater Biol. 37:307-323.

Shatwell T, Köhler J (2019). Decreased nitrogen loading controls summer cyanobacterial blooms without promoting nitrogen-fixing taxa: long-term response of a shallow lake. Limnol Oceanogr. 64:S166-S178.

Simon RD (1971). Cyanophycin granules from the blue-green alga Anabaena cylindrica: a reserve material consisting of copolymers of aspartic acid and arginine. Proc Natl Acad Sci USA. 68:265-267.

Sinang SC, Reichwaldt ES, Ghadouani A (2013). Spatial and temporal variability in the relationship between cyanobacterial biomass and microcystins. Environ Monit Assess. 185:6379-6395.

Sitoki L, Kurmayer R, Rott E (2012). Spatial variation of phytoplankton composition, biovolume, and resulting microcystin concentrations in the Nyanza Gulf (Lake Victoria, Kenya). Hydrobiologia. 691:109-122.

Sivonen K (1990). Effects of light, temperature, nitrate, orthophosphate, and bacteria on growth of and hepatotoxin production by Oscillatoria agardhii strains. Appl Environ Microbiol. 56:2658-2666.

Skulberg OM, Skulberg R (1985). Planktic species of Oscillatoria (Cyanophyceae) from Norway. Characterization and classification. Arch Hydrobiol Algol Stud. 38-39:157-174.

Smith FM, Wood SA, van Ginkel R, Broady PA, Gaw S (2011). First report of saxitoxin production by a species of the freshwater benthic cyanobacterium, Scytonema Agardh. Toxicon 57:566-573.

Smith VH (1983). Low nitrogen to phosphorus ratios favor dominance by blue-green algae in lake phytoplankton. Science. 221:669-671.

Søndergaard M, Lauridsen TL, Johansson LS, Jeppesen E (2017). Nitrogen or phosphorus limitation in lakes and its impact on phytoplankton biomass and submerged macrophyte cover. Hydrobiologia. 795:35-48.

Soto D (2002). Oligotrophic patterns in southern Chilean lakes: the relevance of nutrients and mixing depth. Revista Chilena de Historia Natural. 75:377-393.

Steenhauer LM, Wierenga J, Carreira C, Limpens RW, Koster AJ, Pollard PC et al. (2016). Isolation of cyanophage $\mathrm{CrV}$ infecting Cylindrospermopsis raciborskii and the influence of temperature and irradiance on $\mathrm{CrV}$ proliferation. Aquatic Microbial Ecol. 78:11-23.

Steffen MM, Davis TW, McKay RML, Bullerjahn GS, Krausfeldt LE, Stough JM et al. (2017). Ecophysiological examination of the Lake Erie Microcystis bloom in 2014: linkages between biology and the water supply shutdown of Toledo, OH. Environ Sci Technol. 51:6745-6755.

Stein JR, Hellebust JA, Craigie J, editors (1980). Handbook of phycological methods: culture methods and growth measurements. Cambridge, UK: Cambridge University Press. Sterner RW (2008). On the phosphorus limitation paradigm for lakes. Int Rev Hydrobiol. 93:433-445. 
Sterner RW, Andersen T, Elser JJ, Hessen DO, Hood JM, McCauley E et al. (2008). Scale-dependent carbon:nitrogen:phosphorus seston stoichiometry in marine and freshwaters. Limnol Oceanogr. 53:1169-1180.

Stough JM, Tang X, Krausfeldt LE, Steffen MM, Gao G, Boyer GL et al. (2017). Molecular prediction of lytic $v s$ lysogenic states for Microcystis phage: Metatranscriptomic evidence of lysogeny during large bloom events. PLoS One 12:e0184146.

Stumm W, Morgan JJ (1996). Aquatic chemistry: chemical equilibria and rates in natural waters, third edition. Chichester: John Wiley \& Sons:1040 pp.

Suda S, Watanabe MM, Otsuka S, Mahakahant A, Yongmanitchai W, Nopartnaraporn $\mathrm{N}$ et al. (2002). Taxonomic revision of water-bloom-forming species of oscillatoroid cyanobacteria. Int J Syst Evol Microbiol. 52:1577-1595.

Šulčius S, Mazur-Marzec H, Vitonytė I, Kvederavičiūtė K, Kuznecova J, Šimoliūnas E et al. (2018). Insights into cyanophage-mediated dynamics of nodularin and other non-ribosomal peptides in Nodularia spumigena. Harmful Algae 78:69-74.

Svirčev Z, Lalić D, Savić GB, Tokodi N, Backović DD, Chen L et al. (2019). Global geographical and historical overview of cyanotoxin distribution and cyanobacterial poisonings. Arch Toxicol. 93:2429-2481.

Takamura N, Yasuno M, Sugahara K (1984). Overwintering of Microcystis aeruginosa Kütz. in a shallow lake. J Plankton Res. 6:1019-1029.

Teubner K, Feyerabend R, Henning M, Nicklisch A, Woitke P, Kohl J-G (1999). Alternative blooming of Aphanizomenon flos-aquae or Planktothrix agardhii induced by the timing of the critical nitrogen:phosphorus ratio in hypertrophic riverine lakes. Arch Hydrobiol Spec Issues Advanc Limnol. 54:325-344.

Thomas MK, Litchman E (2016). Effects of temperature and nitrogen availability on the growth of invasive and native cyanobacteria. Hydrobiologia. 763:357-369.

Triest L, Stiers I, Van Onsem S (2016). Biomanipulation as a nature-based solution to reduce cyanobacterial blooms. Aquat Ecol. 50:461-483.

Uehlinger U (1981). Experimentelle Untersuchungen zur Autökologie von Aphanizomenon flos-aquae. Algol Stud/Arch Hydrobiol. 60:260-288.

Van Liere L, Mur LR (1980). Occurrence of Oscillatoria agardhii and some related species, a survey. SIL Workshop on Hypertrophic Ecosystems, Växjö, Sweden. Dordrecht:Springer:67-77.

Van Wichelen J, van Gremberghe I, Vanormelingen P, Debeer AE, Leporcq B, Menzel D et al. (2010). Strong effects of amoebae grazing on the biomass and genetic structure of a Microcystis bloom (Cyanobacteria). Environ Microbiol. 12:2797-2813.

Van Wichelen J, Vanormelingen P, Codd GA, Vyverman W (2016). The common bloom-forming cyanobacterium Microcystis is prone to a wide array of microbial antagonists. Harmful Algae. 55:97-111.

Vanderploeg HA, Liebig JR, Carmichael WW, Agy MA, Johengen TH, Fahnenstiel GL et al. (2001). Zebra mussel (Dreissena polymorpha) selective filtration promoted toxic Microcystis blooms in Saginaw Bay (Lake Huron) and Lake Erie. Can J Fish Aquat Sci. 58:1208-1221.

Vasas G, Surányi G, Bácsi I, Márta M, Máthé C, Gonda S et al. (2013). Alteration of cylindrospermopsin content of Aphanizomenon ovalisporum (Cyanobacteria, Nostocales) due to step-down from combined nitrogen to dinitrogen. Adv Microbiol. 3:557. 
Verspagen JMH, Snelder EOFM, Visser PM, Huisman J, Mur LR, Ibelings BW (2004). Recruitment of benthic Microcystis (Cyanophyceae) to the water column: internal buoyancy changes or resuspension? J Phycol. 40:260-270.

Visser PM, Ibelings BW, Bormans M, Huisman J (2016a). Artificial mixing to control cyanobacterial blooms: a review. Aquat Ecol. 50:423-441.

Visser PM, Passarge J, Mur LR (1997). Modelling vertical migration of the cyanobacterium Microcystis. Hydrobiologia. 349:99-109.

Visser PM, Verspagen JM, Sandrini G, Stal LJ, Matthijs HC, Davis TW et al. (2016b). How rising $\mathrm{CO}_{2}$ and global warming may stimulate harmful cyanobacterial blooms. Harmful Algae. 54:145-159.

Vollenweider RA (1968). Scientific fundamentals of the eutrophication of lakes and flowing waters, with particular reference to nitrogen and phosphorus as factors in eutrophication. Paris: OECD. 1-250.

Vollenweider RA (1976). Advances in defining critical loading levels for phosphorus in lake eutrophication. Mem Ist Ital Idrobiol. 33:53-83.

Vollenweider RA, Kerekes JJ (1982). Eutrophication of waters. Monitoring, assessment and control. Paris: Environment Directorate OECD:154 pp.

Wagner C, Adrian R (2009). Cyanobacteria dominance: quantifying the effects of climate change. Limnol Oceanogr. 54:2460-2468.

Wallace BB, Hamilton DP (2000). Simulation of water-bloom formation in the cyanobacterium Microcystis aeruginosa. J Plankton Res. 22:1127-1138.

Walsby A, Schanz F (2002). Light-dependent growth rate determines changes in the population of Planktothrix rubescens over the annual cycle in Lake Zürich, Switzerland. New Phytol. 154:671-687.

Walsby AE (2005). Stratification by cyanobacteria in lakes: a dynamic buoyancy model indicates size limitations met by Planktothrix rubescens filaments. New Phytol. 168:365-376.

Wang S, Zhu L, Li Q, Li G, Li L, Song L et al. (2015). Distribution and population dynamics of potential anatoxin-a-producing cyanobacteria in Lake Dianchi, China. Harmful Algae. 48:63-68.

Welker M, Brunke M, Preussel K, Lippert I, von Döhren H (2004a). Diversity and distribution of Microcystis (Cyanobacteria) oligopeptide chemotypes from natural communities studied by single colony mass spectrometry. Microbiology. 150:1785-1796.

Welker M, Christiansen G, von Döhren H (2004b). Diversity of coexisting Planktothrix (Cyanobacteria) chemotypes deduced by mass spectral analysis of microcystins and other oligopeptides. Arch Microbiol. 182:288-298.

Welker M, Erhard M (2007). Consistency between chemotyping of single filaments of Planktothrix rubescens (cyanobacteria) by MALDI-TOF and the peptide patterns of strains determined by HPLC-MS. J Mass Spectrom. 42:1062-1068.

Welker M, Šejnohová L, von Döhren H, Nemethova D, Jarkovsky J, Maršálek B (2007). Seasonal shifts in chemotype composition of Microcystis sp. communities in the pelagial and the sediment of a shallow reservoir. Limnol Oceanogr. 52:609-619.

Welker M, von Döhren H, Täuscher H, Steinberg CEW, Erhard M (2003). Toxic Microcystis in shallow lake Müggelsee (Germany) - dynamics, distribution, diversity. Arch Hydrobiol. 157:227-248. 
Wetzel RG (2001). Limnology: lake and river ecosystems, third edition. San Diego (CA): Academic Press. 1005 pp.

Whitton BA (2012). Ecology of cyanobacteria II: their diversity in space and time. New York: Springer:760 pp.

Wiedner C, Rücker J, Brüggemann R, Nixdorf B (2007). Climate change affects timing and size of populations of an invasive cyanobacterium in temperate regions. Oecologia. 152:473-484.

Wiedner C, Visser PM, Fastner J, Metcalf JS, Codd GA, Mur LR (2003). Effects of light on the microcystin content of Microcystis strain PCC 7806. Appl Environ Microbiol. 69:1475-1481.

Wilson AE, Sarnelle O, Tillmanns AR (2006a). Effects of cyanobacterial toxicity and morphology on the population growth of freshwater zooplankton: metaanalyses of laboratory experiments. Limnol Oceanogr. 51:1915-1924.

Wilson AE, Wilson WA, Hay ME (2006b). Intraspecific variation in growth and morphology of the bloom-forming cyanobacterium Microcystis aeruginosa. Appl Environ Microbiol. 72:7383-7389.

Winder M, Sommer U (2012). Phytoplankton response to a changing climate. Hydrobiologia. 698:1-12.

Wood SA, Biessy L, Puddick J (2018). Anatoxins are consistently released into the water of streams with Microcoleus autumnalis-dominated (cyanobacteria) proliferations. Harmful Algae. 80:88-95.

Wood SA, Depree C, Brown L, McAllister T, Hawes I (2015). Entrapped sediments as a source of phosphorus in epilithic cyanobacterial proliferations in low nutrient rivers. PLoS One. 10:e0141063.

Wood SA, Kelly LT, Bouma-Gregson K, Humbert JF, Laughinghouse IV HD, Lazorchak J et al. (2020) Toxic benthic freshwater cyanobacterial proliferations: Challenges and solutions for enhancing knowledge and improving monitoring and mitigation. Freshwater Biol. 65:1824-1842.

Wood SA, Puddick J (2017). The abundance of toxic genotypes is a key contributor to anatoxin variability in Phormidium-dominated benthic mats. Marine Drugs. 15:307.

Wood SA, Selwood AI, Rueckert A, Holland PT, Milne JR, Smith KF et al. (2007). First report of homoanatoxin-a and associated dog neurotoxicosis in New Zealand. Toxicon. 50:292-301.

Yepremian C, Gugger MF, Briand E, Catherine A, Berger C, Quiblier C et al. (2007). Microcystin ecotypes in a perennial Planktothrix agardhii bloom. Water Res. 41:4446-4456.

Yoshida T, Takashima Y, Tomaru Y, Shirai Y, Takao Y, Hiroishi S et al. (2006). Isolation and characterization of a cyanophage infecting the toxic cyanobacterium Microcystis aeruginosa. Appl Environ Microbiol. 72:1239-1247.

Yoshida-Takashima Y, Yoshida M, Ogata H, Nagasaki K, Hiroishi S, Yoshida T (2012). Cyanophage infection in the bloom-forming cyanobacteria Microcystis aeruginosa in surface freshwater. Microbes Environ. 27:350-355.

Yuan LL, Jones JR (2020). Rethinking phosphorus-chlorophyll relationships in lakes. Limnol Oceanogr. 65:1847-1857.

Zhang X, Xie P, Huang X (2008). A review of nontraditional biomanipulation. Sci World J. 8:1184-1196.

Ziegler K, Diener A, Herpin C, Richter R, Deutzmann R, Lockau W (1998). 
Molecular characterization of cyanophycin synthetase, the enzyme catalyzing the biosynthesis of the cyanobacterial reserve material multi-L-arginyl-poly-Laspartate (cyanophycin). Eur J Biochem. 254:154-159.

Zimmermann U (1969). Ökologische und physiologische Untersuchungen an der planktischen Blaualge Oscillatoria rubescens DC unter besonderer Berücksichtigung von Licht und Temperatur. Schweiz Z Hydrol. 31:1-58.

Znachor P, Jurczak T, Komárková-Legnerová J, Jezberova J, Mankiewicz J, Kastovska K et al. (2006). Summer changes in cyanobacterial bloom composition and microcystin concentration in eutrophic Czech reservoirs. Environ Toxicol. 21:236-243. 